\title{
THE ACUSTICO-LATERAL CENTERS AND THE CEREBELLUM, WITH FIBER CONNECTIONS, OF FISHES
}

\author{
ANTHONY A. PEARSON \\ Laboratory of Comparative Neurology, Department of Anatomy, University of \\ Michigan ${ }^{2}$ \\ TWENTY-EIGHT FTGURES
}

(Accepted for publication September 21, 1935)

\section{CONTENTS}

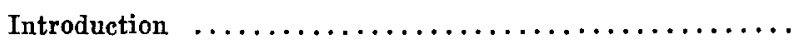

The area acustico-lateralis and the cerebellum ........

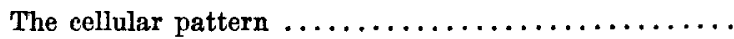

A rea acustico-lateralis $\ldots \ldots \ldots \ldots \ldots \ldots \ldots \ldots$

Nucleus medialis $\ldots \ldots \ldots \ldots \ldots \ldots \ldots \ldots \ldots$

Nucleus dorsalis..$\ldots \ldots \ldots \ldots \ldots \ldots \ldots \ldots$

Nucleus ventralis .................

Nucleus oetavo-motorius anterior .........

Related periventricular gray ............

Nucleus tangentialis $\ldots \ldots \ldots \ldots \ldots \ldots \ldots \ldots$

Nucleus vestibularis descendens ..........

Layer arrangement of the cerebellum .........

Stratum granulosum and stratum Purkinje ...

Stratum moleculare $\ldots \ldots \ldots \ldots \ldots \ldots \ldots \ldots$

Stratum fibrosum ..................

Crista cerebellaris $\ldots \ldots \ldots \ldots \ldots \ldots \ldots \ldots \ldots$

Auricula cerebelli $\ldots \ldots \ldots \ldots \ldots \ldots \ldots \ldots \ldots \ldots$

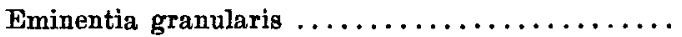

Valvula cerebelli $\ldots \ldots \ldots \ldots \ldots \ldots \ldots \ldots \ldots \ldots$

Nucleus lateralis valvulae $\ldots \ldots \ldots \ldots \ldots \ldots \ldots \ldots$

Nucleus cerebelli $\ldots \ldots \ldots \ldots \ldots \ldots \ldots \ldots \ldots \ldots$

Fiber connections $\ldots \ldots \ldots \ldots \ldots \ldots \ldots \ldots \ldots \ldots$

The VIII nerve and the lateral line nerves ........

The VIII nerve ..................

Anterior lateral line nerve ............

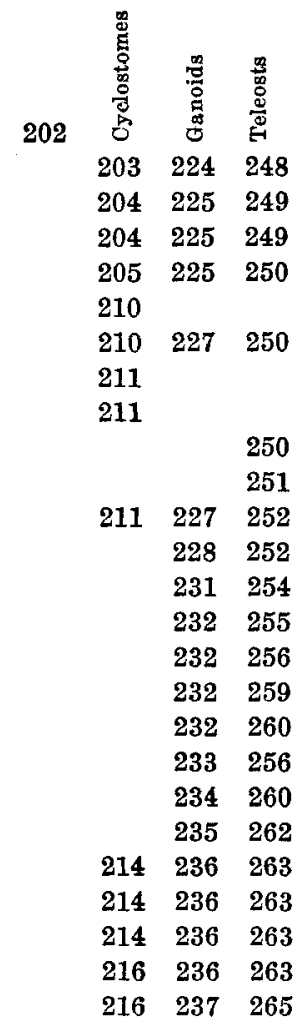

\footnotetext{
${ }^{1}$ A dissertation submitted in partial fulfilment of the requirements for the degree of doctor of philosophy in the University of Michigan.
} 


\begin{tabular}{|c|c|c|c|}
\hline The spino-acustico-latero-cerebellar system & 217 & 239 & 266 \\
\hline Bulbo-cerebellar system . . . . . . . . . . . . . & 218 & 239 & 268 \\
\hline Lemniscus bulbaris $\ldots \ldots \ldots \ldots \ldots \ldots \ldots \ldots$ & 218 & & \\
\hline Lemniscus acustico-iateralis $\ldots \ldots \ldots \ldots$ & & 241 & 269 \\
\hline Primordial cerebellar crest $\ldots \ldots \ldots \ldots \ldots \ldots$ & 219 & & \\
\hline $\begin{array}{c}\text { Cerebellar commissural system. Decussation of } \\
\text { the IV nerve } \ldots \ldots \ldots \ldots \ldots \ldots \ldots \ldots \ldots \ldots \ldots\end{array}$ & 219 & 242 & 272 \\
\hline Acustico-latero-motorius system $\ldots \ldots \ldots \ldots \ldots$ & 221 & 243 & 71 \\
\hline Tractus octavo-motorius anterior. & 221 & & \\
\hline Tractus tecto-cerebellaris $\ldots \ldots \ldots \ldots \ldots \ldots$ & 222 & 243 & \\
\hline Tractus tecto-acustico-lateralis $\ldots \ldots \ldots \ldots \ldots$ & & & 271 \\
\hline Tractus cerebello-tectalis $\ldots \ldots \ldots \ldots \ldots \ldots$ & & 245 & \\
\hline Tractus lobo-cerebellaris $\ldots \ldots \ldots \ldots \ldots \ldots$ & 222 & 246 & 277 \\
\hline Tractus cerebello-tegmentalis $\ldots \ldots \ldots \ldots \ldots \ldots$ & 222 & 246 & 278 \\
\hline Cerebello-motorius system $\ldots \ldots \ldots \ldots \ldots \ldots$ & 222 & 247 & 278 \\
\hline Tractus cerebello-spinalis $\ldots \ldots \ldots \ldots \ldots \ldots$ & & 248 & \\
\hline Tractus mesencephalo-cerebellaris anterior ...... & & & 274 \\
\hline Tractus mesencephalo-cerebellaris posterior ..... & & 246 & 276 \\
\hline Tractus cerebello-tectalis $\ldots \ldots \ldots \ldots \ldots \ldots$ & & & 274 \\
\hline ustatory connections $\ldots \ldots \ldots \ldots \ldots \ldots \ldots \ldots$ & & & \\
\hline
\end{tabular}

Summary and discussion $\ldots \ldots \ldots \ldots \ldots \ldots \ldots \ldots \ldots \ldots \ldots, 282$

\section{INTRODUCTION}

While the literature contains a number of studies which deal more or less incidentally with the nuclear pattern and fiber connections of the acustico-lateral and cerebellar centers of fishes, and a more limited number of papers primarily concerned with these centers, together with résumés in certain neurological texts, there are still many gaps to be filled in the present knowledge of these areas in lower vertebrates. In the following account an attempt has been made to compare and homologize the results obtained in a study of examples of various cyclostomes, ganoids and teleosts. In the material selected, in passing from the more generalized to the more specialized forms, the cerebellum and the associated acusticolateral areas change from relatively simple structures to those showing much greater differentiation and complexity.

The preparations on which this contribution is based form a part of the collection of the Laboratory of Comparative Neurology of the Department of Anatomy at the University of Michigan, a large proportion of which were prepared by 
Dean G. Carl Huber, consisting of complete series cut in various planes and prepared for a study of the nuclear configuration, with the constituent cells, by the use of toluidin blue staining (Huber, '27), or for the consideration of fiber systems by employing pyridine-silver methods (Huber and Guild, '13). For a study of certain of the forms, material stained in iron-haematoxylin was available.

The writer wishes to express his appreciation for the help and encouragement extended him by Drs. G. Carl Huber and Elizabeth C. Crosby.

\section{THE AREA ACUSTICO-LATERALIS AND THE CEREBELLUM IN CERTAIN CYCLOSTOMES}

Investigators are not agreed as to the presence of a cerebellum in myxinoids. Although Holmgren ('19) and others described a cerebellum in Myxine, Jansen ('30) was in doubt as to its occurrence in the adult Myxine glutinosa and Conel ('29, '31) was uncertain with regard to its presence during the development of the brain of Bdellostoma stouti. Lack of myxinoid material available for study precludes any consideration of this question here.

As early as 1849 the cerebellum of Petromyzontia was recognized by Robin, his account being followed by various descriptions of the cerebellum and the acustico-lateral region by Jeleneff (1879), Ahlborn (1883), Johnston ('02), Clark ('06) and Tretjakoff ('07 and '09). Résumés of the results of these workers, with comments and discussions, are to be found in such comparative neurological texts as those of Edinger ('00), Johnston ('06), Papez ('29), Ariëns Kappers ('20-'21 and '29) and Ariëns Kappers, Huber and Crosby ('36). The pertinent literature will be considered as the areas, nuclei or fiber paths, to which it relates specifically, are discussed in the following pages.

In the Petromyzontia the acustico-lateral area is situated in the dorsolateral part of the medulla oblongata (figs. 1 to 4) and the cerebellum is in the form of a bridge placed above 
the fourth ventricle (fig. 3), caudal to the tectum and connecting the cephalic ends of the acustico-lateral areas of the two sides. As its name implies, the acustico-lateral area is associated with the terminations of the fibers of the VIII and the lateral line nerves (figs. 2, 5 and 7 ). Johnston ('02) termed the area the tuberculum acusticum and Ariëns Kappers ('20) called it the tuberculum staticum. In certain forms the name acustico-lateral area or region has been applied, a designation more suggestive of the relations of this region with the VIII nerve and the lateral line nerves, and so given preference in the following pages. The cerebellum and the acustico-lateral areas in the Petromyzontia are so closely interrelated structurally and functionally that a discussion of one area is not complete without a discussion of the other.

The cellular pattern of the area acustico-lateralis and the cerebellum

Area acustico-lateralis. The acustico-lateral area is situated in the dorsal part of the medulla oblongata, extending from a plane a little frontal to the calamus scriptorius to a plane through the cerebellum. Following the nomenclature of Ariëns Kappers ('20), the area is divided into dorsal, medial and ventral nuclei. With it may be grouped the nucleus octavo-motorius anterior. The dorsal nucleus is the cell mass termed the lobus lineae lateralis of Petromyzon by Johnston ('02), while the medial nucleus corresponds to his dorsomedial nucleus, together with that part of his ventrolateral nucleus which extends cephalad to fuse with the cerebellar gray. The ventral nucleus of the present account falls within the ventrolateral nucleus of Johnston ('02), but does not include the forward extension just mentioned. Tretjakoff ('09) divided the acustico-lateral area into two parts: a dorsal coordinating zone and a lateral association zone. The group of spindle-shaped cells designated as the nucleus octavo-motorius anterior (Ariëns Kappers, '20) had been recognized by Johnston ('02) and by Tretjakoff ('09). 
Various theories have been advanced with regard to these cells. Clark ('06) believed that they were part of the nucleus (or ganglion) isthmi, while van Hoevell ('16) suggested that they might precede in phylogeny the development of the cerebellar nuclei.

In the following account, the nuclei of the acustico-lateral area in Petromyzon marinus unicolor are described. A similar though less definite distribution of the gray is found in Entosphenus appendix and Ichthyomyzon unicolor. Such differences as occur are of minor importance and are expressed by the less regular distribution of the gray and the less clear demarcation of the nuclear groups.

Nucleus medialis. In cross sections a little frontal to the calamus scriptorius, a line of cells (fig. 1) may be recognized in the fiber bundles near the dorsolateral wall of the medulla oblongata. Caudal to this plane the line of cells is lost in the scattered gray of the region, while frontal to it the line becomes larger and is divisible into two portions, a larger dorsal and a smaller ventral part. This gray is surrounded completely by the fibers of the region. The dorsal part constitutes the caudal end of the acustico-lateral gray, represented at this level by the nucleus medialis. The ventral part is the nucleus of the descending root of $\mathrm{V}$ as identified by Johnston ('02). Traced forward these gray masses remain relatively distinct, but it is difficult in certain sections to draw a sharp line between the two. Cephalically the whole acustico-lateral area, while keeping the same general position, becomes larger. The nucleus of the descending root of $\mathrm{V}$ also retains the same relative position, but becomes somewhat scattered and consequently is followed with difficulty. The acustico-lateral gray increases and then occupies the greater part of the dorsolateral region of the medulla oblongata. The majority of its cells are small, but, at certain levels, there are a varying number of larger cells which apparently do not present a definite arrangement. Small neurons appear among the most dorsal fibers of this region, which, until now, has been unoccupied by any considerable number of cells. These 


\section{ABBREVIATIONS FOR ALL FIGURES}

a, fibers from the ventral molecular layer turning into the stratum Purkinje

a. ac. lat., area acustico-lateralis aur., aurieula

$b$, fiber bundles forming the stratum fibrosum of the cerebellum

c, space continuous with the cranial cavity

cal. serip., calamus seriptorius

can, cer., canalis cerebelli

cell Mauth., cell of Mauthner

cell Müll., cell of Müller

cell Purk., cells of Purkinje

cer., cerebellum

col. mo., columna motoria

com. ans., commissura ansulata

com. cer., commissura cerebelli

com. col. sup., commissura colliculi superioris

cr. cer., crista cerebelli

d, periventricular fiber system between the cerebellum and the tectum

dec. N.IV, decussatio nervi trochlearis dee. teg., decussatio tegmenti

dec.tr.eer.teg., decussatio tractus cerebello-tegmentalis

$e$, junction of the auricle with the stratum granulosum pars ventralis

em. gran., eminentia granularis

epend., ependyma

fasc. sol., fasciculus solitarius

fib. arc., fibrae arcuatae

fib. com.cer., fibrae commissurae cerebelli

f.l. m., fasciculus longitudinalis medialis

gang. N. VIII, ganglion nervi acustici gr. perivent., griseum periventriculare hyp., hypothalamus

lem. ac. lat., lemniseus acustico-lateralis lem. bulb., lemniseus bulbaris

lob. fac., lobus facialis

lob. inf. hyp., lobus inferior hypothalami med. obl., medulla oblongata
N. III, nervus oculomotorius

N. IV, nervus trochlearis

$N$. $V$, nervus trigeminus

N. VIII, nervus acusticus

N. l. lat.ant., nervus lineae lateralis anterior

N. l. lat. ant. p. dors., nervus lineae lateralis anterior pars dorsalis

N. l. lat. ant. p. vent., nervus lineae lateralis anterior pars ventralis

N.l. lat. post,, nervus lineae lateralis posterior

n. IV, nucleus trochlearis

n. cer., nucleus cerebelli

n. dors., nucleus dorsalis

n. gust. see, nuelens gustatorius seeundus

n. lat. valv., nucleus lateralis valvulae

n. med., nucleus medialis

n. med. p. dors., nucleus medialis pars dorsalis

n. med. p. vent., nucleus medialis pars ventralis

n. mo. N. V, nucleus motorius nervi trigemini

n. oct, mo, ant, nucleus octavo-motorius anterior

n. r. d. N. V, nucleus radieis deseendentis nervi trigemini

n. tang., nueleus tangentialis

n. vent., nueleus ventralis

n. vest. d., nucleus vestibularis descendens

pl. ch., plexus chorioideus

pr. tor. semic., primordial torus semicircularis

r. asc. N. VIII, radix ascendens nervi acustici

r. asc. N.l.lat., radix ascendens nervi lineae lateralis

r. asc.N. l. lat. ant, radix ascendens nervi lineae lateralis anterioris

r. asc. N.l. lat. post., radix ascendens nervi lineae lateralis posterioris

r, d. N. V, radix descendens nervi trigemini 
r. d.N. VIII, radix descendens nervi acustici

r. d. N. l. lat. ant., radix descendens nervi lineae lateralis anterioris

ree. lat., recessus lateralis

r. mo.N.V, radix motoria nervi tri. gemini

r. mo.N. VII, radix motoria nervi facialis

r. N. V, radix nervi trigemini

r. N. VIII, radix nervi acustici

r. sens. N. VII, radix sensibilis nervi facialis

sac. vasc., saceus vasculosus

str. alb. cent., stratum album centrale

str. fib., stratum fibrosum

str. fib.et mol. cer., stratum fibrosum et moleculare cerebelli

str. fib. p. com., stratum fibrosum pars commissuralis

str. gran. p. prin., stratum granulosum pars principalis

str. gran. p. prin. lat, stratum granulosum pars principalis lateralis

str. gran.p. prin.med., stratum granulosum pars principalis medialis

str. gran. p. vent., stratum granulosum pars ventralis

str. gran. valv., stratum granulosum valvulae

str. gr. perivent., stratum griseum periventrienlare

str. gr. prof. cer., stratum griseum profundum cerebelli

str. gr. superf. cer., stratum griseum superficialis cerebelli

str. mol., stratum moleculare

str.mol.p.prin., stratum moleculare pars principalis

str. mol.p. vent., stratum moleculare pars ventralis str. mol. vaiv., stratum moleculare valvulae cerebelli

str. Purk., stratum of Purkinje cells tect. op., tectum opticum tor. long., torus longitudinalis tor. semic., torus semicircularis

tr. ac. lat. mo., tractus acustico-lateromotorius

tr. bulb. cer., tractus bulbo-cerebellaris

tr. cer. mo., tractus cerebello-motorius

tr. cer. spin., tractus cerebello-spinalis

tr. cer. teet., tractus cerebello-tectalis

tr. cer. teg., tractus eerebello-tegmentalis

tr. gust. sec., tractus gustatorius secundus

tr. lob. bulb., tractus lobo-bulbaris

tr. lob.cer., tractus lobo-cerebellaris

tr. mes.cer., tractus mesencephalo-cerebellaris

tr. mes, cer. ant., tractus mesencephalocerebellaris anterior

tr. mes. cer. post., tractus mesencephalocerebellaris posterior

tr. oc. mo. ant., tractus octavo-motorius anterior

tr. op., tractus opticus

tr. spin. ac. lat. et cer., tractus spinoacustico-lateralis et cerebellaris

tr. spin, cer., tractus spino-cerebellaris

tr. tect. cer., tractus tecto-cerebellaris

tr. tect. cer. p. lat., tractus tecto-cerebellaris pars lateralis

tr. tect. cer. p. med., traetus tecto-cerebellaris pars medialis

v., ventriculus

v. IV, ventriculus quartus

valv. cer., valvula cerebelli

vel. med. ant., velum medullare anterius

vel, med. post., velum medullare posterius

$x$, region of fusion of the acusticolateral gray with the cerebellar gray 

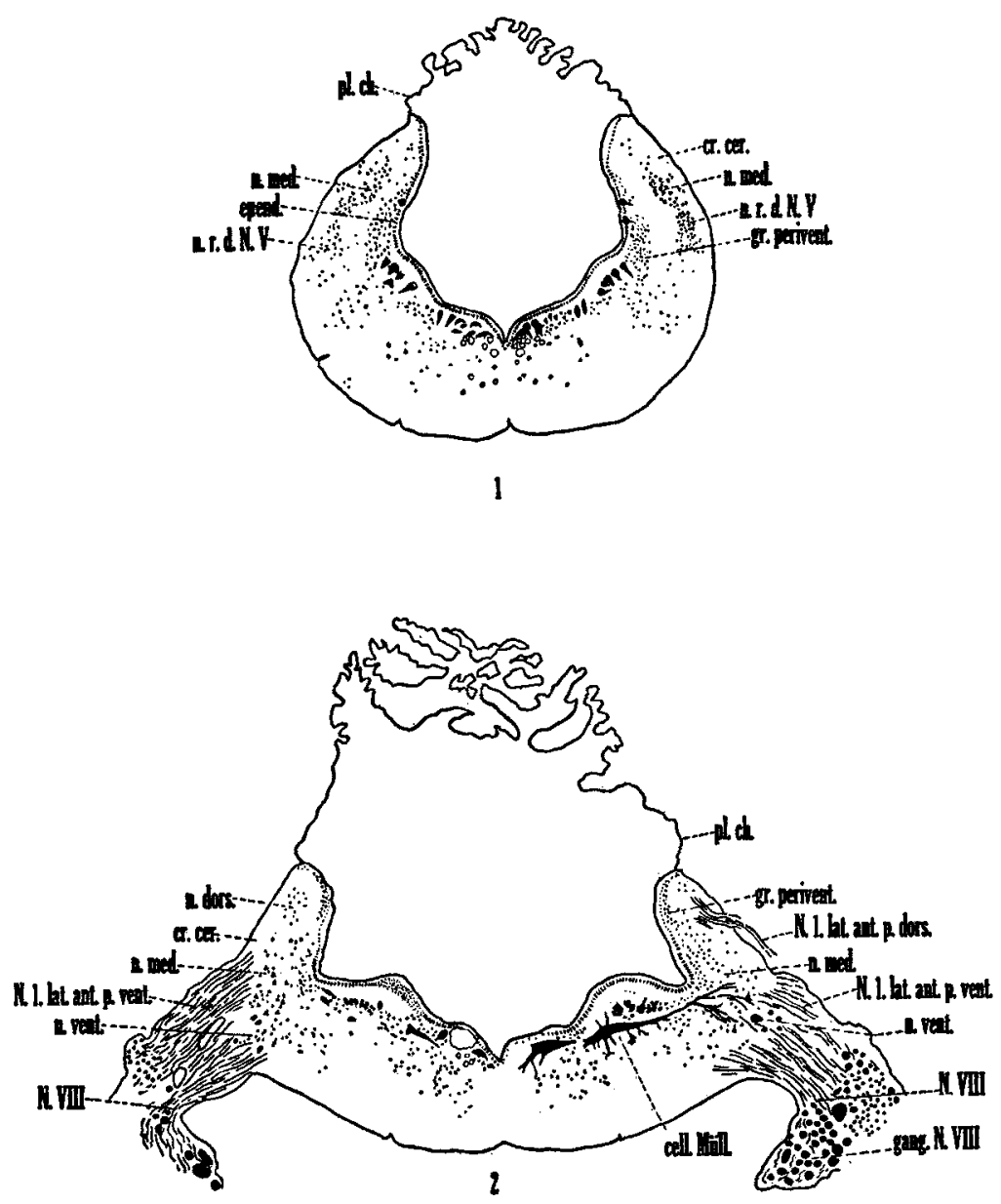

Fig. 1 A transverse section through the caudal end of the medulla oblongata of Petromyzon marinus unicolor, slightly in front of the ealamus scriptorius, showing particularly the caudal pole of the nucleus medialis of the acusticolateral area. Toluidin blue preparation. $\times 20$.

Fig. 2 A transverse section through the medulla oblongata of Petromyzon marinus unicolor at the level of entrance of the VIII and anterior lateral line nerves, illustrating the relations of the dorsal, medial and ventral nuclei of the acustico-lateral area. Toluidin blue preparation. $\times 20$. 
small, more dorsally placed neurons mark the caudal tip of the dorsal nucleus. The larger neurons do not appear in this dorsal region. As the region of entrance of the VIII nerve is approached, the larger cells of the acustico-lateral gray accumulate, particularly in the ventral part of the area, to constitute the ventral nucleus. The foregoing presentation makes it evident that, caudal to the plane of entrance of the VIII nerve, there is no sharp line between the nuclear masses. At levels where the VIII nerve enters the medulla oblongata, perhaps partly due to the increase of the root fibers, the three nuclei-the dorsal, medial and ventral-can be more readily identified (fig. 2), although the line of demarcation between the medial and ventral nuclei is quite indistinct in many planes. On the medial side of the medial nucleus is a layer of periventricular gray with which, at intervals, the nucleus appears to be continuous.

In front of the entrance of the VIII nerve, the medial nucleus becomes continuous with the cerebellar gray (fig. 3; see particularly the right side). This nucleus may be divided secondarily into two divisions, a dorsal portion, which passes forward dorsal to the nucleus octavo-motorius anterior, and a ventral portion, which passes cephalad, medial and, at certain levels, slightly ventral to the nucleus octavo-motorius anterior. The ventral portion probably includes that part of the ventrolateral nucleus of Johnston ('02) which he regarded as extending forward to fuse with the cerebellar gray. The dorsal portion, on entering the cerebellum, in part merges with the deep cerebellar gray, and in part appears to scatter through the whole molecular layer, where it is continuous with the superficial cerebellar gray (fig. 3). The entire ventral division, as it becomes continuous with the deep cerebellar gray, enlarges somewhat and partly fuses with the cephalic end of the nucleus of the descending root of $V$ and with the periventricular gray of the region. In Entosphenus appendix the medial nucleus and the corresponding periventricular gray are continuous frontalward with the cerebellar gray. 
Nucleus dorsalis. The dorsal nucleus (figs. 2 and 5) is not a conspicuous cell mass but is a loose cellular aggregation among the fibers of the most dorsal part of the medulla oblongata. As the acustico-lateral gray is followed forward from its caudal end, small neurons appear among the most dorsal fiber bundles of the region. Traced forward, these cells become somewhat numerous and make up the nucleus dorsalis. The caudal end of this nucleus is separated from the dorsal part of the lateral wall of the ventricle by a layer of fibers, but, in the region of entrance of the VIII nerve (fig. 2, left), this fiber layer no longer separates the nucleus dorsalis from the ventricle, being replaced by a layer of periventricular gray along the dorsal part of the lateral ventricular wall. At a plane through the dorsal root of the anterior lateral line nerve, the dorsal nucleus has almost dropped out, leaving the corresponding part of the periventricular gray, which extends forward to a plane slightly caudal to the cerebellum, where it, too, disappears.

Nucleus ventralis. The ventral nucleus (figs. 2, 5 and 7), as has been stated previously, is not sharply separable caudally from the nucleus medialis of the acustico-lateral area. Just behind the level of entrance of the VIII nerve it appears as a gradual accumulation of large cells, and, at planes in which the VIII nerve fibers enter the medulla oblongata, it is identified easily by the presence of such cells. These lie directly in the path of the entering nerve fibers. Certain of them are spindle-shaped and, in pyridine silver preparations, the spoon-shaped terminations of the incoming VIII nerve fibers (as described by Johnston, '02 and Tretjakoff, '07, '09) may be seen in relation with some of them. This nucleus is confined for the most part to the region of entrance of the VIII nerve, its cephalic pole not extending beyond the upper limits of the nerve fibers.

The Müller cell at the level of the nucleus ventralis (fig. 2) sends a branching process among the entering fibers of the VIII nerve. The relations of this cell strongly suggest that it is the forerunner of Mauthner's cell found in fishes and 
amphibians. The arrangement of Müller's cells in petromyzonts has been described by Johnston ('02) and Tretjakoff ('09).

Nucleus octavo-motorius anterior. A plane through the medulla oblongata and the caudal portion of the cerebellum will pass through a group of large cells (figs. 3, 7) situated dorsal to the nucleus of the descending root of $\mathrm{V}$, and partly between the dorsal and ventral portions of the medial nucleus. These form the nucleus octavo-motorius anterior of Ariëns Kappers ('21; see also p. 221).

Related periventricular gray. Along the dorsal part of the lateral ventricular wall there is a portion of the periventricular gray, which lies in relation to the dorsal nucleus (fig. 2). Its extent is approximately from a plane through the entrance of the VIII nerve to one just caudal to the cerebellum. Ventral to the periventricular gray just described, but directly continuous with it, is another portion of this gray having a like morphologic character. This portion is limited ventrally by the sulcus limitans and lies in particularly intimate relationship with the medial nucleus. It overlaps this nucleus in its caudal extent, being continuous with the general periventricular gray. Frontally it is fused with the ventral part of the medial nucleus. The cell mass thus formed is continuous with the stratum griseum profundum of the cerebellum. At certain levels, other than those through the cephalic pole of the medial nucleus, there is more or less continuity between this nucleus and the associated periventricular gray. The relations here suggest, what probably the embryologic history would substantiate, that these acustico-lateral nuclei are developed by a migration lateralward of neurons of the central gray under the neurobiotactic influence of the entering VIII and lateral line nerve fibers.

Layer arrangement of the cerebellum. Jeleneff (1879) and Schaper (1899) were among the first to describe the structure of the cerebellum in Petromyzon. Johnston ('02) gave a more complete account of the histology of the cerebellum in this form. He divided the region into an inner cell layer and 
an outer fiber layer and found the inner layer to be composed largely of small cells, similar to those in the dorsomedial or medial nucleus and homologous to the granule cells of higher vertebrates, but to contain also the somewhat larger cell bodies of neurons which he regarded as the forerunners of Purkinje cells. The latter neurons present dendrites which ramify in the molecular layer. Johnston found the fiber layer to be continuous with the cerebellar crest and the dorsal commissure to interconnect the cerebellar regions of the two sides. Ariëns Kappers ('21) and Herrick ('24) pointed out that the cerebellum in its primitive form, such as in Petromyzon, is the result of the direct continuation and bilateral fusion of the lateral line and vestibular nuclei, and that these elements take part in the formation of this primitive cerebellum.

The presence of a superficial fibrous layer within the cerebellum has been recognized by Jeleneff (1879), Schaper (1899), Johnston ('02) Tretjakoff ('09) and Ariëns Kappers ('21). To this layer, for reasons which will become evident in the present account, the name of stratum fibrosum et moleculare cerebelli (figs. $3,4,6,8,9$ ) has been applied. A large proportion of the afferent fibers for the cerebellum enter this stratum superficial to the cerebellar gray. In part such fibers terminate in the gray of the same side, in part they decussate in the cerebellar commissure (figs. 3, 6, 7). This entrance of the fiber bundles peripheral to the cerebellar gray represents a primitive condition, as will be seen in comparing this region in Petromyzontia with the homologous areas in ganoids and teleosts. Scattered among these entering fibers are occasional cell bodies and the dendritic processes of neurons of the cerebellar gray. The presence of such intrinsic cells and dendritic processes indicates that the stratum fibrosum et moleculare is potentially capable of differentiation into the molecular and the fibrous layers of the cerebellum of higher forms.

The cerebellar gray in Petromyzon is composed of two layers, a superficial and a deep (figs. 3 and 4). The super- 
ficial layer of cerebellar gray (fig. 3) lies nearer the dorsolateral surface, its main mass being separated from that surface by the stratum fibrosum et moleculare, containing scattered cells. The superficial cerebellar gray is continuous
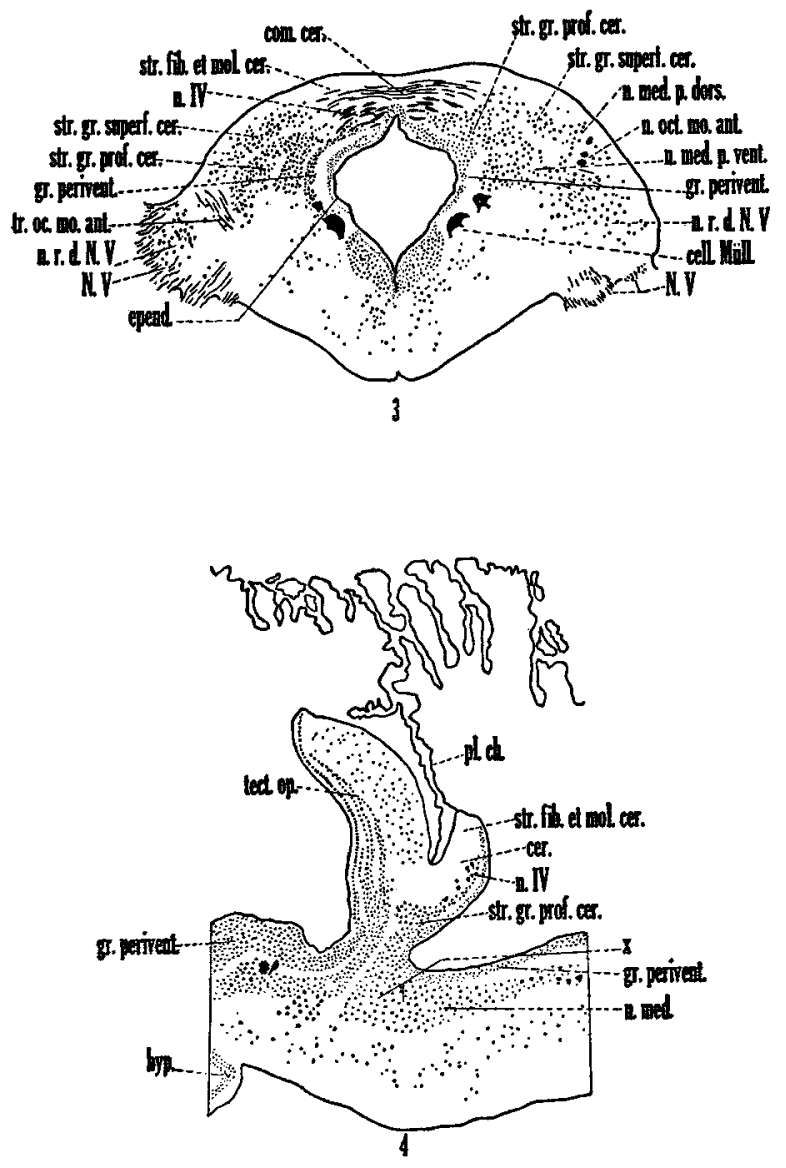

Fig. 3 A transwerse section through the cerebellum of Petromyzon marinus unicolor. On the left, the cerebellar strata are seen and, on the right, the relations of the cerebellar gray to the dorsal and ventral portions of the medial nucleus of the acustico-lateral area. Toluidin blue preparation. $\times 20$.

Fig. 4 A sagittal section through the cerebellum of Petromyzon marinus unicolor, showing the relations of the cerebellar gray to the gray of the midbrain and to the medial nucleus of the acustico-lateral area. Toluidin blue preparation. $\times 20$. 
with the dorsal part of the medial nucleus of the acusticolateral area. At selected levels the superficial and deep layers of cerebellar gray are separated by fiber bundles with intermingled scattered cells, but at certain other levels these layers are continuous. The deep layer is separated from the ependyma of the region by a thin layer of white, and from the dorsal wall by the stratum fibrosum et moleculare and by the superficial cerebellar gray. The deep cerebellar gray is formed by the continuation forward into the cerebellum of the fused eephalic portions of the ventral part of the medial nucleus of the acustico-lateral area and the corresponding portion of the periventricular gray (fig. $4, x$ ). There may be a slight fusion between the dorsal part of the medial nucleus and the deep cerebellar gray. The cerebellar gray of one side is not continuous with that of the other side nor with the gray of the midbrain; for, although sagittal sections (fig. 4) show the gray of the cerebellum in close apposition to that of the midbrain, it is possible to see a separation between the two.

In the cerebellum (fig. 3 ) on either side of the midline, dorsal and medial to the cerebellar gray, is a conspicuous nucleus of elongated cells. According to Tretjakoff ('09) this is the nucleus of the IV nerve. As Addens ('28) has pointed out, in no other animal has this nucleus been found in the cerebellum dorsal to the sulcus limitans.

Fiber connections of the area acustico-lateralis and the cerebellum in Entosphenus appendix and Petromyzon marimus unicolor

The VIII nerve and the lateral line nerves. The VIII nerve. The descriptions of the VIII nerve by Rohm (1882) and by Ahlborn (1883) are of greater historical interest than of scientific importance. The course and central connections of VIII have been more completely described by Johnston ('02), Tretjakoff ('07 and '09) and Ariëns Kappers ('20). Their studies indicate that this nerve has two roots, composed of fibers of varying thickness, some of which bifurcate after entrance to the medulla oblongata, and that the root fibers distribute to the acustico-lateral gray and to the cerebellum. 
In Entosphenus appendix, VIII (figs. 5,7) enters the ventrolateral part of the medulla oblongata a little caudal to the entrance of the $V$ nerve. Many of the fibers bifurcate on entering. Some of the more ventral fibers pass toward the midline in company with those from the acustico-lateral
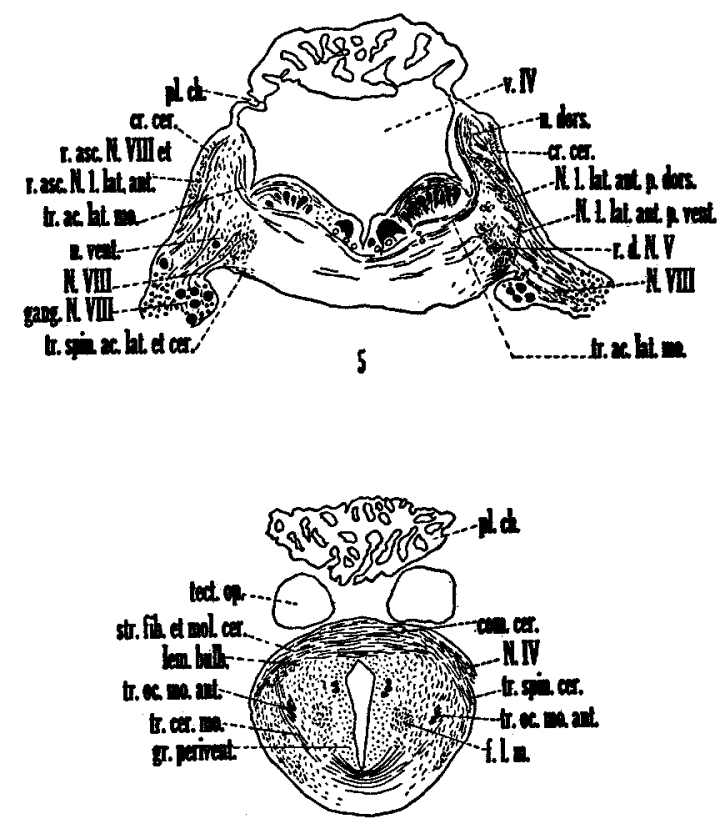

6

Fig.5 A transverse section through the level of entrance of the anterior lateral line and the VIII nerves of Entosphenus appendix, illustrating the distribution of these nerves to the acustico-lateral area. Pyridine silver preparation. $\times 20$.

Fig. 6 A transverse section through the level of the cerebellar commissure of Entosphenus appendix, showing various fiber tracts associated with the cerebellum. Pyridine silver preparation. $\times 20$.

region destined to enter the medial longitudinal fasciculi of the same and opposite sides. In the material studied it was not possible to deteirmine the endings of the VIII nerve as distinct from those of other fibers crossing the midline. Fibers pass directly to the ventral nucleus of the acusticolateral area, and many of them end in synaptic relation with 
the large, spindle-shaped cells by means of spoon-shaped terminations (p. 210), while others turn caudalward (figs. 7, 8 ) and distribute to the medial nucleus of the acustico-lateral area behind the level of entrance of the VIII nerve. Some fibers of this nerve pass directly to the medial nucleus. Still others turn frontalward (figs. 7,8 ) to distribute to the more cephalic portion of the medial nucleus and to the homolateral and contralateral cerebellar gray.

Anterior lateral line nerve. Johnston ('02), Tretjakoff ('09) and Ariëns Kappers ('20) identified two roots of the anterior lateral line nerve. The following account agrees for the most part with Johnston's ('02) description of this nerve in Petromyzon. The relations of the anterior lateral line nerve can be demonstrated in the material of Entosphenus appendix and Petromyzon marinus unicolor. As this nerve (figs. 2, 5) enters the lateral wall of the medulla oblongata, dorsal to the entering fibers of the VIII nerve, two bundles can be recognized. The dorsal bundle is distributed largely to the dorsal nucleus of the acustico-lateral area, while the ventral bundle passes in part to the medial nucleus of this area at the level of entrance of its fibers and in part sends fascicles spinalward to the caudal end of the medial nucleus and forward to the cephalic end of that nucleus and to the cerebellar gray. A small number of fibers of the dorsal bundle ends in the medial nucleus and there is a similar distribution of the ventral bundle to the dorsal nucleus. Johnston traced a few fascicles frontalward to the nucleus octavo-motorius anterior.

Posterior lateral line nerve. As Johnston ('02), Tretjakoff ('09) and Ariëns Kappers ('20) have observed, the posterior lateral line nerve, after entering the caudal end of the medulla oblongata, distributes its fibers throughout the whole extent of the acustico-lateral area. Certain fibers are thought to bifurcate into ascending and descending branches, which terminate largely in the medial nucleus. A few fibers appear to reach the cerebellum. 
The spino-acustico-latero-cerebellar system. The spinocerebellar tract appears not to have been described in cyclostomes. Clark ('06) thought it to be present but was not able to trace fibers from the spinal cord. Addison ('29) indicated that this tract is probably to be found in cyclostomes but did not describe it.

In the silver preparations of Petromyzon marinus unicolor and of Entosphenus appendix, the spino-acustico-laterocerebellar system (figs. 5, 8) is seen as an accumulation of fibers at the lower end of the medulla oblongata, ventral to the descending root of the $V$ nerve and its nucleus. This system is directly continuous caudally with a complex of fibers within the lateral funiculus of the cord. Followed cephalad the system soon becomes separable into an acustico-lateral component and a cerebellar component.

The acustico-lateral component swings dorsalward and slightly lateralward, a few fascicles at a time, into practically the whole extent of the acustico-lateral area. At the region of entrance of VIII and the lateral line fibers, the fascicles of the acustico-lateral component are broken up into even smaller fiber groups by the entering root fibers. This acustico-lateral component establishes spino-acustico-lateral interrelations. Certain of the bundles of this component, particularly the more cephalic, may constitute merely fibers of passage which course with the bulbo-cerebellar bundles to the cerebellum, but the evidence for this is not conclusive.

The main mass of the cerebellar component of the spinoacustico-latero-cerebellar system retains a position ventral to the acustico-lateral area, but gradually a few fibers pass dorsalward. As the level of entrance of the $\mathrm{V}$ nerve is approached such fibers are joined by fascicles which interdigitate with the lower fibers of the entering $V$ nerve. The main cerebellar component then sweeps suddenly dorsalward and medialward, for the greater part in front of the entering $\mathrm{V}$ nerve fibers, in order to reach the cerebellar gray of the same and opposite sides, the decussation occurring in the cerebellar commissure, of which it forms a considerable portion. In 
close association with the spino-acustico-latero-cerebellar system is the spino-tectal tract, which proceeds forward in front of the cerebellum to enter the roof of the midbrain.

Bulbo-cerebellar system. Clark ('06), Tretjakoff ('09) and Ariëns Kappers ('20) have recognized fibers which arise in the acustico-lateral area and pass to the cerebellum. This bulbo-cerebellar system of fibers is formed by processes of neurons of the second order, the cell bodies of which are situated in all three nuclei of the acustico-lateral area, and by fibers of the nucleus of the descending root of the $\mathrm{V}$ nerve. It includes, then, secondary acustico-latero-cerebellar fibers and secondary trigemino-cerebellar fibers. The bulbo-cerebellar system sweeps forward to aid in the formation of the cerebellar crest, but part of the fascicles enter the cerebellum as scattered bundles. Both groups of fascicles approach the region of the cerebellar commissure and become incorporated in part within it, having thus a contralateral distribution. The proportion of fibers which cross is uncertain, since it is frequently impossible, by reason of the richness of impregnation in the material studied, to trace individual fascicles after they have approached the region of the commissure.

Lemniscus bulbaris. The lemniscus bulbaris of Jansen ('30), or the general bulbar lemniscus of Herrick ('30), is well shown in the pyridine silver preparations of Entosphenus appendix (fig. 6). This tract has its cells of origin in the gray of the acustico-lateral region, in the nucleus of the descending root of $\mathrm{V}$, and possibly in other sensory centers within the medulla oblongata. As Herrick ('30) has pointed out for Necturus, the chief sources of activation of this lemniscus in Petromyzontia are the lateral line organs, the acoustic apparatus and the end organs of the $\mathrm{V}$ nerve. In Entosphenus appendix, the fibers contributing to this lemniscus can be seen swinging toward the midline, largely ventral to those forming the acustico-latero-motorius system, and decussating through almost the entire extent of the acustico-lateral area, in largest numbers perhaps near the level of entrance of the VIII nerve. The fascicles of this system, after crossing, accumulate 
in small bundles ventral to the motor cell column and medial and somewhat ventral to the acustico-lateral region. The lemniscus is easily recognized at the level of the $\mathrm{V}$ nerve, where it sweeps dorsalward and slightly cephalad in a broad curve. In figure 6 it is shown as it crosses the tractus octavomotorius anterior almost at right angles. The fibers pass under the cerebellar commissure into the caudal end of the optic tectum, where the majority of them terminate. It is possible, as Herrick has pointed out for Necturus, that certain of these fibers may reach the dorsal thalamus. The acusticolateral component of the bulbar lemniscus can be homologized with the acustico-lateral lemniscus in higher forms (p. 241) and without doubt terminates in the primordial torus semicircularis (fig. 9).

Primordial cerebellar crest. The caudal continuation of the stratum fibrosum et moleculare over the dorsolateral wall of the medulla oblongata of petromyzonts forms a fiber band of varying thickness, which constitutes the anlage of the cerebellar crest of fishes (see also Johnston, '02). This primordial cerebellar crest (figs. 1, 2, 5, 7), which is composed of fibers of passage of the lateral line and VIII nerves and fascicles of the bulbo-cerebellar system, can be followed to planes caudal to the level of entrance of the VIII nerve, where it becomes less distinct.

Cerebellar commissural system. Decussation of the IV nerve. The commissural system (figs. 3, 6, 7) uniting the cerebellar gray of the two sides, and so forming the roof of the medulla oblongata in this region, has been divided by Johnston ('02) into a thick dorsal and a thin ventral commissure. Here decussating bundles, which include crossing fibers of the anterior lateral line and VIII nerves, have been described. The cell bodies of the nucleus of the IV nerve (fig. 3) occupy a position in the cerebellum near the midline (Tretjakoff, '09, fig. 42, and Addens, '28), dorsal to the cerebellar gray, and send their neuraxes medialward to decussate in the overlying commissure and then to emerge as the trochlear nerve. 
In the available series of Petromyzon marinus unicolor and Entosphenus appendix the following decussating components of this dorsal cerebellar commissure have been identified: 1) fibers which enter the cerebellum by way of the cerebellar

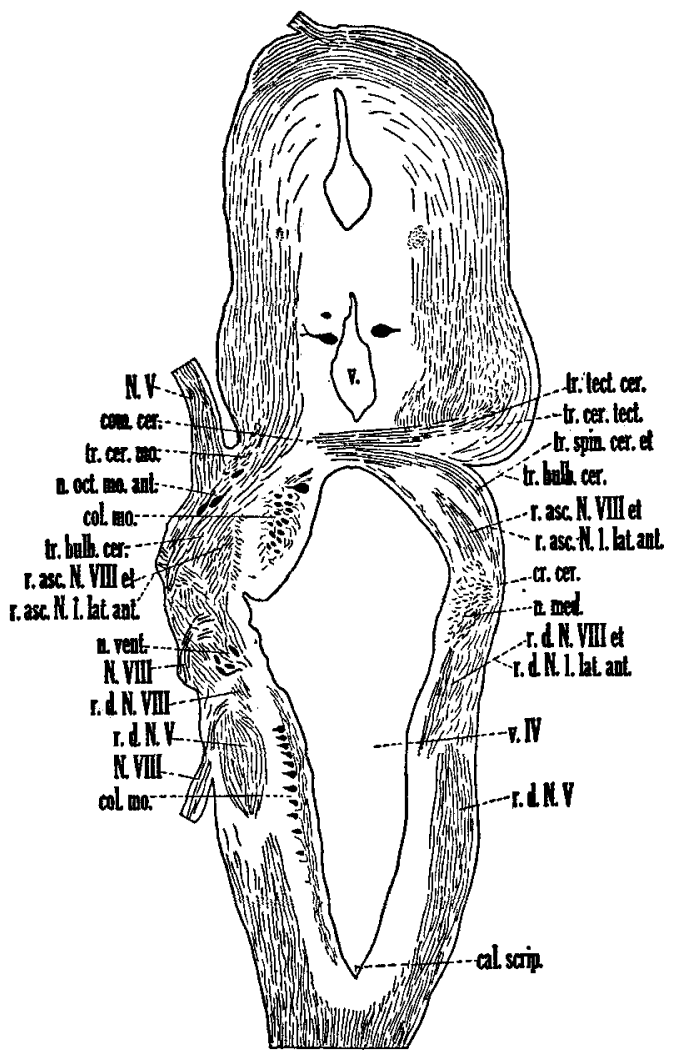

Fig. 7 A horizontal section through the brain of Entosphenus appendix at the level of the cerebellar commissure and the entrance of the VIII nerve. The figure illustrates certain eomponents of the cerebellar commissure and ascending fibers of the VIII and lateral line nerves and the bulbo-cerebellar system. Pyridine silver preparation. $\times 20$.

crests and which include primary lateral line and VIII nerve fibers and certain bulbo-cerebellar fibers; 2) fibers of bulbo- and spino-cerebellar tracts which enter the cerebellum in front of the cerebellar crest; 3 ) fibers establishing interrelations between the optic tectum and the cerebellum; 
4) fibers of the IV nerve. It is to be noted that complete decussations of the above systems do not occur with the exception of the motor root of the IV nerve.

Acustico-latero-motorius system. Efferent connections of the acustico-lateral area have been described by Johnston ('02) and Tretjakoff ('09) as part of their arcuate fibers. In Petromyzon marinus unicolor and Entosphenus appendix, the acustico-latero-motorius system (fig. 5) is composed of bundles which swing from the acustico-lateral area toward the medial longitudinal fasciculus. As the fibers course toward the midline, beneath the lateral angle of the ventricle, they become grouped into two divisions. A smaller dorsal or periventricular division, which passes into the fiber layer that separates the motor cell column from the ependyma, is composed of small, dark fibers derived largely from the dorsal and medial nuclei of the acustico-lateral area and the related periventricular gray. The ventral division of the acusticolatero-motorius system passes toward the midline ventral to the motor cell column. At the level of the VIII nerve it is composed of fibers from all three nuclei of the acustico-lateral area. Certain of the fascicles enter the medial longitudinal fasciculus of the same side, while others cross the midline and enter the contralateral fasciculus. Some fibers are lost in the general region about the efferent neurons. Toward the cephalic and caudal ends of the acustico-lateral area this system arises only from the medial nucleus, since the dorsal and ventral nuclei have ceased to be present. Caudally the system gradually disappears as the acustico-lateral area becomes smaller.

Tractus octavo-motorius anterior. The tractus octavomotorius anterior of Tretjakoff ('09) and Ariëns Kappers ('20) may be considered as part of the general acustico-lateromotorius system. Johnston ('02) described it as a tract of arcuate fibers arising from the large cells at the cephalic end of the acustico-lateral area.

In the material studied, this tract (figs. 6, 8,9) appears as a small bundle of coarse fibers, which passes forward and 
ventralward from the nucleus octavo-motorius anterior (figs. 3, 7). As the bundle approaches the level of the nucleus of the III nerve it begins to turn toward the midline and helps in the formation of a conspicuous decussation directly ventral to the crossing fibers of the III nerve. Many of the fibers of the tract bifurcate, sending branches to the tegmental gray and into the medial longitudinal fasciculus of the same and opposite sides. They also end in part in the nuclei of the III nerve.

Tractus tecto-cerebellaris; tractus lobo-cerebellaris; tractus cerebello-tegmentalis; cerebello-motorius system. Clark ('06) described a tecto-cerebellar tract but he did not mention a decussation of its components or discuss its direction of conduction. Tretjakoff ('09) noted a tecto-cerebellar and Ariëns Kappers ('21) a cerebello-tectal path. Johnston ('02) found fibers passing from the inferior lobes of the hypothalamus to the cerebellum, a part of which fibers he believed to cross in the postoptic decussation. Clark ('06) and Ariëns Kappers ('21) called attention to the fibers connecting the tegmentum with the cerebellum. The cerebello-motorius system of the following account probably includes the arcuate fibers described by Johnston ('02) as sweeping out of the cerebellum and is represented in those fascicles described by Ariëns Kappers ('21) as arising from the Purkinje-like cells and ending in the motor region of the bulb and the midbrain.

Swinging forward and ventralward from the cerebellum is a great fan of fibers which may be separated secondarily into dorsal, intermediate and ventral portions. The dorsal portion includes the tecto-cerebellar and cerebello-tectal systems (figs. 7,9 ) composed of fibers which interconnect the optic tectum and the cerebellum. Of the two components the tecto-cerebellar system lies nearer the midline. It leaves the deep layer of the tectum and passes caudalward beneath the cerebellar commissure, to distribute partly to the cerebellar gray of the same side and partly, after a decussation in the cerebellar commissure, to the cerebellar gray of the opposite side. Certain fine fascicles accompanying the tecto-cerebellar 
fibers distribute to a mass of subtectal gray (fig. 9) which bulges slightly into the optic ventricle and which is probably the forerunner of the torus semicircularis of ganoids and teleosts. These fascicles are well shown in the sagittal series
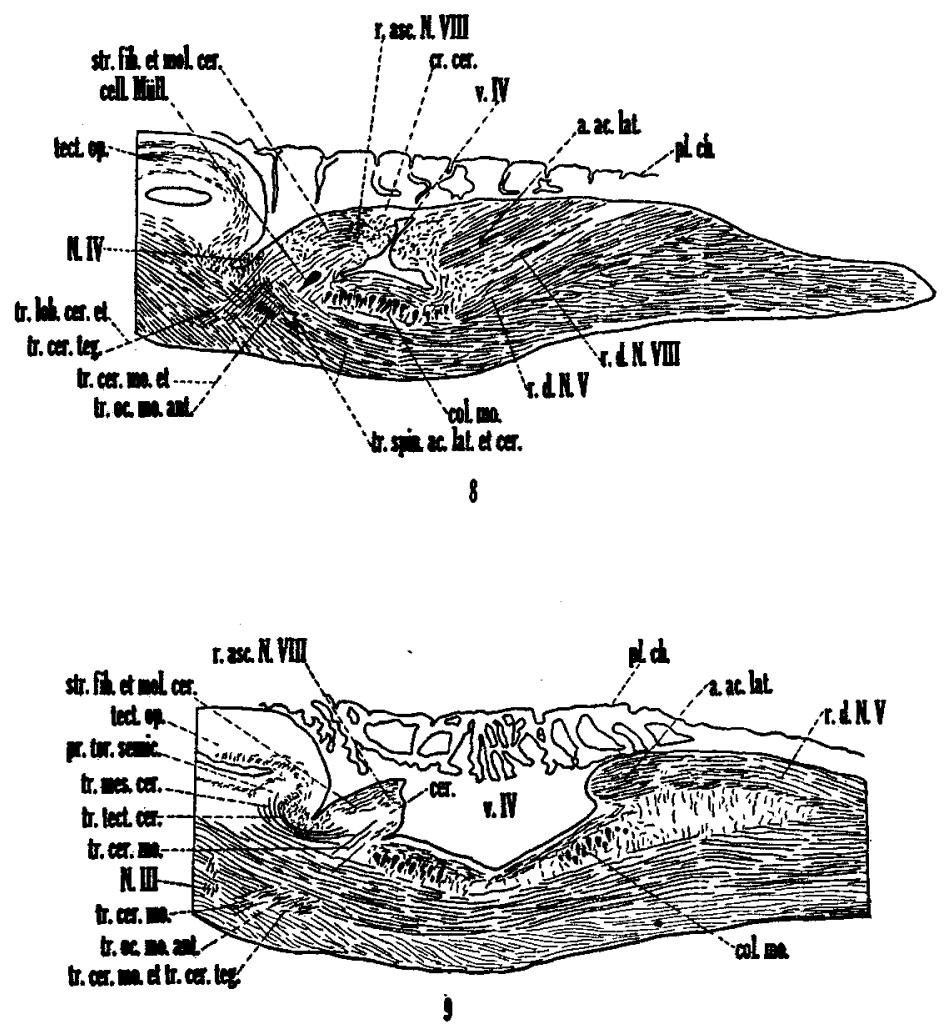

Fig. 8 A sagittal section through the more lateral portion of the brain wall of Entosphenus appendix, illustrating the course of the spino-cerebellar tract. Pyridine silver preparation. $\times 20$.

Fig. 9 A sagittal section of the brain of Entosphenus appendix medial to that illustrated in figure 8 and intended to show especially the connections between the cerebellum and the tectum. Pyridine silver preparation. $\times 20$.

(fig. 9) and, in ganoids, form one of the components of the tractus mesencephalo-cerebellaris. The more lateral fibers of the dorsal portion include the cerebello-tectal fibers, which, after a decussation in the cerebellar commissure, pass forward 
to enter the superficial layers of the tectum. In the material available, uncrossed fibers are not demonstrable.

The intermediate portion of this fan of fibers is formed by the forerunners of the lobo-cerebellar and uncrossed cerebellotegmental systems of higher forms. These fibers pass forward, ventralward and somewhat medialward. Certain fascicles run internal to the ventrolateral rostral nucleus of the III nerve, some bundles swing toward the midline to decussate together with those of the cerebello-motorius system, while other fascicles distribute to the tegmental gray of the same side, extending forward to the hypothalamic gray. This system probably carries the crossed and uncrossed lobocerebellar tract of Johnston ('02; see also Clark, '06). In their course these bundles are associated with a large tract connecting the hypothalamic regions with the bulb.

The ventral portion of the fan of fibers forms largely a cerebello-motorius (figs. 6 to 9) and a crossed cerebellotegmental system (figs. 8,9), but any line drawn between these fibers and those of the foregoing system is arbitrary. On leaving the cerebellum, the more cephalic bundles of the ventral portion swing ventralward and forward and certain of them distribute immediately to the ventrolateral rostral III nucleus of Addens ('28), which is situated at the periphery of the brain in Petromyzontia. The more caudal bundles are directed ventralward. Fibers of both the caudal and cephalic groups gradually converge toward the midline in a broad curve, corresponding to that of the brain wall, and decussate ventral to the ventricle. This decussation extends forward beneath the nuclei of the III nerves. Partly before and partly after the decussation, these fibers distribute to the nucleus dorsomedialis of the III nerve, the medial longitudinal fasciculus and the motor nuclear column of the medulla oblongata.

THE AREA ACUSTICO-LATERALIS AND THE CEREBELLUM IN CERTAIN GANOIDS

To review adequately all of the literature dealing with the acustico-lateral system and the cerebellum of ganoids and 
teleosts is far beyond the limits of this discussion. For such reviews the reader is referred to texts, such as that of Ariëns Kappers, Huber and Crosby ('36). In the following account only references pertinent to the subject under discussion will be mentioned.

The cellular pattern of the area acustico-lateralis and the cerebellum in Amia calva ${ }^{2}$

Area acustico-lateralis. The acustico-lateral area in ganoids, as in cyclostomes, may be divided into a dorsal, a medial and a ventral nucleus. The nucleus dorsalis is well developed in certain ganoids, Acipenser (Johnston, '01, lobus lineae lateralis) and Polyodon (Hocke Hoogenboom, '29), but is completely absent in Amia, since there is no gray of the acustico-lateral area dorsal to the cerebellar crest and no dorsal division of the anterior lateral line nerve such as distributes to the nucleus dorsalis where present.

Nucleus medialis. The nucleus medialis of this account corresponds to the medial nucleus of Ariëns Kappers ('20), Hocke Hoogenboom ('29) and Ariëns Kappers, Huber and Crosby ('36). In petromyzonts, the acustico-lateral area represents a forward continuation of a differentiated portion of the dorsal gray in the caudal end of the medulla oblongata. In this respect Amia is similar, in that the medial nucleus is continuous with the nucleus funiculi posterioris. The medial nucleus of the acustico-lateral area (figs. 10 to 12 and 18) extends from the region of the calamus scriptorius to the cerebellum, where it becomes continuous with the gray of the eminentia granularis. It is not possible to point out a definite caudal limit, as there is no differentiation between the gray of the cephalic end of the nucleus funiculi posterioris and the caudal end of the acustico-lateral area. The caudal pole of the medial nucleus is seen as a small mass of gray in the dorsal part of the medulla oblongata, in a plane a little cephalad to the calamus scriptorius. As it is followed forward, the medial

\footnotetext{
Amia belongs to the Holostei, a group of fishes commonly referred to as ganoids, which also includes Chrondrostei and Crossopterygii.
} 
nucleus keeps the same relative position and gradually enlarges (figs. 10, 11). A fiber layer, the crista cerebellaris, which is quite thin at first, accumulates along its dorsal boundary, while along its ventromedial border lies the solitary fasciculus. Ventrally and laterally its neurons are scattered
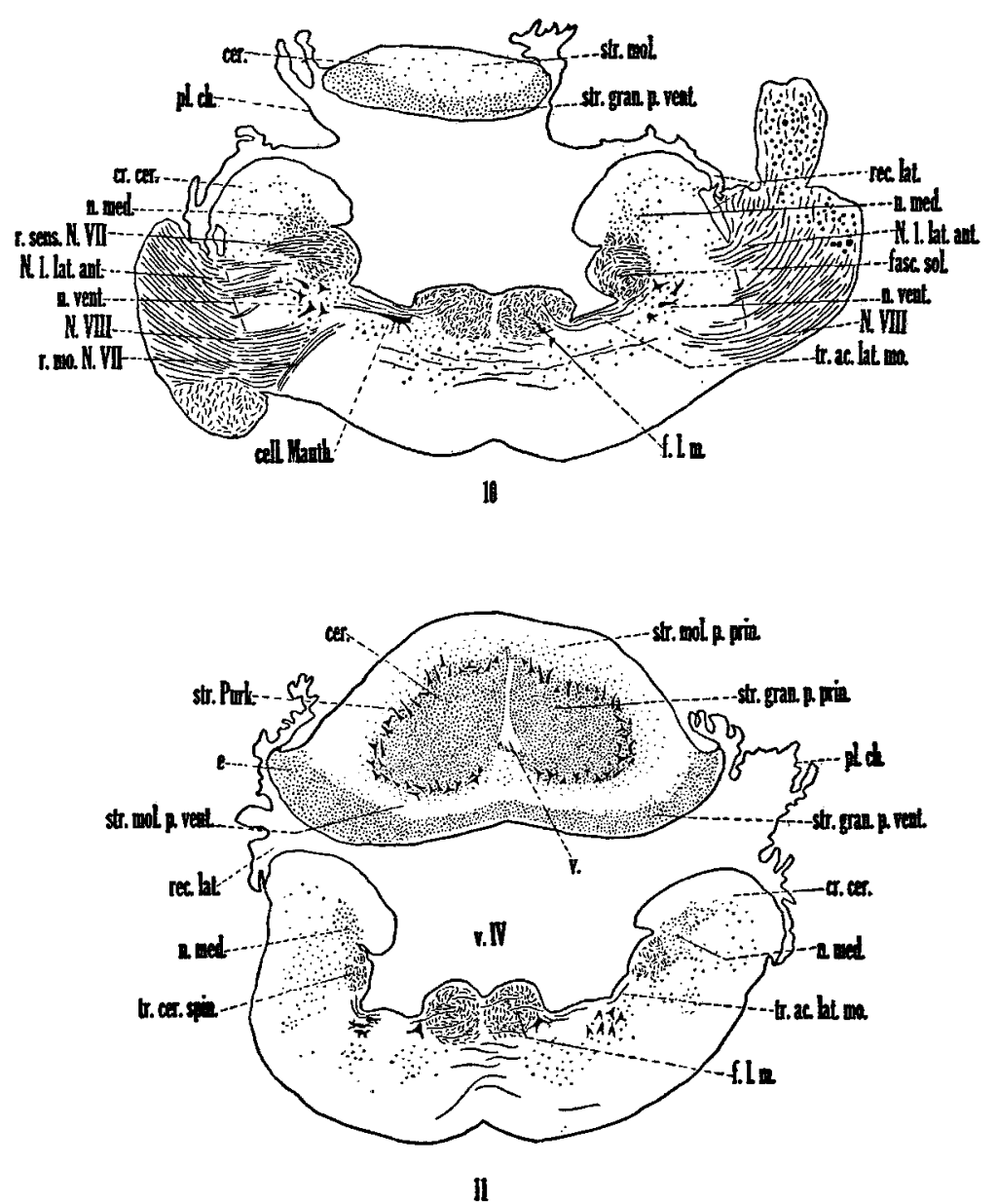

Fig. 10 A transverse section of the medulla oblongata of Amia calva at the level of entrance of the VIII and the anterior lateral line nerves, showing the position of the medial and ventral nuclei of the acustico-lateral area. Toluidin blue preparation. $\times 10$.

Fig. 11 A transverse section through the brain of Amia calva, passing through the more caudal portion of the cerebellum and showing particularly the relations of the granular and the molecular layers. Toluidin blue preparation. $\times 10$. 
among fiber bundles but are more densely packed nearer the ventricular wall. In a plane just caudal to the entrance of the VIII nerve, the medial nucleus is larger and occupies the greater part of the dorsal and lateral regions of the medulla oblongata. At the level of entrance of this nerve (fig. 10), the medial nucleus is broken into by fiber bundles, which give it a more scattered appearance. Here it lies in particularly intimate relation with the ventral nucleus of the acustico-lateral area. The cephalic end of the medial nucleus, before becoming continuous with the gray of the eminentia granularis, becomes separable (fig. 12) into a dorsal portion of small cells (a nucleus medialis pars dorsalis), and a ventral portion of somewhat larger, irregular cells (a nucleus medialis pars ventralis). The two portions are differentiable for a short distance only, for if traced forward they are lost in the gray of the eminentia granularis, while, if followed caudalward, the dorsal portion soon becomes scattered while the ventral portion becomes continuous with the remainder of the medial nucleus.

Nucleus ventralis. The ventral nucleus of the acusticolateral area has been recognized by Kingsbury (1897), Ariëns Kappers ('20), and others. Certain authors consider it to be homologous with Deiter's nucleus of higher forms. At the level where it is most conspicuous this nucleus (fig. 10), made up of large, multipolar cells, is situated lateral to the motor cell column, ventrolateral to the fasciculus solitarius, in close relation with the medial nucleus, and directly in the path of the entering fibers of the VIII nerve. More than five or six of its characteristically large cells are seldom seen in one section. Cephalic to the level of entrance of the VIII nerve fibers, these large cells soon disappear.

Layer arrangement of the corpus cerebelli. Studies of the structure of the cerebellum of ganoids have been made by Johnston ('01, Acipenser), Ariëns Kappers ('07, Amia), Palmgren ('21, Acipenser and Lepidosteus) and Hocke Hoogenboom ('29, Polyodon). A brief comparison of the cerebellum of Amia with that of Ceratodus was given by van der Horst ('25). 
Stratum granulosum and stratum Purkinje. In Amia there are two distinct portions of the gray of the corpus cerebelli: a stratum granulosum pars ventralis, which is a thin band ventral to the ventral part of the molecular layer, and a stratum granulosum pars principalis, which is the main portion of the cerebellar gray and is deep to the molecular layer. The pars ventralis (figs. 10,11, 16, 17) is shown in the caudal part of the cerebellum, between the molecular layer and the ventral cerebellar wall. It thins out somewhat toward the midline but thickens laterally. A sulcus in the lateral wall of the cerebellum indicates externally the boundary between the ventral molecular layer and this part of the granular layer. The pars ventralis bifurcates at the level where the cerebellar ventricle opens ventrally and each of the two portions thus formed extends forward in the ventrolateral part of the cerebellum. The pars ventralis can be traced frontalward in this position to the region where the ventrolateral part of the cerebellum fuses with the acustico-lateral area. It is this prolongation of the pars ventralis on either side of the brain-a prolongation situated in relation to the lateral recess-which represents the auricle in Amia. Laterally its cephalic portion gradually thins out and passes, without distinct demarcation, into the cerebellar molecular layer, dorsally, and into the cerebellar crest, ventrally. The remaining gray spreads along the ventricular wall adjoining the cerebellar crest and thus becomes continuous with the dorsal portion of the medial nucleus of the acustico-lateral area. In a plane slightly caudal to the eminentia granularis, the pars ventralis of the cerebellar gray is markedly reduced. In a similar section van der Horst ('25) designated it as the 'rest of the auricle.' It is termed the auricle (fig. 12, left) in the present account. For a short distance frontal to this level, the pars ventralis is seen as a mass of gray adjoining the ventricular wall in the region of the sulcus marking the boundary between the molecular layer of the cerebellum and the cerebellar crest, but it is ultimately lost in the gray of the eminentia granularis. This stratum granulosum pars ventralis probably 
includes the scattered granule cells which van der Horst ('25) found between the fibers on the ventricular side of the cerebellum in Amia, and corresponds to the 'string of granular cells' in Lepidosteus osseus figured by Palmgren ('21).

The stratum granulosum pars principalis (figs. 11 to 14,16 , 17) constitutes the main portion of the cerebellar gray. It is surrounded on three sides by the molecular layer and on the fourth side is adjacent to the ventricular wall. The cerebellar ventricle separates it completely into bilateral halves. Each half is divisible into two parts: a lateral portion, the stratum granulosum pars principalis lateralis (figs. $12,16)$, which is continuous laterally with the gray of the eminentia granularis, and a medial part, the stratum granulosum pars principalis medialis (figs. 12 to $14,16,17$ ), which is continuous with the gray of the valvula. The two parts are fused completely at the caudal end of the cerebellum (fig. 11). In cross sections through this caudal end, the pars principalis is seen as a mass of gray on either side of the cerebellar ventricle, bounded dorsally, laterally and ventrally by the molecular layer. Traced forward these gray masses begin to extend ventrally and laterally. A sulcus appears in the dorsolateral wall of the cerebellum, which indicates externally the line of separation between the medial and lateral portions of the pars principalis. This line is indicated further by a thinning of the gray between the two parts. As the pars principalis is traced forward, the two positions become completely separated. The lateral part extends in a ventral and lateral direction in order to fuse with the gray of the eminentia granularis. The medial part continues forward for a short distance and then extends directly ventrally. This is well shown in sagittal sections (fig. 17), where the shape of the cerebellum resembles that of a question mark.

Most of the neurons constituting the gray of the corpus cerebelli have medium or small sized cell bodies and probably are comparable to the granule cells of the cerebellum of higher forms. The stratum granulosum pars ventralis consists 
almost exclusively of such granule cell types. However, the pars principalis presents more cellular differentiation, in that certain of its neurons are somewhat larger, with cell bodies evidencing a tendency to migrate to a position between the
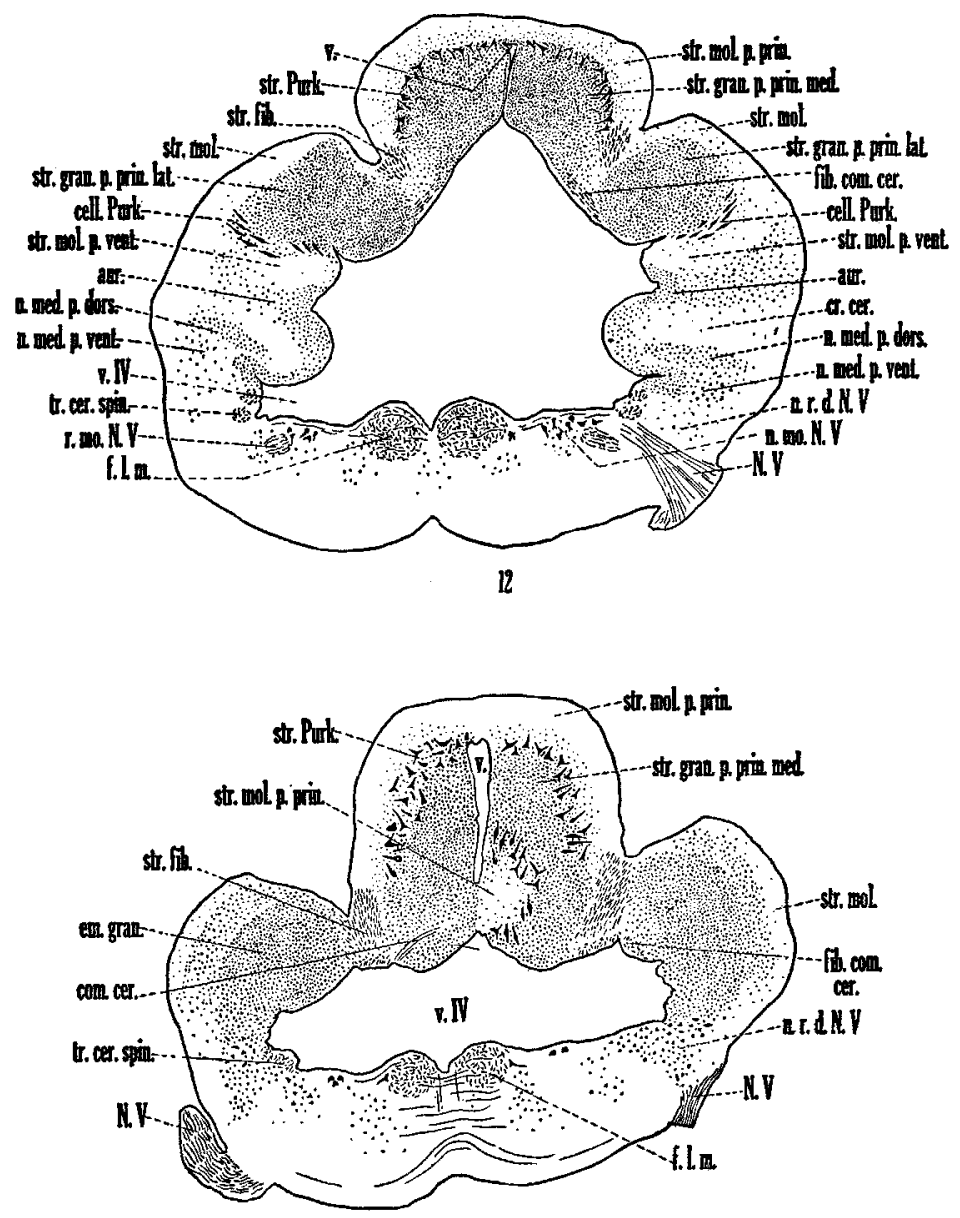

13

Fig. 12 A transverse seetion through the brain of Amia calva at the level of junction of the cerebellum with the acustico-lateral area, showing the layers of the cerebellum. Toluidin blue preparation. $\times 10$.

Fig. 13 A transverse section through the more cephalic end of the cerebellum of Amia calva. This section shows the position of the corpus cerebelli and of the eminentia granularis. Toluidin blue preparation. $\times 10$. 
cerebellar molecular layer and the cerebellar gray. In some places these cells show the beginning of a layer formation but, for the most part, are scattered through the peripheral portion of the gray constituting the pars principalis. The Purkinje cells showing this inclination toward layer formation are associated with certain small fiber bundles which are more conspicuous in planes toward the midline. This layer of cells and fiber bundles will be designated the stratum Purkinje (figs. 11 to 14, 16, 17) and the fibers contributing to it will receive consideration with the tracts of which they are a part. The arrangement of the Purkinje cells in Amia is very similar to that of the homologous cells in Ceratodus as described by Holmgren and van der Horst ('25).

Stratum moleculare. The moleculare layer is mainly superficial to the cellular layers. Johnston ('01) observed that, in Acipenser, the ground substance consists largely of fine fibers, chiefly from the granular layer, into which the dendrites of the Purkinje cell spread widely. Van der Horst ('25) designated a dorsal molecular mass and a ventral molecular mass in Amia and pointed out that the ventral molecular mass consists of crossing fibers from the crista cerebellaris, forming the tractus vestibulo-cerebellaris.

The cerebellar molecular layer, although fused in the caudal end of the cerebellum, divides into two laminae as it is followed cephalad. These two laminae are named with respect to their relations to the stratum granulosum pars principalis, one lying dorsal and lateral, a stratum moleculare pars principalis or stratum moleculare dorsalis (figs. 11 to $14,16,17,21$, 22 ), and the other being ventral and lateral, a stratum moleculare ventralis (figs. 11, 12,16, 17, 21, 22). The principal molecular layer, in turn, becomes divided frontally into two portions: a medial part, which continues over the body of the cerebellum and into the cerebellar valvula, and a lateral part, on either side, which is superficial to the stratum granulosum pars principalis lateralis. The ventral layer, the stratum moleculare ventralis, is partly separated from the ventricular wall by the stratum granulosum pars ventralis. This ventral 
layer is continuous across the candoventral part of the cerebellum, but, followed cephalad, it recedes laterally as the eminentia granularis is approached and fuses, in part, with the cerebellar crest; the remainder loses itself in the region.

Stratum fibrosum. In addition to the molecular, the granular, and the Purkinje cell layers, there is a definite fiber layer, the stratum fibrosum (figs. 12 to 14, 16, 17, 21, 22), which is formed by the afferent and efferent fiber systems of the corpus cerebelli. This stratum is roughly divisible into two parts; of these a superficial portion lies lateral and partly in front of a deep portion, which is nearer the midline. The superficial portion is thought to be formed chiefly by fiber tracts entering the cerebellum, while the deep portion is constituted largely by the efferent systems arising from that center.

Cerebellar crest. Kingsbury (1897) pointed out that the acustico-lateral area is capped by a caudal extension of the molecular layer of the cerebellum, the cerebellar crest of most investigators. In Amia this crest (figs. 10 to 12, 18, 21) can be followed caudalward as a definite layer to about the level of entrance of the $\mathrm{X}$ nerve, where it gradually disappears. Into this area extend dendrites of neurons, the cell bodies of which lie in the acustico-lateral area, so that the crest has much the same relations to the underlying region that the molecular layer has to the granular layer of the cerebellum.

Auricula cerebelli. The auricle is represented in Amia by the prolongation forward, on either side of the cerebellum, of the pars ventralis of the stratum granulosum (p. 228, and fig. 12). All of the neurons constituting the auricular gray appear to be granule cells.

Eminentia granularis. This part of the cerebellum has been identified in Amia by van der Horst ('25) and is homologous with the same structure as described for teleosts (p. 260). The eminentia granularis (figs. 13,14) is constituted largely of granule cells. Caudally this mass of cells is separated partially from the brain wall by a portion of the molecular layer (that portion continuous caudally with the principal 
part of the molecular layer overlying the stratum granulosum pars principalis lateralis and with the cerebellar crest). On its medial surface, the eminentia granularis is bounded by the stratum fibrosum of the cerebellum and the adjacent portion of the ventricular wall. At certain levels the eminence is pushed away from the ventricular wall by fiber bundles (fig. 14). Farther forward it disappears. The gray of the eminentia granularis is continuous caudally with the stratum granulosum pars principalis lateralis and with the medial nucleus of the acustico-lateral area. Van der Horst ('25) mentioned a band of granule cells along the roof of the fourth ventricle in the frontal part of the cerebellum, connecting the two eminentiae granulares. It has not been possible to identify this band in the material available.

The valvula cerebelli. The valvula, as well as the corpus cerebelli, shows striking modifications in the various forms. It has been recognized in ganoids of Johnston ('01), Ariëns Kappers ('07) and Hocke Hoogenboom ('29). Johnston found the several types of neurons which he identified in the valvula to be comparable to those present in the cerebellum.

The valvula cerebelli (figs. 17, 19, 22) in Amia is very small as compared with the homologous structure in teleosts (p. 256). It consists of a fiber layer, continuous with the cerebellar molecular layer (figs. 17, 22), and of a mass of gray, continuous with the medial portion of the stratum granulosum pars principalis medialis. This gray of the valvula borders on the dorsal wall of the fourth ventricle (figs. 15, 17) and is surrounded on the other three sides by fiber bundles. It continues forward for only a short distance. At intervals it is broken into by components of the cerebellar commissure (fig. 17). The major number of cells constituting the valvula cerebelli belongs to the granule type of neuron. However, a few larger cells, possibly representatives of Purkinje cells, are found in the caudal portion of the valvula where this portion is continuous with the pars principalis medialis of the corpus cerebelli. 
Nucleus lateralis valvulae. In Amia, the nucleus lateralis valvulae (figs. 15 to 17 ) is formed by a collection of small neurons extending from a plane a little frontal to the corpus cerebelli to the level of the nucleus of the III nerve. The caudal end of the nucleus lateralis valvulae is recognized as scattered gray, lateral to the cerebellar valvula, from which it is separated by bundles of fibers. This nucleus lies ventral
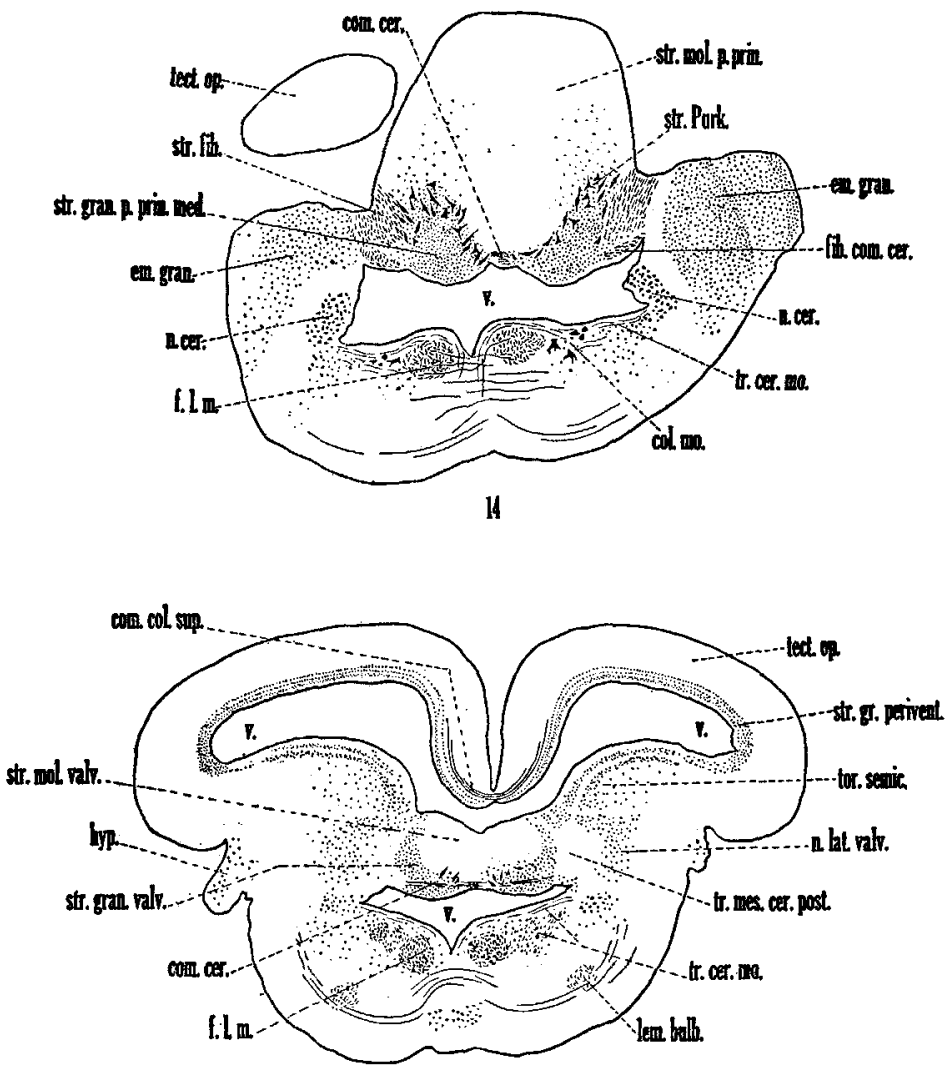

15

Fig. 14 A transverse section through the cephalic portion of the cerebellum of Amia calva, illustrating particularly the eminentia granularis and the nucleus cerebelli. Toluidin blue preparation. $\times 10$.

Fig. 15 A transverse section through the midbrain of Amia calva, drawn with special reference to the nucleus lateralis valvulae and the valvula cerebelli. Toluidin blue preparation. $\times 10$. 
to the torus semicircularis and lateral to the ventricle. Along its lateral border are fibers of passage. A nucleus lateralis valvulae described in Polyodon by Hocke Hoogenboom ('29) is homologous with the similarly named cell area in teleosts (p. 260).

Nucleus cerebelli. In a plane through the cephalic end of the cerebellum a mass of gray will be seen along the lateral wall of the ventricle (figs. 14, 16, 21), separated by fiber

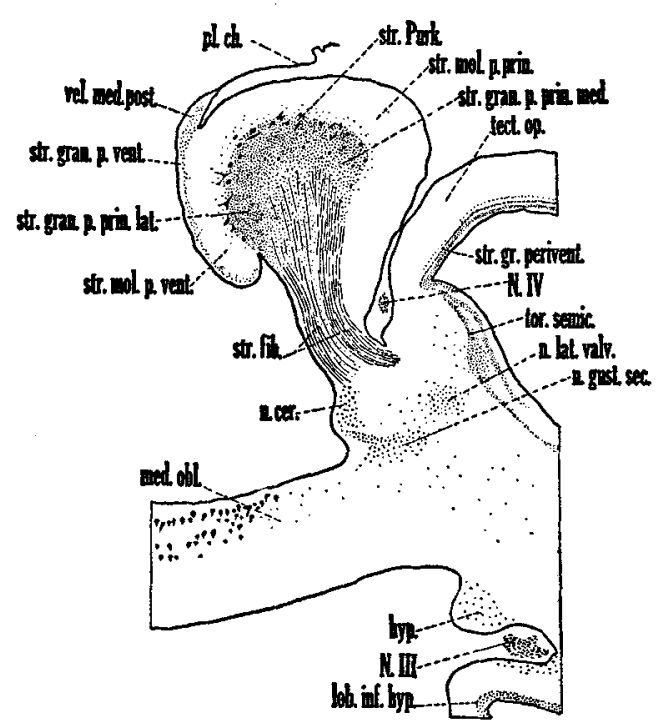

Fig. 16 A sagittal section through the cerebellum of Amia calva, demonstrating the layers of the cerebellum and the position of the nucleus cerebelli. Toluidin blue preparation. $\times 10$.

bundles from the cephalic end of the gray of the eminentia granularis. Farther forward, this gray mass, after turning the angle of the ventricle, lies in part above it at the junction of the valvula with the corpus cerebelli, and soon thereafter disappears. In Amia this nucleus consists of distinetly multipolar, deeply staining elements which do not show any marked resemblance to the cells of the granular layer. The nucleus here described is probably not the nucleus lateralis cerebelli of teleosts as described by Ariëns Kappers ('06). 
However, possibly it corresponds to the nucleus lateralis cerebelli described by Holmgren and van der Horst ('25) for Ceratodus and by Hocke Hoogenboom ('29) for Polyodon.

Close to the ventral border of the nucleus cerebelli is a cell mass which extends forward in front of this nucleus and into relationship with the nucleus lateralis valvulae. This cell mass is homologous with the superior secondary gustatory nucleus described by Herrick ('05) for teleosts. At its caudal pole it is not sharply separable from the nucleus cerebelli of Amia, but, followed forward, differences in position and massing of the cells permit such differentiation.

Fiber connections of the area acustico-lateralis and the cerebellum in Amia calva

The VIII nerve and the lateral line nerves. The VIII nerve. The central course of the fibers of VIII has been studied in Amia by Kingsbury (1897) and Ariëns Kappers ('07), in Acipenser by Johnston (1898 and '01), and in Polyodon by Hocke Hoogenboom ('29). The following account agrees in general with the findings of the above investigators.

In Amia the VIII nerve (fig. 10) enters the medulla oblongata ventral to the anterior lateral line nerve. Certain of its fibers are thought to bifurcate, while many of them pass directly medialward to end in the nucleus ventralis (fig. 10). Other fibers of this nerve course frontalward or caudalward, many of them being grouped into small bundles. The fascicles which course caudalward are distributed to that portion of the medial nucleus behind the level of entrance of the nerve. A portion of the fibers turning frontalward break up among the cells of the cephalic part of the medial nucleus, while others run in close relation to the cerebello-spinal tract and appear to terminate in the nucleus cerebelli. Fascicles of the VIII nerve extend beyond the acustico-lateral gray to end in the eminentia granularis.

Anterior lateral line nerve. As van der Horst pointed out, the lateral line fibers in Amia enter the medulla oblongata 
ventral to the cerebellar crest. In Acipenser (Johnston, '01), Polyodon (Hocke Hoogenboom, '29) and Ceratodus (Holmgren and van der Horst, '25), the anterior lateral line nerve enters by two roots, one dorsal to the cerebellar crest and the other ventral to it. Hocke Hoogenboom described the dorsal root (the nervus lateralis anterior dorsalis) as coursing both caudalward and frontalward and as coming into relation with the nucleus dorsalis (lobus dorsalis). She found the ventral root (the nervus lineae lateralis anterior ventralis) to have ascending and descending fibers, which distributed chiefly to the nucleus medialis of the acustico-lateral area. She traced a few fascicles of the ventral root to the dorsal nucleus (dorsal lobe), a few to the cerebellum and a small number to the cerebellar crest.

In Amia, the anterior lateral line nerve (fig. 10) enters the medulla oblongata, ventral and a little caudal to the visceral sensory root of the VII nerve. The fibers pass into the medial nucleus of the acustico-lateral area and distribute throughout its extent. Within the nucleus, part of the fascicles extend frontalward and a part caudalward, as Ariëns Kappers observed. The remaining fibers are scattered throughout the acustico-lateral area. Part of these frontally directed fibers end in the eminentia granularis and possibly in the valvula.

Posterior lateral line nerve. Kingsbury (1897) described lateral line fibers in both the IX and $X$ nerves in Amia. The posterior lateral line nerves of certain of the ganoids have been considered as entering with the IX nerve (Ariëns Kappers, '07 and '20, and Hocke Hoogenboom, '29). Norris ('25) carried in lateral line fibers with the $X$ nerve in Amia and Lepidosteus. In the Dipnoi, Ceratodus, Holmgren and van der Horst ('25) found lateral line fibers entering the medulla oblongata dorsal to the IX nerve and in front of it. After entering, the major portion of the posterior lateral line root fibers can be traced either rostralward or caudalward (Ariëns Kappers, '07; Johnston, '01; Holmgren and van der Horst, '25; and Hocke Hoogenboom, '29), according to certain observers (Ariëns Kappers), after a bifurcation of the 
entering fibers. Some of the rostrally coursing fibers have been traced to the cerebellum by Johnston ('01) and by Hocke Hoogenboom ('29), and also, according to the latter

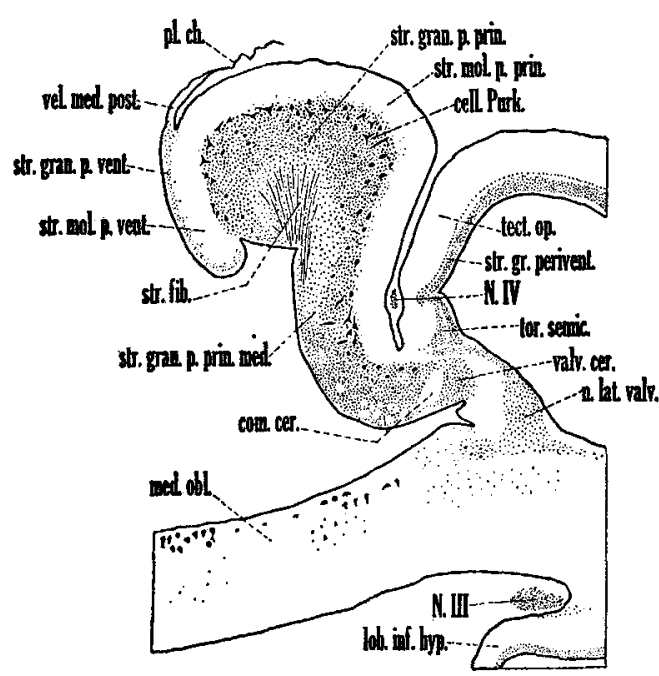

17

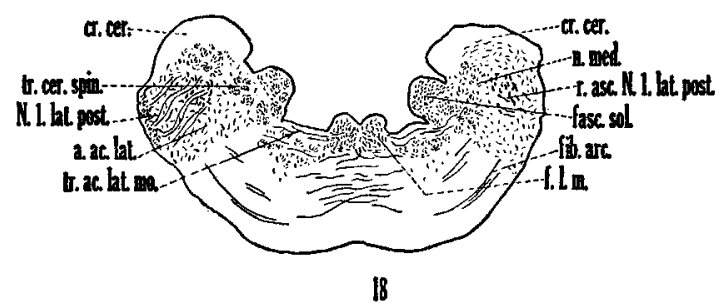

Fig. 17 A sagittal section through the brain of Amia calva. The positions of the corpus cerebelli and the valvula cerebelli are indicated in the figure. Toluidin blue preparation. $\times 10$.

Fig. 18 A transverse section through the medulla oblongata of Amia calva at the level of the posterior lateral line nerves. Pyridine silver preparation. $\times 10$.

observer, to the auricle. The small size of the auricle in Amia makes it difficult to trace lateral line fibers to it. Along the course of these ascending bundles, branches are given off 
which terminate in the medial nucleus of the acustico-lateral area (fig. 18) and in the eminentia granularis. The descending fibers terminate in the gray of the medial nucleus along their course.

The spino-(acustico-latero-) cerebellar system. Ariëns Kappers ('07) considered the possibility of a spino-cerebellar connection in Amia. Hocke Hoogenboom ('29) identified this tract in Polyodon and found the greater part of its fibers to be uncrossed.

The spino-cerebellar tract in Amia (fig. 19) constitutes a large bundle of fibers which passes forward from the caudal end of the medulla oblongata, in close relation to the descending root of the $V$ nerve. At the level of entrance of the $\mathrm{V}$ root this tract begins to swing dorsalward in a broad curve. The more lateral fibers of the tract end in the eminentia granularis, while the deeper fibers swing medially and dorsally into the cerebellum. Many of the most medial fibers continue toward the midline to cross in the cerebellar commissure. This system without doubt contains fibers interconnecting the spinal cord with the acustico-lateral area, and such fibers would correspond to the spino-acustico-lateral component in Petromyzontia.

Bulbo-cerebellar system. Ariëns Kappers ('07) pointed out ascending secondary fibers from the medulla oblongata to the cerebellum, which he designated the nucleo-cerebellar tract. It was found that the secondary acustico-lateral connections to the cerebellum form a large but scattered system of fibers in Amia. These fibers have their origin in the acustico-lateral gray and the nucleus of the descending root of $\mathrm{V}$, and course frontalward in small bundles or as scattered fibers without definite arrangement. In sagittal sections many of them are found to swing in broad curves, deep to the eminentia granularis, into the corpus cerebelli, the majority ending in the corpus and in the eminentia granularis. A portion of such fibers, particularly those to the corpus cerebelli, decussate in the cerebellar commissure before their termination. Without doubt, certain of these fibers sweep more rostrally to end in the valvula cerebelli. 
Secondary fibers from the acustico-lateral region pass into the cerebellum by way of the cerebellar crest, entering the ventral molecular layer. Such fibers are well shown in sagittally cut pyridine silver preparations, as darkly staining fascicles situated in the ventral molecular layer, and can be

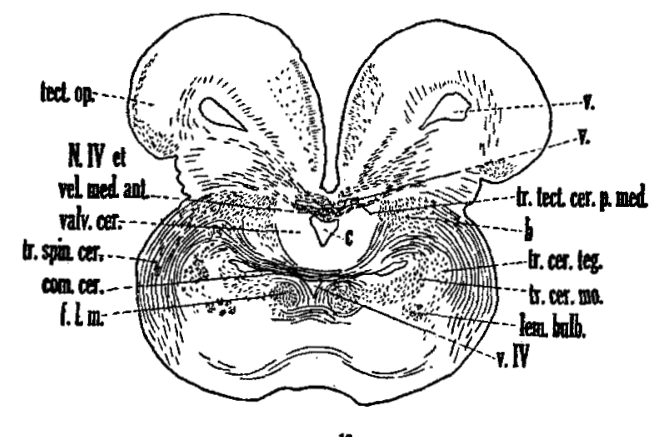

19

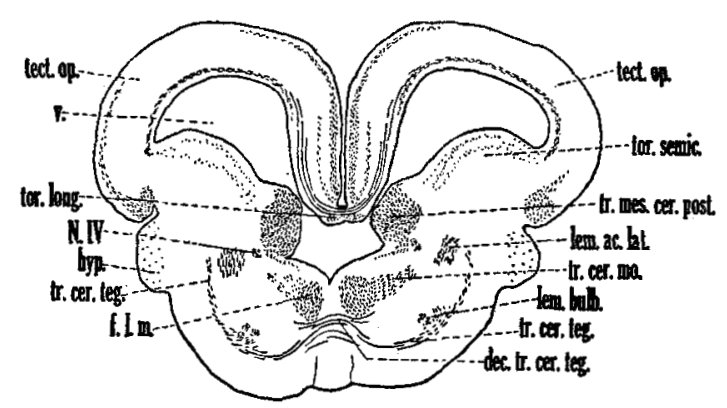

20

Fig. 19 A transverse section of the brain of Amia calva at the level of the cerebellar commissure. Pyridine silver preparation. $\times 10$.

Fig. 20 A transverse section through the midbrain of Amia calva, showing in particular the lemniscus acustico-lateralis, the tractus mesencephalo-cerebellaris posterior, the tractus cerebello-tegmentalis and the tractus cerebello-motorius. Pyridine silver preparation. $\times 10$.

followed to the midline, where many of them decussate. These fibers from the cerebellar crest crossing through the ventral molecular layer probably are the bundles designated as the tractus vestibulo-cerebellaris by van der Horst ('25). 
In Amia they distribute to the corpus cerebelli (fig. 22, a) by extending dorsalward and then forward into the fiber layer associated with the Purkinje cell layer (p. 231). The fibers turning into the Purkinje cell layer are best seen in sagittal sections, close to the midline.

Lemniscus acustico-lateralis. From the secondary sensory centers of the medulla oblongata, including the acusticolateral area, ascending fibers arise and extend forward, forming the homologue of the bulbar lemniscus of Petromyzontia. The acustico-lateral portion of this general bulbar lemniscus system is much better developed in Amia than in Entosphenus appendix and, for a part of its course, is distinct from the general bundle. Consequently the name of acustico-lateral lemniscus is used in Amia (as in teleosts) to distinguish this portion of the general bulbar lemniscus. These secondary ascending fibers from the acustico-lateral area of ganoids have been termed the lateral longitudinal fasciculus by Ariëns Kappers ('07, '20 and '29), Hocke Hoogenboom ('29) and others, and, less preferably, the lateral lemniscus by Ariëns Kappers ('20 and '29). The acustico-lateral lemniscus in Amia is formed largely of arcuate fibers, which arise from practically the whole extent of the acustico-lateral area. These fibers (fig. 18) decussate and accumulate in close relation to the bulbar lemniscus which lies approximately halfway between the midline and the lateral surface, lateral and somewhat ventral to the medial longitudinal fasciculus. On approaching the level of the IV nerve, the fibers forming the acustico-lateral lemniscus (fig. 20) turn slightly dorsalward, at the same time continuing rostralward. They may be accompanied by other fibers of the bulbar lemniscus, the major portion of which continues forward in much the same position, to terminate in higher centers. The fibers of the acusticolateral lemniscus can be followed into a position lateral to the nucleus lateralis valvulae, where they are joined by fibers from the cerebellum, which accompany them cephalad. Fibers of the acustico-lateral lemniscus are believed to enter the nucleus lateralis valvulae. The remainder of the bundle 
distributes to the torus semicircularis (the nucleus medialis tegmenti of Hocke Hoogenboom, '29).

Ariëns Kappers ('29) considered that, by this path, static impulses are carried to the torus semicircularis, which has become a center per se, and that the roof and the tegmentum of the midbrain are important as somatic correlation centers for optic, static, and cutaneous impulses and those arising from muscles. He further pointed out that such correlations are transmitted in part to the cerebellum, by the tecto- and mesencephalo-cerebellar tracts, and in part to motor centers.

Cerebellar commissural system. Decussation of the IV nerve. There is a conspicuous system of fibers (com.cer., figs. 13 to $15,17,19,22$ ) crossing the midline through the base of the corpus cerebelli and the valvula cerebelli. As these fibers approach the midline, they collect in compact bundles close to the ventricular wall. This commissural system of fibers is very complex and difficult to analyze; however, without doubt it contains: 1) certain fibers from the spinoand bulbo-cerebellar tracts; 2) fibers connecting the corpus cerebelli, the valvula cerebelli, the eminentia granularis, the nucleus lateralis valvulae, the nucleus cerebelli and the secondary gustatory nucleus, with centers on the opposite side; 3) possibly direct fibers from VIII and the lateral line nerves to the contralateral cerebellar gray. Pyridine silver sections, cut in the sagittal plane, reveal bundles of dark fibers turning out of the commissure (fig. 22) and passing dorsalward, at first close to the ventricular wall and then into a fiber zone associated with the Purkinje cells and situated between the molecular and the granular layers of the corpus cerebelli.

In Petromyzontia the decussation of the IV nerve was incorporated with other components of the cerebellar commissure. In Amia the central course of the IV nerve (figs. 19, 20, 22 ) is of interest because of its relation to the valvula cerebelli. The fibers of this nerve are seen as darkly stained bundles, passing lateralward and slightly dorsalward from the nucleus of the IV nerve, which is situated dorsal to the medial longitudinal fasciculus. On reaching a position 
ventrolateral to the tractus mesencephalo-cerebellaris posterior (fig. 20), the fibers of IV turn caudad in small bundles and become intermingled somewhat with the fiber bundles of that region. At the level of the cephalic end of the valvula, these fascicles run toward the midline and, passing through the tractus mesencephalo-cerebellaris, enter the frontal end of the valvula as a scattered sheet of darkly staining fibers, which mingle with the cephalic fibers of the cerebellar commissure. Here they pass to the dorsomedial wall of the valvula where they turn caudalward. Toward the caudal end of the valvula, the fascicles of the two sides fuse to form a single fiber mass in the midline. This relation is seen for only a short distance, for at the level of the caudal end of the tectum and the cephalic end of the cerebellum, the fibers separate into two bundles, one for each side, which constitute the two IV nerves.

Acustico-latero-motorius system. This system corresponds to the tractus vestibulo-motorius of Ariëns Kappers ('07) and the tractus octavo-motorius of Hocke Hoogenboom ('29). The tractus acustico-latero-motorius (figs. 10, 11, 18) might well be described with the cerebello-motorius bundles. It constitutes a scattered system of fibers, with cells of origin in the nuclei of the acustico-lateral area, which swings along the ventrolateral wall of the ventricle toward the medial longitudinal fasciculus. It is difficult to determine the exact distribution, since the fibers of this system do not stand out so clearly as do those of the corresponding system in the Petromyzontia, but it is apparent that they enter the medial longitudinal fasciculus and the region of the motor cell column. Certain fascicles cross the midline to reach the corresponding regions of the opposite side.

Tractus tecto-cerebellaris. In Amia, as in petromyzonts, certain tracts pass out from the cerebellum in the form of a broad fan of fibers (fig. 21), the most dorsal part of which belongs to the cerebello-tectal interconnections and the most ventral part to the cerebello-motorius system, while between, from dorsal to ventral, lie the mesencephalo-cerebellar tract, 
the lobo-cerebellar tract and the cerebello-tegmental system (or the brachium conjunctivum).

In Acipenser, Johnston ('01) identified a tecto-cerebellar system and divided it into two portions, a smaller part made up of coarse fibers which arise in the cephalic portion of the tectum, and a larger part consisting of fine fibers which assemble from the lateral part of the tectum. This observer found that the coarse fibers, on entering the cerebellum, grow larger and divide, one branch of each fiber ending in the valvula cerebelli, the other branch passing into the corpus cerebelli, where the majority of the fibers terminate in the granular layer. He traced the fine fibers into the valvula cerebelli, the corpus cerebelli and the auricles (lateral lobes of Johnston, '01). Hocke Hoogenboom ('29) noted a connection between the tectum and the cerebellum in Polyodon, comparable to that in certain of the teleosts (p. 274), and referred to this as the tractus tecto-cerebellaris, or mesencephalo-cerebellaris, anterior.

In Amia, the tecto-cerebellar system of fibers is made up of a lateral and a medial portion. The lateral part, which constitutes the tractus tecto-cerebellaris pars lateralis (fig. 21), is the larger. Its fibers arise from the caudal part of the efferent layer of the tectum (the stratum album centrale, Huber and Crosby, '33) and swing caudalward and ventralward, forming the most dorsolateral portion of the fan of fibers referred to above. In a plane just lateral to the valvula this tract swings dorsalward into the corpus cerebelli.

The medial part, the tractus tecto-cerebellaris pars medialis (figs. 19, 22), is medial to the fan-shaped system of fibers just described. It extends out of the caudal part of the efferent layer of the tectum, turns toward the midline and enters the anterior medullary velum (fig. 22), where, after a more or less complete decussation, it extends cephalad for a short distance, forming a small accumulation of fibers on either side of the midline in the velum. These fibers swing lateralward through the cephalic end of the valvula cerebelli and turn caudalward, joining the tractus mesencephalo-cerebellaris 
posterior with which they enter the cerebellum. They are distributed to the corpus and the valvula cerebelli.

Tractus cerebello-tectalis. The cerebello-tectal fibers arise in the cerebellum and pass frontalward, lateral to the valvula, the more medial fibers becoming partially intermingled with
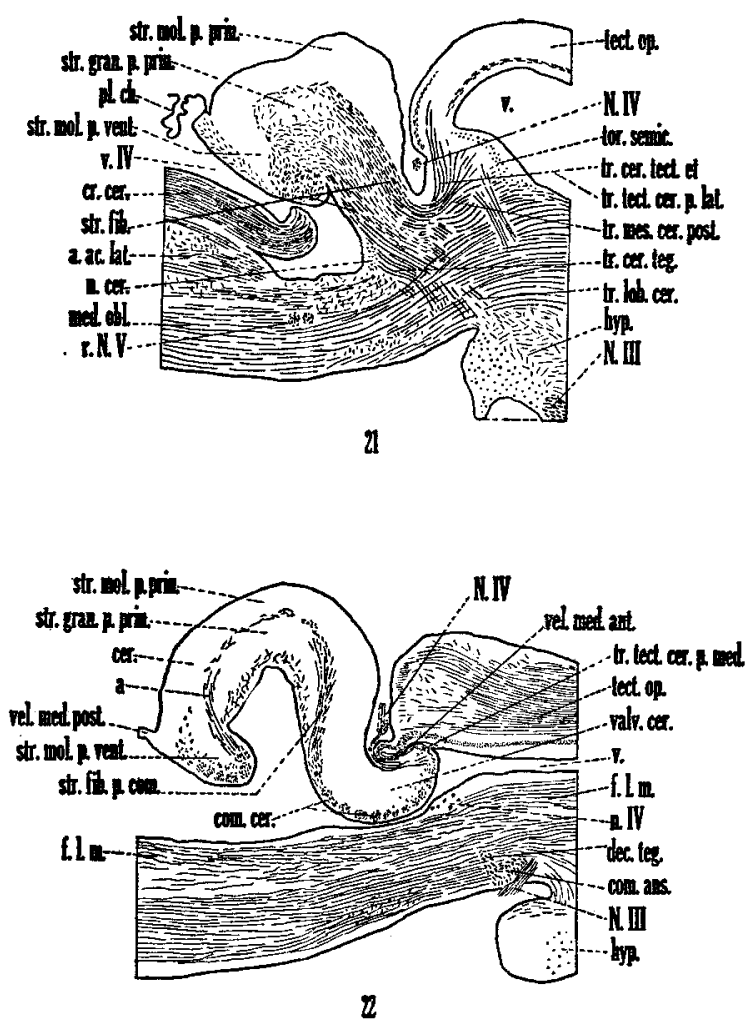

Fig. 21 A sagittal section through the brain of Amia calva, illustrating especially the fan-shaped arrangement of the fibers of certain of the cerebellar tracts. Pyridine silver preparation. $\times 10$.

Fig. 22 A sagittal section through the brain of Amia calva. In this figure the medial part of the tecto-cerebellar system is seen, and also the fiber bundles from the cerebellar commissure and from the ventral molecular layer are spreading out into the stratum Purkinje. Pyridine silver preparation. $\times 10$.

the lateral part of the tecto-cerebellar tract (fig. 21) and the more lateral fibers with those of the spino-tectal tract. These cerebello-tectal fibers swing dorsalward and lateralward, 
caudal to the torus semicircularis, and enter the afferent layers of the tectum.

Tractus mesencephalo-cerebellaris posterior. A tract arising from the nucleus lateralis valvulae has been designated the tractus mesencephalo-cerebellaris posterior by Hocke Hoogenboom, because of its homology with a tract of that name in teleosts. In Amia, a similar tract (figs. 15, 20) arises not only from the nucleus lateralis valvulae but, to some extent, from the gray of the torus semicircularis. It forms along the medial side of the nucleus lateralis valvulae, at first separating this nucleus from the ventricular wall, and later, on approaching the cerebellum, from the gray of the valvula. The tract passes directly caudalward in order to enter the cerebellum ventral to the tecto-cerebellar system of fibers and forms part of the afferent system to the cerebellum and the valvula.

Tractus lobo-cerebellaris. Johnston ('01) and Ariëns Kappers ('07) noted a crossed and an uncrossed connection between the hypothalamus and the cerebellum. In Amia, as in Polyodon (Hocke Hoogenboom, '29), this tract (fig. 21) probably arises in the inferior lobes of the hypothalamus. Fibers from the inferior lobes can be traced caudally and, at the same time, dorsally, joining the more ventral components of the fan-shaped system of fibers related to the cerebellum. It is possible that these lobo-cerebellar fibers are accompanied by bundles arising in the cerebellum and passing to the hypothalamus.

Tractus cerebello-tegmentalis or brachium conjunctivum. This connection probably includes the fiber system which Ariëns Kappers ('07) designated as the tractus cerebellotegmentalis cruciatus. In Polyodon, Hocke Hoogenboom ('29) traced homologous fascicles from the nucleus lateralis cerebelli to the midbrain region.

In Amia, the fibers forming this system (figs. 19, 20, 21) appear to come partly from the Purkinje cells and partly from the nucleus cerebelli. They pass forward and, at the same time, ventralward from the base of the corpus cerebelli 
and the region of the nucleus cerebelli, appearing in figure 19 as cross-cut bundles lateral to the ventricle. Before reaching the level of the III nerve they turn toward the midline in a broad curve and cross in a decussation (fig. 20) ventral to the medial longitudinal fasciculus and dorsal to the interpeduncular nucleus. Certain fibers turn more directly ventralward and cross in a similar manner before reaching this level. Still other bundles may extend forward to the tegmental gray of the same side. The exact distribution of all of these fibers is uncertain. Part of the fascicles break up in the tegmental gray of the midbrain, looking forward to the development in phylogeny of a connection with the red nucleus-hence the name brachium conjunctivum sometimes applied to this bundle. Other fascicles reach the ventral region of the diencephalon, possibly the hypothalamus, but this latter relation has not been fully established.

Cerebello-motorius system. The cerebello-motorius system was observed by Ariëns Kappers ('07), who regarded its constituents as arising from the Purkinje cells. Hocke Hoogenboom ('29) found that, in Polyodon, this system is divisible into a caudal and a frontal part. The brachium conjunctivum described for Ceratodus by Holmgren and van der Horst ('25) may form a constituent of this cerebellomotorius system.

The tractus cerebello-motorius (figs. 19, 20) consists, in Amia, of small bundles of fibers, which swing ventralward from the cerebellum and cerebellar valvula and distribute to the motor nuclei of the mid-brain and of the medulla oblongata. Some of the fibers are not definitely grouped into bundles but are easily recognized as they sweep ventralward and slightly forward in a position lateral to the ventricle and turn toward the midline close to the ventricular floor. Many of them cross the midline, part of the bundles passing dorsal to or through the medial longitudinal fasciculus before decussating. However, the majority run ventral to this fasciculus. A large number of cerebello-motorius fibers enter the medial longitudinal fasciculus, others turn cephalad or caudad, appearing as scattered fibers lateral to this bundle. 
Tractus cerebello-spinalis. The cerebello-spinal tract is thought to arise in part in the nucleus cerebelli and courses directly caudalward, at first in a position close to the ventricular wall (figs. 11 to 13 and 18). On reaching the level of the entering fibers of the VII nerve, it is pushed slightly lateralward by the fasciculus solitarius and, in this position, passes through the medulla oblongata and into the spinal cord. Other fibers join this bundle during its course, including ascending and descending fibers of the VIII nerve. It is probable that this bundle gives off fibers to centers in the medulla oblongata.

\section{THE AREA ACUSTICO-LATERALIS AND THE CEREBELLUM IN TELEOSTS}

The literature dealing with the teleost brain for the present purposes may be divided into two subdivisions: a) papers concerned with the teleostean nervous system as a whole, among which may be mentioned the work of Jackson and Clark (1876), Mayser (1881), Fusari (1887), van Gehuchten (1893), Haller (1898), Herrick (1899, '01 and '05), Ariëns Kappers ('06, '20-'21 and '29), Wallenberg ('07), Tello ('09), Franz ('11 a), Bartelmez ('15), Berkelbach van der Sprenkel ('15), Kooy ('17), Burr ('28) and Brickner ('29); b) contributions dealing with either the cerebellum or the acusticolateral areas or both as represented by the accounts of Schaper (1893, 1894 and 1894 a) ; Burckhardt (1897), Bianchi ('03), Ramón y Cajal ('08), Franz ('11), Schepman ('18), Ariëns Kappers ('20-'21), Palmgren ('21), Addison ('23 and '29), Herrick ('24), van der Horst ('25 and '26), and Ariëns Kappers, Huber and Crosby ('36). To review adequately all of these contributions would be impossible within the limits set for this paper. The literature pertinent to the discussion at hand is referred to in each case in the following account of the nuclear pattern and fiber connections. 
The cellular pattern of the area acustico-lateralis and the cerebellum in teleosts

The teleost brain offers a form for study in which the cerebellum and the acustico-lateral areas are relatively highly specialized, there being greater differentiation in the nuclear arrangement and fiber pattern than in the homologous areas in Amia and in the Petromyzontia. While the cerebellum and the acustico-lateral areas are closely related in teleosts, the two regions are more clearly defined.

Area acustico-lateralis. In addition to the medial nucleus and the ventral nucleus described in the less specialized forms, there is a further differentiation of the acustico-lateral area into a tangential nucleus and into a mass of gray, the homologue of the nucleus vestibularis descendens of higher forms. The dorsal nucleus, identified in cyclostomes and in certain ganoids, is totally absent in all the teleosts studied, as in Amia. The medial and ventral nuclei have been recognized in teleosts by Haller (1898), Wallenberg ('07), Ramón y Cajal ('08), Tello ('09), Franz ('11), Bartelmez ('15) and others under various names. The terminology here, as in preceding accounts, follows to a large extent that used by Ariëns Kapers ('20). The nucleus tangentialis was described in the trout by Ramón y Cajal ('08), Tello ('09) and Beccari ('30 and '34).

The following description of the nuclear configuration is based on brook trout (Salvelinus fontinalis) material. A description of the nuclei of the acustico-lateral area for the rainbow trout (Salmo gairdneri irideus) and the land-locked salmon trout (Salmo salar sebago) would be essentially the same. In the sunfish (Eupomotis gibbosus) the acusticolateral gray is perhaps more scattered and the nuclei less definitely formed. The acustico-lateral area in the carp (Caprinus carpio) has been crowded forward by the extremely highly developed visceral sensory centers in the medulla oblongata (the facial and vagal lobes of Herrick, '05), and broken into by the very large visceral sensory root of the 
VII nerve, coursing caudad as the fasciculus solitarius, and by the enormous secondary gustatory tract, passing through the ventral part of the acustico-lateral area. The relations of this area in the cyprinoids and siluroids are discussed more completely in another paper (Pearson, '36).

Nucleus medialis. The nucleus medialis of the acusticolateral area in the teleosts studied is similar to that in the Petromyzontia and in Amia, for this nucleus occupies the dorsolateral region of the medulla oblongata and extends the whole length of the acustico-lateral region, being continuous with the dorsal gray in the caudal end of the medulla oblongata and extending cephalad to levels through the cerebellum. However, the medial nucleus is larger, more compactly formed, and more easily recognized than in either Petromyzontia or Amia. The general relations of this nucleus in the brook trout are illustrated in figures 23 to 25 . It is small toward its caudal end but enlarges as the region just caudal to the entrance of the VIII nerve is approached. Here it occupies the greater part of the dorsolateral region of the medulla oblongata. In planes passing through the level of entrance of the VIII nerve (fig. 24), the medial nucleus is reduced markedly, occupying a small region of the medulla oblongata dorsal to the ventral nucleus, in which position it extends forward, its cells being grouped under the cerebellar crest near the ventricular wall. The medial nucleus gradually disappears, in part fusing with the ventromedial border of the eminentia granularis and in part becoming lost in the scattered gray ventral to the eminentia granularis.

Nucleus ventralis. The ventral nucleus of the acusticolateral area (fig. 24) in the brook trout is situated at the level of the entering fibers of the VII and VIII nerves. It is much larger than the ventral nucleus in Amia and is made up of large, medium sized and small cells. In cross sections, at appropriate levels, this nucleus is recognized easily by the presence of its characteristically large cells.

Nucleus tangentialis. The nucleus tangentialis (fig. 24) is situated close to the ventrolateral wall of the medulla 
oblongata among the more ventral root fibers of the VIII nerve. It is composed of small and medium sized cells, which have a strong tendency to wander out among the entering root fibers.

Nucleus vestibularis descendens. The small and medium sized cells of the ventral and the tangential nuclei continue caudalward for a short distance, fusing to form a mass of

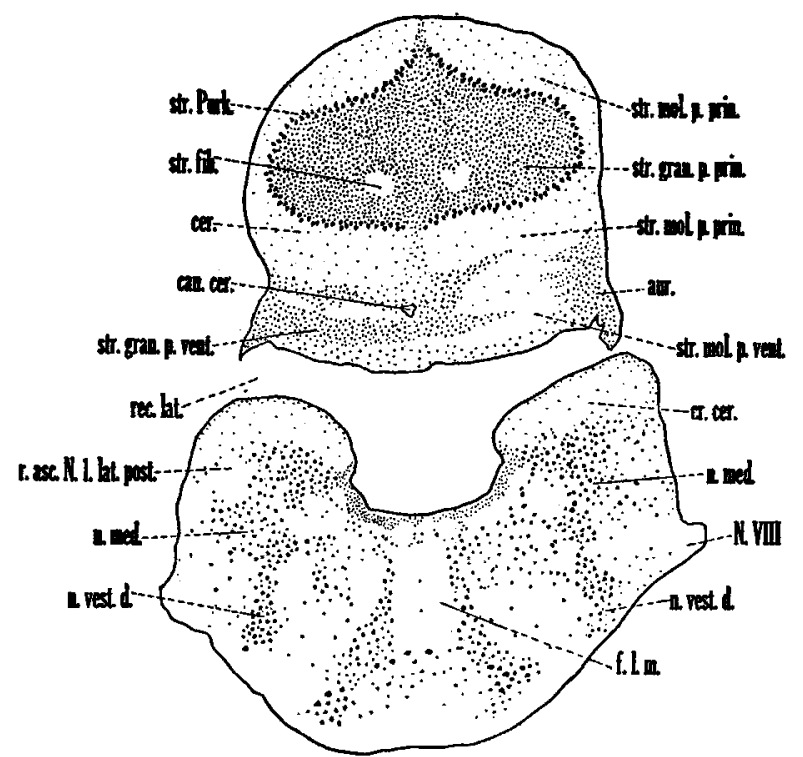

Fig. 23 A transverse section through the brain of the brook trout (Salvelinus fontinalis) at a level just caudal to the nucleus ventralis of the area acusticolateralis. The section shows the nucleus medialis and the nucleus vestibularis descendens of the acustico-lateral area and the layers of the cerebellum, particularly the stratum granulosum pars ventralis. Toluidin blue preparation. $\times 20$.

cells, the nucleus vestibularis descendens (fig. 23). Caudally, this mass of cells soon becomes continuous with the ventral border of the medial nucleus. It probably forms the homologue of the nucleus descendens of Ramón y Cajal ('08) and of the nucleus vestibularis descendens of higher forms (reptiles, Weston, '36). 
Layer arrangement of the corpus cerebelli. The finer anatomy of the teleostean cerebellum received consideration in the work of Fusari (1887), Schaper (1893) and Franz ('11). The two latter observers described a molecular, a granular and a Purkinje cell layer and pointed out that these layers are homologous with the same layers in higher forms. Schaper (1894 and 1894 a) has shown that, during development, the teleostean cerebellum is derived from paired anlagen in the cephalic end of the medulla oblongata, the corpus cerebelli being formed by the thickening of lateral parts which eventually fuse together in the median plane.

Stratum granulosum and stratum Purkinje. A comparison of the teleostean cerebellum with that of the ganoid Amia permits of the following generalizations. The stratum Purkinje (figs. 23 to 25) in teleosts exhibits a further development as compared with that of ganoids, since the Purkinje cells have a more definite layer formation between the stratum moleculare and the stratum granulosum pars principalis in the corpus cerebelli, and between the stratum moleculare valvulae and the stratum granulosum valvulae in the valvula. At selected levels the layer is several cells in thickness. In teleosts these cells stain more deeply, are more like the Purkinje cells of higher forms and appear to send their dendrites more directly into the molecular layer. The layers of the cerebellum are more definitely formed in the teleosts and show changes in relationships due in part to the enlargement of both the corpus and the valvula cerebelli and in part to the complete fusion of the bilateral halves of the corpus cerebelli.

The stratum granulosum in teleosts, as in Amia, is divisible into two layers, a pars ventralis and a pars principalis. The pars ventralis is well shown in cell preparations of the trout material studied. It consists of a band of gray stretching between the caudal tips of the auricles, partly separating the ventral molecular layers from the ventricular wall. It is homologous with the stratum granulosum pars ventralis in Amia (p. 228), but is placed more ventrally and extends more 
directly across from one auricle to the other. The majority of the neurons of this layer appear to be granule cells. The stratum granulosum pars ventralis (figs. 23, 24) probably corresponds to the 'string of granular cells' figured by Palmgren ('21), and to the subcerebellar granular layer described by van der Horst ('25, p. 743) and Ariëns Kappers ('29, p. 118) and considered by these latter authors as con-

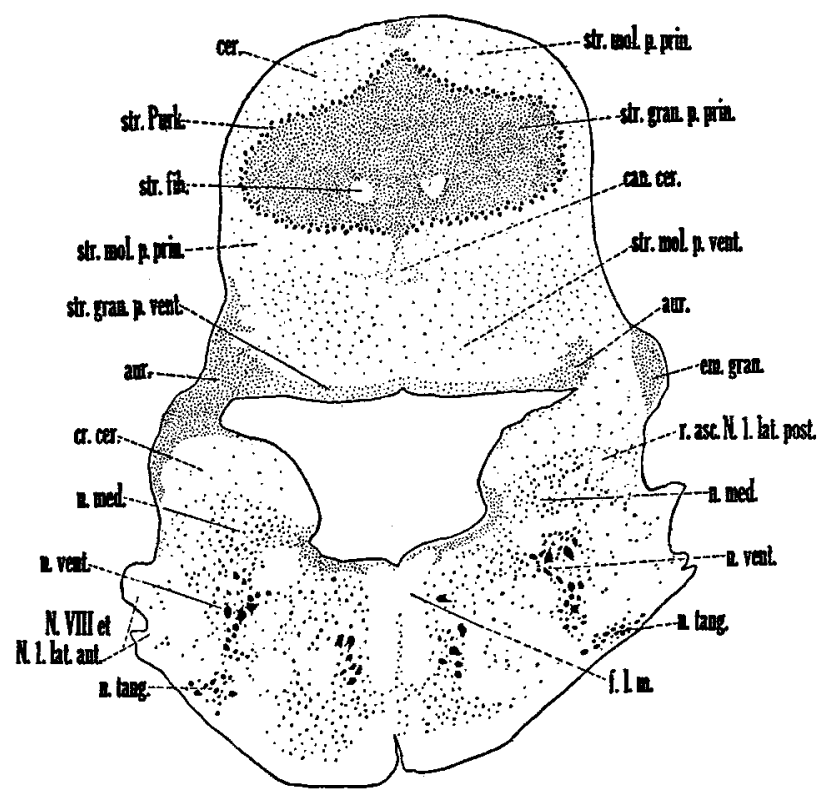

Fig. 24 A transverse section through the brain of the brook trout (Salvelinus fontinalis) at the level of entrance of the VIII nerve. This section emphasizes the interrelations of the nuclei of the acustico-lateral area and the position of the auricle. Toluidin blue preparation. $\times 20$.

necting the eminentiae granulares of the two sides. Neither in Amia nor in any of the teleosts studied does this layer connect the eminentiae granulares, but in each case it connects the auricles, as occurs with the granular masses of the auricles of plagiostomes (Ariëns Kappers, '29).

The relations of the stratum granulosum pars principalis (figs. 23 to 25,28 ) are quite different in the teleosts from those described in Amia. The pars principalis is not separated 
into bilateral halves by the cerebellar ventricle but is seen as a single large mass of gray occupying the greater part of the corpus cerebelli. Palmgren has pointed out that, due to the increase in the granular cell masses (the stratum granulosum pars principalis of this account), the walls of the ventricle have grown together leaving the canal rudiment, the canalis cerebelli (figs. 23, 24). The stratum granulosum pars principalis is surrounded completely by the stratum Purkinje and the stratum moleculare except for a small area at the base of the corpus cerebelli in front of the ventral molecular layer, where it approaches the ventricular wall, and in those places in which it becomes continuous with the eminentiae granulares and the stratum granulosum of the valvula cerebelli. The pars principalis is quite large in the more caudal portion of the corpus cerebelli but becomes somewhat constricted as it is followed forward. In the frontal portion of the corpus cerebelli it extends directly ventralward to fuse with the eminentiae granulares and the stratum granulosum valvulae.

Stratum moleculare. The relations of the molecular layer of the corpus cerebelli to the stratum granulosum pars principalis have been given in the preceding paragraph. The stratum moleculare is continuous in front with the stratum moleculare valvulae and ventrolaterally with the crista cerebellaris. This layer is divisible into two parts: the stratum moleculare pars principalis (figs. 23 to 25,28 ) which is the larger, and the stratum moleculare pars ventralis (figs. 23 to 25,28 ), which forms a molecular band connecting the cerebellar crests of the two sides. The stratum moleculare pars ventralis is situated in the ventral part of the cerebellum, at its region of junction with the medulla oblongata. This stratum covers only a small area of the stratum granulosum pars principalis and is partly separated from the ventricular wall by the stratum granulosum pars ventralis. The stratum moleculare pars principalis not only extends on the dorsal and lateral surfaces of the corpus cerebelli but also partly over its ventral surface, being continuous with the stratum moleculare pars ventralis. However, a fold in the molecular layer indicates the region of junction (fig. 28). 
Stratum fibrosum. The teleostean stratum fibrosum (figs. $23,24,28$ ), which is completely surrounded by the granular layer, is formed by fiber bundles entering and leaving the cerebellum. It is not a continuous layer and can best be described in connection with the afferent and efferent fiber systems of the cerebellar region.

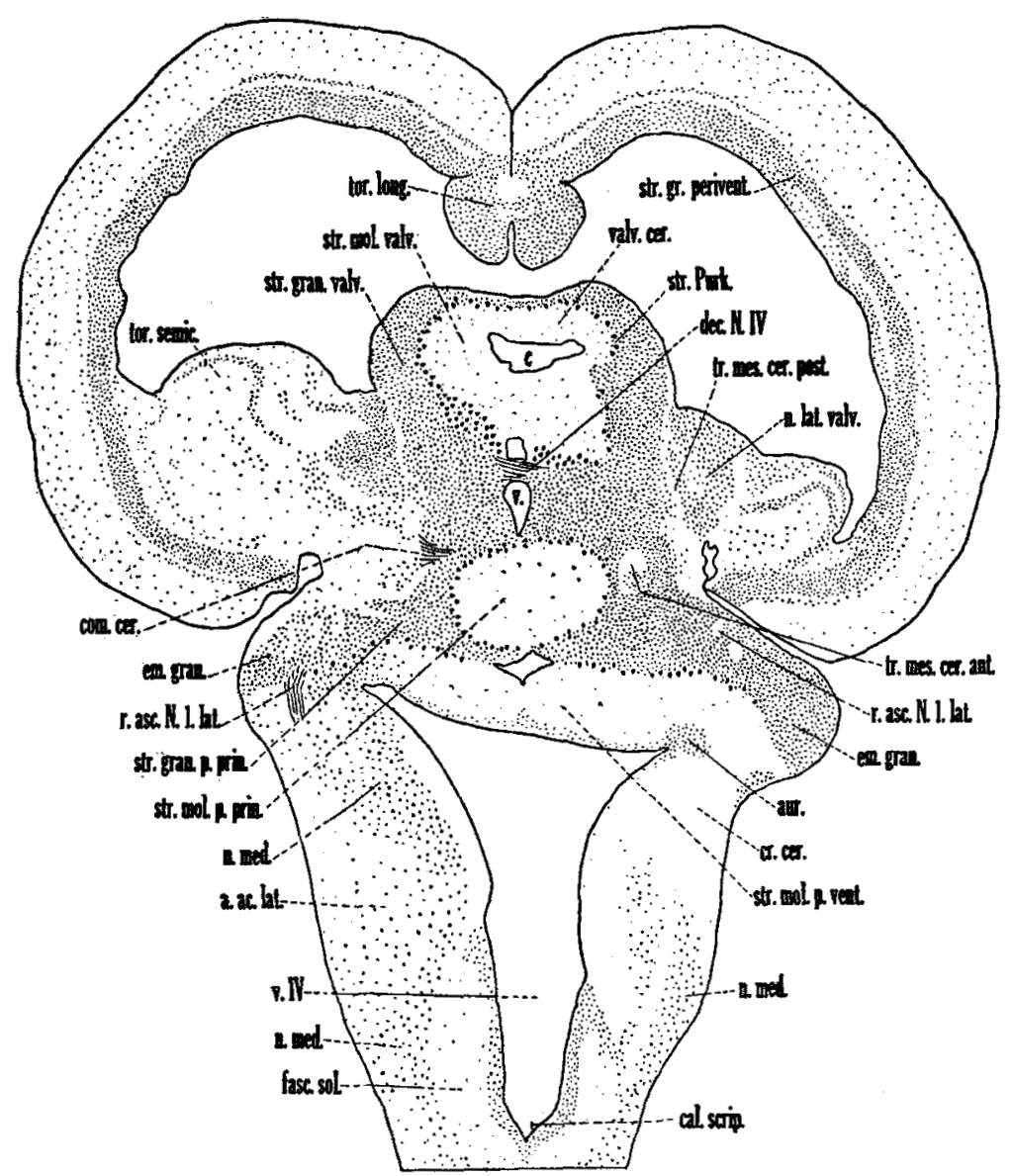

Fig. 25 A horizontal section through the brain of the brook trout (Salvelinus fontinalis) passing through the valvula cerebelli and the calamus scriptorius. The figure illustrates particularly the relations of the valvula and the acusticolateral areas to the corpus cerebelli, and the position of the eminentia granularis. Toluidin blue preparation. $\times 20$. 
Crista cerebellaris. The cerebellar crest (figs. 23 to 25, 28) is a caudal continuation of the molecular layer of the cerebellum and covers practically the whole extent of the acusticolateral area. The relations are very similar to those found in Amia. In the carp, the cerebellar crest extends caudalward for only a short distance, due to the fact that the acustico-lateral area has been crowded frontalward into a very small area.

Valvula cerebelli. In the valvula cerebelli (figs. 25 to 28) the three main layers of the corpus cerebelli can be identified: 1) the stratum granulosum valvulae, directly continuous with the stratum granulosum pars principalis; 2) the Purkinje cell layer, directly continuous with the same layer in the corpus cerebelli; 3 ) the stratum moleculare valvulae, continuous with the stratum moleculare pars principalis. The cell types found in the valvula are very similar to those found in the corpus cerebelli. The valvula cerebelli is a complicated structure in all the teleosts studied, but is more simple in the trout and the sunfish than in the carp and certain other fishes, where the valvula expands laterally into large lateral lobes.

The valvula cerebelli in the trout (figs. 25 to 27 ) is continued forward into the midbrain region beneath the optic tectum and directly ventral to the torus longitudinalis. It appears to have been folded upon itself, there being one major or primary fold and several minor or secondary folds. This folding is evident principally in the molecular layer and is best shown in sagittal series near the median plane. Due to this folding, the molecular layer of the valvula has a dorsal and a ventral layer, separated, except at the cephalic end of the valvula, by a narrow space connected with the cranial cavity. At the cephalic end the layers are continuous with each other, the place of junction forming the major fold. The minor folds occur in the so-called dorsal and ventral molecular layers; those occurring in the dorsal molecular layer will be referred to as the dorsal folds and those in the ventral layer as the ventral folds. There are three dorsal folds and one ventral fold in the valvula of the land-locked 
salmon trout, four dorsal folds and one ventral fold in the rainbow trout, and two dorsal folds in the sunfish, the ventral fold being absent. In each case the dorsal fold nearest the anterior medullary velum is small or incomplete.

Just caudal to the level where the corpus cerebelli and the valvula become continuous, the stratum granulosum pars principalis separates into bilateral halves, the stratum moleculare pars principalis intervening (fig. 25). Here these

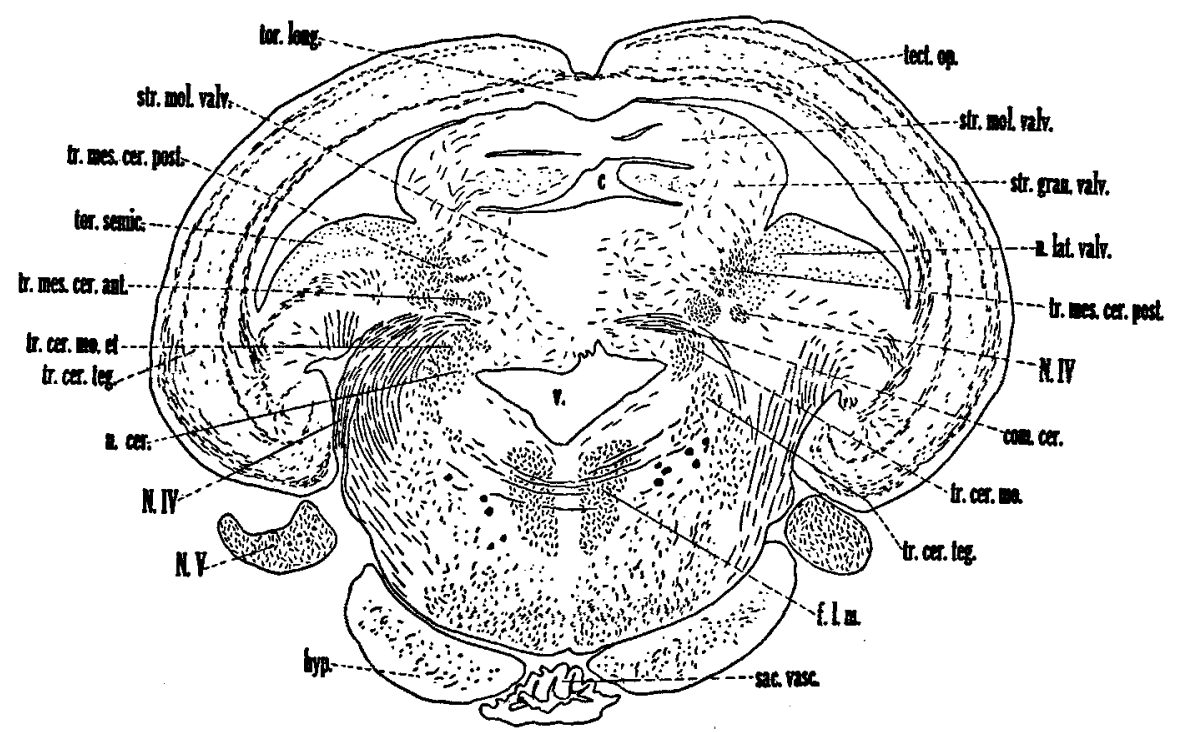

Fig. 26 A transverse section through the brain of the land-locked salmon trout (Salmo salar sebago) at the level of the nucleus cerebelli and the cerebellar commissure. Pyridine silver preparation. $\times 20$.

two layers, the stratum granulosum pars principalis and the stratum moleculare pars principalis, continue forward into the valvula, becoming continuous with the stratum granulosum valvulae and the stratum moleculare valvulae respectively. The valvula cerebelli extends forward from the base of the corpus cerebelli, and the granular layer continues into the valvula, in a position lateral and superficial to the molecular layer. The relation of the two layers is similar to that in the base of the corpus cerebelli, in that the molecular layer 
intervenes between the two masses of the granular layer. The Purkinje cell layer of the valvula is situated superficial or external to the molecular layer and deep to the granular layer, as would be expected, due to this reversal in the position of the layers. The relations of the granular layer in the valvula are best studied in the cross sections. These relations are well shown in cell preparations of the brook trout, in planes a little cephalad to the cerebellar commissure. The two halves of the stratum granulosum valvulae appear to be held apart by the dorsal and ventral molecular layers of the valvula. In such sections (fig. 26) these granular masses resemble somewhat the shape of one printed figure 3 facing another $3(\varepsilon 3)$, the dorsal and ventral parts being continuous across the midline in certain planes. Throughout the length of the valvula the stratum granulosum keeps a position lateral to the stratum moleculare; however, it does not completely surround the molecular layer, as these granular masses are continuous across the midline only at certain levels. The Purkinje cells almost completely surround the molecular layer; however, none of these cells border the space between the dorsal and ventral parts of the layer. Throughout the greater part of its extent, the stratum moleculare valvulae is separated from the ventricle, on its dorsal and ventral surfaces, only by the Purkinje cell layer. A dorsal and a ventral fissure indicate the bilateral origin of the valvula cerebelli.

The valvula of the carp (fig. 28) is very large, when compared with the relative size of the whole brain, and enormous compared with the valvula of Amia or even of the trout. However, when compared with the valvula in Mormyrus (Franz, '11 a) and in certain other fishes, it is relatively small. It is composed of an unpaired central portion and paired lateral lobes. As in the trout, the stratum moleculare valvulae of the carp is almost completely surrounded by the stratum granulosum valvulae, the stratum Purkinje being placed between the two. Berkelbach van der Sprenkel ('15) considered that the hypertrophy of the valvula cerebelli in Mormyrus is explainable through the large size of the lateral line nerves and their secondary and tertiary connections. 
Auricula cerebelli. Van der Horst ('26) and Ariëns Kappers ('29) were of the opinion that teleosts in general are without auricles. Van der Horst, however, recognized an auricle in Megalops. The illustrations of Palmgren ('21, fig. 112) show a mass of gray, which may be interpreted as the auricle and a band of granular cells connected with the opposite auricle. He also recognized the lateral recess.

The auricle (figs. 23 to 25 ) is well shown in toluidin blue preparations of the trout, where it is seen as a forward continuation of the stratum granulosum pars ventralis along the ventrolateral border of the ventral molecular layer. In the brook trout it can definitely be called the auricle at about the level of junction of the acustico-lateral region with the cerebellum. Here it is seen as a small mass of gray occupying a position partly adjoining the lateral recess along the ventricular wall and partly adjacent to the lateral brain wall; a few of its cells extend for a short distance in a caudal direction along the dorsolateral border of the cerebellar crest. As the auricle is traced frontalward, it becomes slightly smaller, recedes from the lateral brain wall and occupies a position close to the ventricular wall at the place of junction of the ventral molecular layer with the cerebellar crest (fig. 24 right). It disappears at about the level of the caudal tip of the eminentia granularis, from which it is separated by fiber bundles. The neurons of the auricle are granule cells.

A small but well-defined auricle can be identified easily in the cell preparations of the various trout studied and of the sunfish, the relations being much the same in all of these forms. In the pyridine silver and Weigert preparations of the carp, it is difficult to identify an auricle with certainty; however, its presence is suggested. A small recess of the fourth ventricle adjacent to the auricle can be demonstrated in all the available preparations of teleostean brains. It is somewhat larger in the carp and in the rainbow trout. The cephalic portion of the lateral recess ends in a small pocket, which extends frontalward, in relation to the auricle, to levels passing through the caudal portion of the eminentia 
granularis. This pocket is surrounded completely by nervous tissue-being bounded above by the auricle, ventrally by the cerebellar crest, and laterally by the junction of the cerebellar crest with the ventral molecular layer of the cerebellum-and is the anterior diverticulum of the lateral recess as described in the developing brain of Amblystoma (Larsell, '32).

The preceding account indicates clearly that the auricle is present in a number of teleosts. How general its presence is in these forms cannot be determined until a wider range of representatives has been studied.

Eminentia granularis. Franz ('11) designated this enlargement the eminentia granularis and it has been recognized and similarly named by many others. Van der Horst ('25) emphasized that the eminentia granularis receives both vestibular and lateral line connections, while the auricle has only lateral line connections.

The eminentia granularis (figs. 24 and 25) is smaller, with somewhat more compactly arranged cells, in the teleosts studied than in Amia. Cross sections passing through the cephalic end of the auricle cut through a mass of gray adjacent to the lateral wall of the brain. This mass, which is the caudal tip of the eminentia granularis (fig. 25) and is separated from the auricle by fiber bundles, enlarges slightly frontalward, the dorsal part of its medial border being continuous with the stratum granulosum pars principalis. It remains as a distinct structure for only a short distance and then fuses completely with the stratum granulosum pars principalis. In horizontal series (fig. 25), the eminentia granularis appears as a projection of gray from the main mass of cerebellar gray.

Nucleus lateralis valvulae. This nucleus has been identified as the nucleus lateralis valvulae by Herrick ('05) and others. It is homologous to the similarly named nucleus in ganoids, but is larger and more compactly formed and, due at least partly to the enlargement of the valvula, has somewhat different relations in the teleosts studied. It is well shown in the toluidin blue preparations of the rainbow trout, the 
brook trout (figs. 25 to 27 ), the land-locked salmon trout and the sunfish. It is situated medial to the torus semicircularis and lateral and partly ventral to the valvula, from which it is more or less completely separated by fiber bundles. It extends, in a caudo-cephalad direction, approximately from the level of the cerebellar commissure to that of the nucleus of the III nerve. An elevation in the ventricular wall between

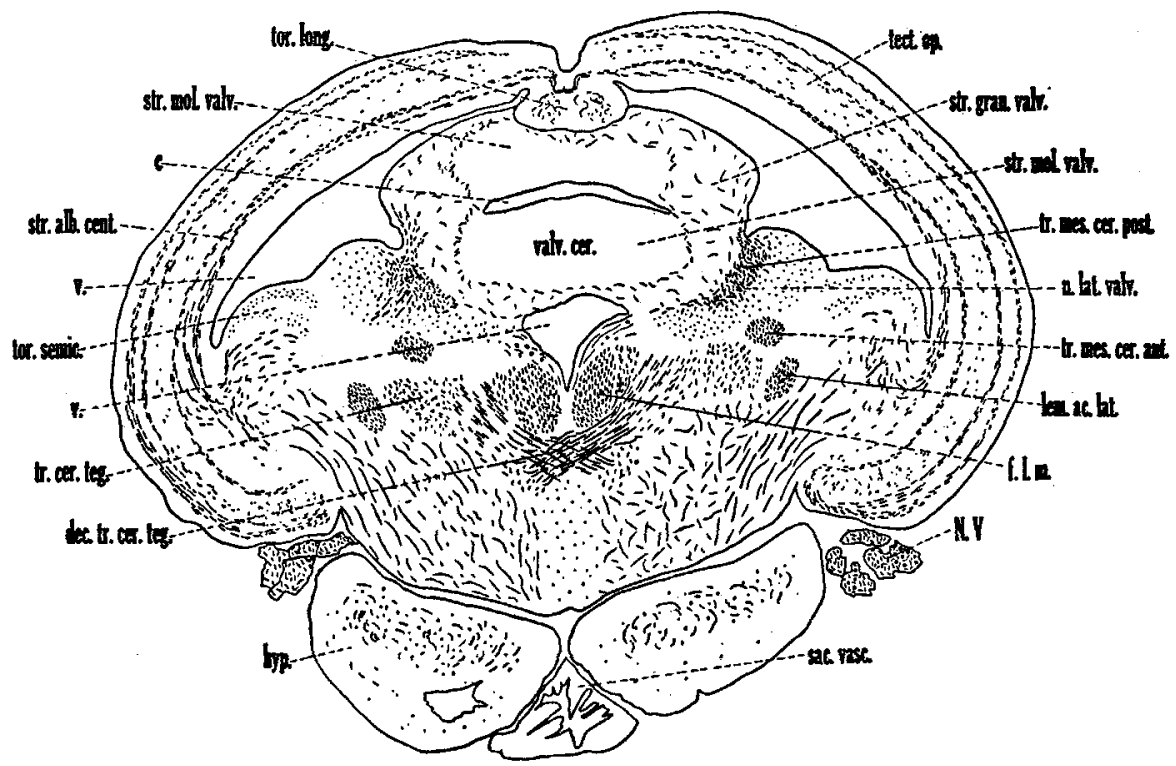

Fig. 27 A transverse section through the brain of the land-locked salmon trout (Salmo salar sebago) at the level of the nucleus of the IV nerve. The figure shows the positions of the tractus mesencephalo-cerebellaris posterior, the tractus mesencephalo-cerebellaris anterior and the lemiscus acustico-lateralis, and the decussation of the tractus eerebello-tegmentalis. Pyridine silver preparation. $\times 20$.

the valvula and the torus semicircularis indicates its position. The caudal portion of the nucleus lateralis valvulae is less compactly formed, due largely to fiber bundles which enter this nucleus and, in certain planes, divide it into two distinct cell masses. However, this division is evident for only a short distance, the cell masses fusing completely farther cephalad. The cephalic portion is thus seen as a single mass 
of cells which becomes smaller on approaching the level of the nucleus of the III nerve and soon disappears.

Nucleus cerebelli. The nucleus cerebelli in teleosts is possibly homologous with the nucleus cerebelli in the frog (Larsell, '25 and '29). However, it is not the same as the teleostean nucleus lateralis cerebelli described by Ariëns Kappers, which, as he stated, corresponds to the 'Rindenknoten' or secondary vagus nucleus of earlier observers. The 'Rindenknoten' is the secondary gustatory nucleus of Herrick ('05). The writer wishes to postpone a discussion of the existence of possible homologies between the nucleus lateralis cerebelli of selachians, as labeled and described by Ariëns Kappers ('06) and von Hoevell ('16), and the nucleus cerebelli of the present account until opportunity is afforded for an examination of selachian material.

The nucleus cerebelli is well shown in the toluidin blue preparations of the brook trout and of the land-locked salmon trout, and has relatively the same position as in Amia. Since the relations are much the same throughout the group, a general description will be adequate. In these forms the nucleus cerebelli (fig. 26) is situated slightly frontal to the eminentia granularis and caudad to the cerebellar commissure. It is placed lateral to the ventricle and in close apposition to the cerebellar gray. Its position, partly at the base of and partly within the peduncle, marks the beginning phylogenetically of the inclusion of the cerebellar nuclei within the cerebellum proper. It appears in the scattered gray of the region and can be distinguished easily by the differential staining and more or less characteristic grouping of its constituent neurons.

Due to the large size of the secondary gustatory nucleus, the relations of the nucleus cerebelli in the carp are slightly different. As shown in Weigert preparations, this nucleus in the carp is situated along the lateral ventricular wall deep to the secondary gustatory nucleus, from which it is separated by fiber bundles. Its cephalic end extends for a little way under the large commissure of the secondary gustatory nuclei, while 
its caudal pole is found a little caudal to the secondary gustatory nucleus.

The secondary gustatory nucleus (if present in the trout) is contained in the somewhat more scattered gray in front of the nucleus cerebelli. It is more easily identified in the sunfish where it stands out as a distinct cell group frontal to the nucleus cerebelli and ventral, and slightly caudal, to the caudal end of the nucleus lateralis valvulae. The secondary gustatory nucleus (fig. 28) is very large in the carp and, while occupying a large part of the region at the base of the cerebellum, is distinct from the nucleus cerebelli.

\section{Fiber connections of the area acustico-lateralis and the cerebellum in teleosts}

The VIII nerve and the lateral line nerves. Accounts of the central course of the VIII nerve and the lateral line nerves are found in the studies of Mayser (1881), C. J. Herrick (1899 and '01), Ariëns Kappers ('06 and '20), Wallenberg ('07), Tello ('09), Berkelbach van der Sprenkel ('15), Addison ('23), van der Horst ('26), Burr ('28), Beccari ('30) and others. The present description is in agreement with the consensus of opinion in the literature: that the VIII and the anterior lateral line nerves are composed of coarse and fine fibers, that VIII (and the anterior lateral line nerve in some fishes) is formed by two roots, and that certain fibers bifurcate on entering.

The VIII nerve and the anterior lateral line nerve. In many teleosts the root fibers of these nerves are so closely related on entering the medulla oblongata that an exact analysis of their distribution becomes very difficult. However, the visceral sensory and the motor root fibers of the VII nerve stand out plainly, removing the possibility of confusing these with the nerves under consideration. Due to their close relationship, the central course of the VIII nerve and anterior lateral line nerve will be considered together.

In the rainbow trout and in the land-locked salmon trout, these two nerves enter the ventrolateral wall of the medulla 
oblongata as a large complex of fibers, the more rostrodorsal of which are identified as anterior lateral line nerve fibers, while the remaining fibers are considered to belong to the VIII nerve. Fibers of the anterior lateral line nerve can be seen swinging dorsalward and, at the same time, frontalward. Certain of these join posterior lateral line fibers to distribute to the eminentia granularis, the evidence supporting Addison's ('23) view that VIII and lateral line fibers end in this eminence rather than in the corpus cerebelli. Other fascicles accompanying the posterior lateral line fibers pass to the valvula cerebelli or cross in the decussation of these latter fibers. The exact location of this decussation varies slightly in different forms. Still other small, scattered bundles accompany ascending root fibers of the VIII nerve to distribute to the medial nucleus in front of their level of entrance. Descending root fibers of the anterior lateral line nerve and of the VIII nerve distribute together to that portion of the medial nucleus of the acustico-lateral area caudal to their level of entrance. Large numbers of direct fibers of the VIII nerve can be followed into the ventral nucleus and others into the cerebellar crest. Some of these fibers can be traced toward the midline to be incorporated with fiber bundles crossing in that region, probably to distribute to acusticolateral centers on the opposite side. Bartelmez ('15) and, more recently, Bartelmez and Hoerr ('33) have described in detail the manner in which the VIII nerve fibers end on the Mauthner's cell. The more ventral root fibers of the VIII nerve course among the cells of the nucleus tangentialis. The fibers entering into synaptic relationship with this nucleus are thought to arise peripherally in the cristae of the semicircular canals (Beccari, '30). Many of these more ventrally placed fibers turn caudalward, distributing in part to the nucleus vestibularis descendens and in part to the more caudal portion of the medial nucleus of the acustico-lateral area.

The central course of the fibers of the VIII and anterior lateral line nerves in the carp is essentially the same as in the trout. The fiber bundles are larger and can be traced 
more easily. The descending root fibers of these nerves are readily recognized as a large group of fiber bundles ventral to the ascending root fibers of the posterior lateral line nerves and dorsal to the descending root of the $\mathrm{V}$ nerve and to the secondary gustatory tract. The ascending bundles of these nerves are pushed aside by the very large visceral sensory portion of the VII nerve, part of the fibers passing dorsal and part ventral to this root, but they can be definitely followed into the eminentia granularis. Bundles of root fibers of the anterior lateral line nerve can be traced into the valvula cerebelli. In certain sections, fascicles, which appear to be direct fibers of the VIII nerve, are seen passing dorsal to the fasciculus solitarius and crossing in a commissure connecting the acustico-lateral areas of the two sides. A more complete analysis of these nerves in cyprinoids and siluroids is considered in another paper (Pearson, '36).

The central course of the two nerves may be summarized as follows: Root fibers of the anterior lateral line nerve distribute to the whole extent of the medial nucleus of the acustico-lateral area, to the eminentia granularis and to the valvula cerebelli. Root fibers of the VIII nerve distribute to the whole extent of the medial nucleus, to the ventral nucleus, to the tangential nucleus, to nucleus vestibularis descendens, to the cerebellar crest, to the eminentia granularis and to the acustico-lateral centers of the opposite side.

Posterior lateral line nerve. In the rainbow trout and the land-locked salmon trout, the posterior lateral line nerve enters the dorsocaudal portion of the acustico-lateral area, just ventral to the cerebellar crest. On entering the brain, a small number of fibers of this nerve course candalward, while the majority run forward. As the fibers (figs. 23 to 25) pass forward they are grouped into small bundles ventral to the cerebellar crest. On reaching levels through the eminentia granularis, where they are joined by fibers of the anterior lateral line nerve, they turn dorsalward into the eminence, and here many of the fibers terminate, while others, more dorsally directed, turn toward the midline and then 
forward, distributing for the most part in the valvula. Still others continue toward the midline and decussate in the more cephalic portion of the corpus cerebelli to be distributed to centers on the opposite side.

The course of the posterior lateral line nerve stands out perhaps even more clearly in the preparations of the carp. In this fish the nerve is easily recognized as a large bundle of coarse fibers dorsal to and a little in front of the root of the IX nerve, entering the caudal end of the acustico-lateral region. The central course of the posterior lateral line nerve in the carp is relatively the same as in the trout. In the carp, as in the trout, bundles of these fibers can be seen entering the eminentia granularis or passing through it. In the latter case the fibers turn more sharply toward the midline and in part decussate in the region dorsal and a little caudal to the commissure of the secondary gustatory nucleus, the decussation being more ventrally placed than in the trout.

To summarize: the fibers of the posterior lateral line nerve are distributed to the whole extent of the medial nucleus of the acustico-lateral area, to the eminentia granularis of the same side, by means of the decussating bundle to the eminentia granularis of the opposite side, and to both sides of the valvula.

The spino-acustico-latero-cerebellar system. A connection between the spinal cord and the cerebellum has been identified in various teleosts by Herrick ('06 and '07), Wallenberg ('07), Franz ('11), Ariëns Kappers ('21), Addison ('23), van der Horst ('26), Burr ('28), and others. Certain of these observers (Addison, van der Horst and Ariëns Kappers) included a component arising in the inferior olivary nucleus (Kooy, '17) of teleosts. Ariëns Kappers distinguished a dorsal and a ventral component of this tract.

The spino-cerebellar system in the trout is strikingly similar to that in Amia. Its course is particularly well shown in the sagittal series of chrome-silver preparations of the rainbow trout, where it can be followed through the medulla oblongata in a ventrolateral position to the level of entrance of the $\mathrm{V}$ 
nerve where the fibers sweep dorsalward in a broad curve, partly in front of and partly caudal to or through the root fibers of this nerve. In favorable planes the entire sweep of the fibers, from a ventrolateral position in the medulla oblongata into the corpus cerebelli, can be seen in a single section. While many of the fibers of this system terminate in the corpus cerebelli, the eminentia granularis and possibly in the valvula of the same side, a large number of the more cephalic fibers enter the cerebellar commissure to distribute to the corresponding contralateral regions. The acustico-lateral component is not so strongly developed in the trout as it is in the carp.

The spino-acustico-latero-cerebellar tract forms a conspicuous system as seen in the sagittally cut pyridine silver preparations of the carp. In its course frontalward, it occupies a position in the ventrolateral part of the medulla oblongata directly beneath the secondary gustatory tract. As its fibers swing in a lateral and dorsal direction to enter the acustico-lateral area and the cerebellum, they do not form a continuous system but are interrupted at intervals by the entering root fibers of certain of the cranial nerves. Groups of them pass frontal to fibers of the posterior lateral line nerve and still more cephalic bundles course partly through and partly in front of the VII nerve and the VIII nerve. However, while the majority of these fibers reach the cerebellum, some of them are thought to enter into synaptic relationship with the nuclei of the acustico-lateral area. The most cephalic portion of this tract turns lateralward and dorsalward, a little in front of the entering root of the $V$ nerve. The majority of the fibers pass toward the corpus cerebelli, coursing slightly caudal to the secondary gustatory tract. A few of them run frontal to the secondary gustatory nucleus and enter the valvula cerebelli. It is evident, then, that although dorsal and ventral spino-cerebellar tracts might be described in this general system, as certain observers have done, such subdivisions, in the light of the present knowledge relating to their origin, are in the end purely arbitrary. The 
courses of the bundles in the medulla oblongata appear to be determined chiefly by the presence of areas which permit a free passage of the fibers.

Bulbo-cerebellar system. Secondary fibers arising in the bulb region and passing to the cerebellum have been identified by Franz ('11) and others. Observers are not agreed as to the presence of root fibers of the $V$ nerve to the cerebellum, although their presence has been suggested in other forms.

The bulbo-cerebellar system in the rainbow trout and the land-locked salmon trout, as in Amia, is composed of small scattered fiber bundles which sweep upward into the cerebellum distributing to the eminentia granularis, the corpus cerebelli and the valvula cerebelli. Certain of the fibers enter the cerebellar commissure in company with those of the spino-cerebellar system and distribute to cerebellar regions on the opposite side. The fibers of this system arise from the sensory nuclei of the medulla oblongata, principally from the nuclei of the acustico-lateral area and the nucleus of the descending root of the $\mathrm{V}$ nerve. The extent to which these fibers cross the raphe is difficult to determine. This system is joined by direct root fibers of the $\mathrm{V}$ nerve which can be demonstrated more clearly in the trout than in either the Petromyzontia or in Amia. Such direct root fibers can be traced directly dorsalward toward the cerebellar commissure, beyond which they cannot be followed with certainty.

The bulbo-cerebellar system in the carp has much the same relations as were described for it in the trout. It courses frontalward through the medulla oblongata in scattered bundles, dorsal to the secondary gustatory tract. The more dorsal of these bundles accompany the direct root fibers of the VIII and lateral line nerves coursing toward the cerebellum. The more ventral fibers sweep dorsalward in curves resembling that of the spino-cerebellar fibers as they turn into the cerebellum. In the carp material available for study direct root fibers of the $\mathrm{V}$ nerve were more difficult to demonstrate. 
Lemniscus acustico-lateralis. Arising in the acusticolateral region is a crossed path to the torus semicircularis, which has been recognized in a number of teleosts by Ariëns Kappers ('06 and '21), Wallenberg ('07), Berkelbach van der Sprenkel ('15), Addison ('23), van der Horst ('26), and others. It has received various designations, such as the lateral longitudinal fasciculus, the lateral lemniscus, and the acustico-lateral lemniscus. This tract, as has already been pointed out (p. 242), conveys static impulses to the region beneath the midbrain ventricle. In many respects the course of this acustico-lateral lemniscus in teleosts is similar to that described for it in Amia. It is formed by an accumulation of fibers, lateral to the medial longitudinal fasciculus, which grows larger as it is traced cephalad through the extent of the acustico-lateral region, forming a conspicuous bundle which passes forward into the midbrain (fig. 27). This lemniscus has its cells of origin in the acustico-lateral area of the opposite side, largely from the nucleus medialis. The fibers cross the raphe ventral to the ventricle and dorsal to or through the dorsal portions of the medial longitudinal fasciculi. The decussation of these fibers is quite prominent in the trout and even more conspicuous in the carp, in which the majority of fibers cross at levels through the more caudal portion of the acustico-lateral area. The course of the acustico-lateral lemniscus (fig. 27) through the midbrain is well shown in both the cross and the sagittally cut pyridine silver preparations. The tract gradually takes a more lateral position as it courses cephalad. In the trout it is at first ventral and then lateral to the cerebello-tegmental tract, being medial to the spino-tectal fibers as they sweep in a dorsal direction to the tectum. As it continues cephalad it passes ventrolateral, and then lateral, to the tractus mesencephalocerebellaris anterior, and is in relation with the ventromedial border of the torus semicircularis. A little cephalad to the nucleus of the III nerve the bundle grows rapidly smaller and distributes to the torus semicircularis. 
The relations of this tract (fig. 28) are somewhat different in the carp. As it passes into the midbrain and gradually takes a more lateral position, it lies under the secondary gustatory nucleus and tract, ventral and then lateral to the lobo-bulbar tract of Herrick ('05); farther frontalward it courses first ventral and then lateral to the lobo-cerebellar tract, and later lateral to the tractus mesencephalo-cerebellaris

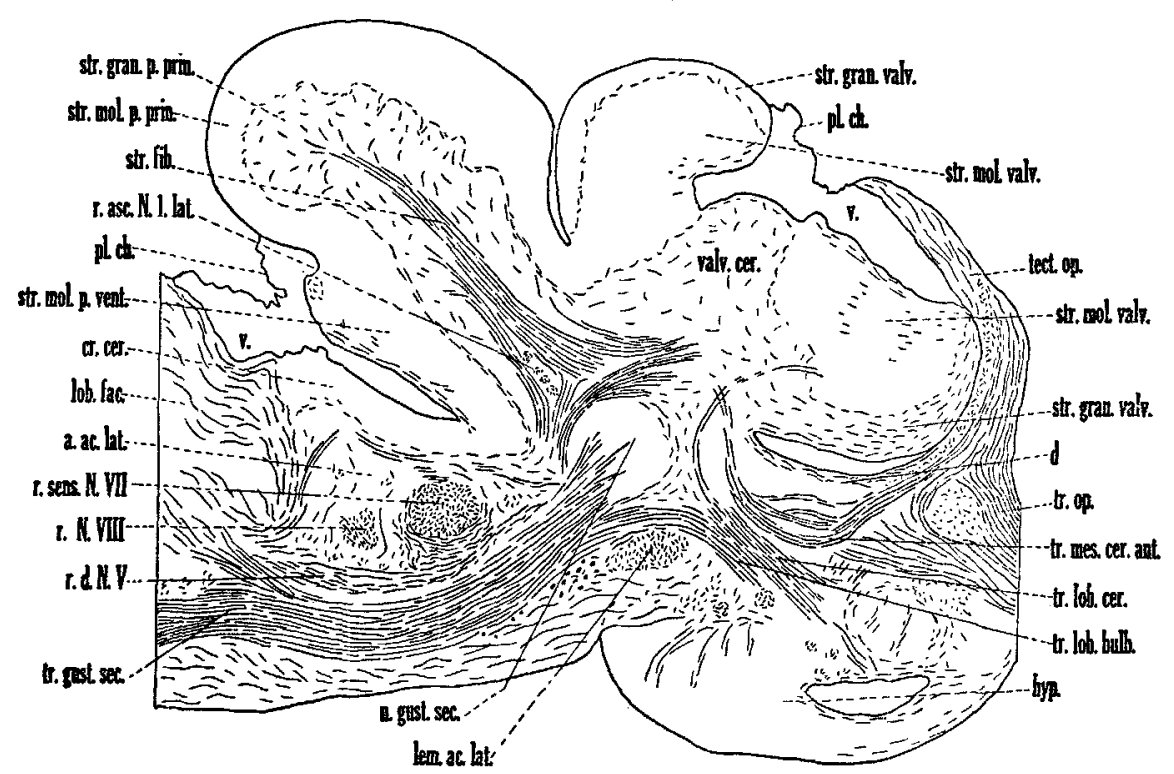

Fig. 28 A sagittal section through the brain of the carp (Caprinus carpio) to illustrate the relations of the corpus cerebelli, the valvula cerebelli and the acusticolateral area. The tractus lobo-cerebellaris and the tractus mesencephalo-cerebellaris anterior are especially clearly seen in the figure. Pyridine silver preparation. $\times 10$.

anterior. As in the trout its course is in relation to the ventromedial border of the torus semicircularis. On reaching the level of the III nerve, a few fiber bundles turn lateralward and then caudalward into the torus semicircularis. The main portion of the bundle continues forward for a short distance, keeping the same relative position. It grows smaller, scatters into the region and then rapidly disappears. These fibers, which assume a lateral and caudal direction, distribute largely 
to the torus semicircularis. A small bundle of them can be traced caudalward, lateral to the acustico-lateral lemniscus and close to the ventral border of the torus semicircularis. This bundle can be followed in this position for some distance, but becomes smaller and disappears before reaching the caudal end of the torus. In the trout fiber bundles can be seen breaking up in the cephalic portion of the torus semicircularis (p. 269), but the bundle which turns caudalward cannot be identified with certainty.

Tractus tecto-acustico-lateralis. The sagittally cut pyridine silver preparations of the rainbow trout, of the land-locked salmon trout and of the carp reveal fibers from the efferent layer of the tectum (the stratum fibrosum centrale, Huber and Crosby, '33) swinging caudalward to join the cephalic end of the acustico-lateral lemniscus. These fibers run with the acustico-lateral lemniscus, following the course already outlined. On reaching the medulla oblongata, they appear to cross the midline with fibers forming the acustico-lateral lemniscus and to distribute to the acustico-lateral area on the opposite side.

Acustico-latero-motorius system. This system has been identified in various teleosts, usually under the name of tractus octavo-motorius (Wallenberg, '07; Ariëns Kappers, '06, '20, '29; and others). Ramón y Cajal ('08) made a rather complete study of the connections and the following account confirms many of his findings. As might be expected, the acustico-latero-motorius system is better developed in teleosts than either in such ganoids as Amia or in the Petromyzontia. Its fibers arise in the nuclei of the acustico-lateral area and distribute to the motor nuclei of the midbrain, the medulla oblongata and the spinal cord. The constituent fibers can best be considered with respect to the nuclei from which they arise.

Those fibers arising in the medial nucleus of the acusticolateral area turn toward the midline, many of them crossing the raphé, and for the most part enter the medial longitudinal fasciculus, in which they probably ascend and descend. 
Fibers arising in the tangential nucleus in the trout can be followed across the raphé. Ramón y Cajal ('08) found that the stem fibers descend in the ventral funiculus of the opposite side but that a fine branch ascends. Beccari ('30) more recently described connections between this nucleus and the eye-muscle nuclei (Pearson, '36).

Fibers arising in the ventral nucleus of the acustico-lateral area enter the homolateral and contralateral medial longitudinal fasciculi, in which they probably ascend and descend. Uncrossed fibers from this ventral nucleus descend in company with the descending fibers of the VIII nerve to distribute to the motor nuclei of the medulla oblongata and to continue into the spinal cord. This connection forms the forerunner of the vestibulo-spinal tract of higher forms. This account agrees in general with that of Ramón y Cajal, who, however, described also a contralateral path descending through the medulla oblongata. Fibers from the nucleus vestibuli descendens of the trout turn toward the midline, many of them crossing and entering the medial longitudinal fasciculus, probably ascending and descending in the same. It is possible that this nucleus contributes to the formation of the uncrossed vestibulo-spinal tract, but of this latter fact the writer is uncertain.

Cerebellar commissural system. Decussation of IV nerve. There are a number of fiber systems crossing in the cerebellum. These decussating systems can be roughly divided into two groups, those which decussate in the valvula and the cephalic part of the corpus cerebelli and those which cross in the ventral molecular layer. The systems crossing in the valvula and the cephalic part of the corpus cerebelli, when considered in the order in which they occur cephalocaudally, are as follows:

1. Decussating fibers of the IV nerve. These fibers course in a dorsal and medial direction (fig. 26) from the nucleus of IV, which is situated ventrolateral to the ventricle, then cross the midline dorsal to the ventricle in the ventral part of the valvula cerebelli. 
2. Commissure of the secondary gustatory nuclei and the decussation of the spino- and bulbo-cerebellar tracts. A large number of fibers cross the midline at approximately the level of junction of the corpus cerebelli with the valvula. In the carp this part of the decussation is formed chiefly by the commissure of the secondary gustatory nuclei, which is so very large in this form that it obscures other fiber systems decussating in the region. In the trout, where the commissure of the secondary gustatory nuclei is smaller, the crossing fibers of the spino-cerebellar and bulbo-cerebellar systems form the conspicuous part of the decussation.

3. Decussation of the lateral line fibers. A little caudal to the decussation of the spino-cerebellar and bulbo-cerebellar tracts, but in the cephalic part of the corpus cerebelli, are the crossing fibers of the lateral line nerves. In the trout these are arranged in small bundles, more dorsally placed than the other decussating systems. In the carp, as these lateral line fibers approach the midline, they turn slightly ventralward to cross the midline dorsal and a little caudal to the commissure of the secondary gustatory nuclei.

In the ventral molecular layer of the cerebellum there is a conspicuous system of decussating fibers, formed in part by fascicles which turn into the ventral molecular layer from the cephalic end of the cerebellar crest and in part by various other bundles interconnecting the two sides of the cerebellum. The more cephalic portion of the decussation passes between the auricles and between the eminentiae granulares, thus correlating the impulses on the two sides, and probably connecting the eminentia granularis of one side with the auricle of the other side. There is no doubt that certain fibers from the cerebellar crest reach the auricle and the eminentia granularis of the same side, and, through this decussation, fibers from the crest reach the auricle and the eminentia granularis of the opposite side. Part of the fibers decussating in the caudal part of the ventral molecular layer turn somewhat dorsalward to distribute to the corpus cerebelli. Thus the acustico-lateral area is closely connected with cerebellar centers through the cerebellar crest. 
Tractus mesencephalo-cerebellaris anterior and tractus cerebello-tectalis. In the literature the tractus mesencephalocerebellaris anterior usually is described as an afferent tract to the cerebellum (Franz, '11, tractus mesencephalo-cerebellaris ; Ariëns Kappers, '21 and '29, and Addison, '23 and '29, tractus mesencephalo-cerebellaris anterior or tecto-cerebellaris). Addison stated that this tract has its origin, "From the cephalic end of the midbrain from the region where the anterior border of the tectum opticum, the torus longitudinalis and the tegmentum come together. This is at the level of the posterior commissure." This component is considered to enter the corpus cerebelli and to end largely in the molecular layer (Franz, '11). In certain of the teleosts (Gadus, Addison, '23) this tract has been described as a crossed connection. Tuge ('34) has recently reviewed the literature on the connections between the cerebellum and the tectum in fishes and has further analyzed these paths with experimental Marchi material in Carrassius auratus. Charlton ('33) and Tuge ('34 a) described fibers arising in the cerebellum which pass to the tectum. Tuge stated that the path is strictly afferent with respect to the cerebellum.

The majority of the fibers of the tractus mesencephalocerebellaris anterior can be traced from the efferent layer of the tectum (the stratum fibrosum centrale, Huber and Crosby, '33). These fibers in the trout unite to form a bundle in the laterocephalic end of the midbrain, where the tegmentum and the tectum come together. This bundle courses caudalward through the dorsal part of the tegmentum, passing along the medial border of the torus semicircularis. Fascicles of fibers, principally from the torus semicircularis and the nucleus of the mesencephalic root of $V$, increase the size of the bundle. Farther caudally, the tractus mesencephalo-cerebellaris anterior (figs. 26, 27) passes first medial and then dorsomedial to the acustico-lateral lemniscus, ventral to the nucleus lateralis valvulae, and, gradually turning in a medial and dorsal direction, enters the corpus cerebelli ventral to the tractus mesencephalo-cerebellaris posterior, part of its fibers 
passing above and part below the IV nerve. It continues in a caudodorsal direction through the stratum granulosum pars principalis (figs. 23, 24), where it contributes to a large bundle which is situated just lateral to the midplane. On approaching the caudal end of the corpus cerebelli the bundle grows rapidly smaller and disappears. The tecto-cerebellar component is thought to distribute largely to the molecular layer (Franz, '11).

Accompanying these cerebello-petal fibers of the tractus mesencephalo-cerebellaris anterior there are without doubt fibers which arise in the cerebellum and pass to the midbrain region. Such fibers can be demonstrated in the land-locked salmon trout as they contribute to the afferent layers of the tectum. To such cerebello-fugal fibers, the name of the tractus cerebello-tectalis may be given.

The tractus mesencephalo-cerebellaris anterior (fig. 28) is a very large system of fibers in the carp. In certain sections of the sagittally cut pyridine silver preparations practically the whole sweep of this tract, as it passes between the tectum and the base of the cerebellum, can be seen in a single section. It contains both tecto-cerebellar and cerebello-tectal components, the former arising in the efferent layers of the tectum, in the cephalic portion of the midbrain, while the cerebello-tectal fibers sweep in a lateral direction out of the cephalic end of this tract into superficial layers of the tectum. This tract is accompanied for a short distance by other fibers of the region. As it courses candalward through the tegmentum of the midbrain, the tractus mesencephalo-cerebellaris anterior takes a slightly more ventral position than does its homologue in the trout. It lies for much of its course medial to the acustico-lateral lemniscus, and dorsal to the lobocerebellar tract and enters the cerebellum in front of the secondary gustatory nucleus and medial to the tractus mesencephalo-cerebellaris posterior. The cerebello-petal fibers distribute to the valvula and to the corpus cerebelli.

In the carp there is a periventricular system of fibers (fig. $28, d)$, connecting the cerebellum and the valvula with the 
tectum and with the tegmentum of the midbrain, which, in the sagittally cut pyridine silver preparations is differentially stained and easily seen. Certain of the cells of the mesencephalic nucleus of the $V$ nerve lie along the course of its constituent fibers and are thus brought into synaptic relation with the cerebellum. Those fibers of this system reaching the tectum enter the deepest layers, the stratum fibrosum periventriculare (Huber and Crosby, '33).

Tractus mesencephalo-cerebellaris posterior. The tractus mesencephalo-cerebellaris posterior or, as it is often called, the tractus tegmento-cerebellaris, has been identified in teleosts by Franz ('11), Ariëns Kappers ('21), Addison ('23 and '29), van der Horst ('26) and others. Addison described this tract in three teleosts giving as its origin the nucleus lateralis valvulae and distinguished two parts to the tract: 1) to the valvula; 2) to the corpus cerebelli. The writer has little to add to the description given by Addison ('23).

In the trout this tract (figs. 25 to 27 ) is seen as an accumulation of fibers coursing caudalward in a position between the nucleus lateralis valvulae and the valvula cerebelli. It arises largely in the nucleus lateralis valvulae and, as it passes in a caudal direction, distributes in part to the valvula and in part to the corpus cerebelli. Through the greater portion of its extent it is dorsal to the tractus mesencephalocerebellaris anterior. In the carp this tract is very well developed and due to the large size of the valvula in this fish the relations appear somewhat different superficially from those in the trout, but in essentials these relations are the same.

Swinging out of the large bundles at the base of the ventrolateral wall of the midbrain in the carp is a strand of fibers of yellow-brown color which has a dorsolateral and caudal course toward the general direction of the cerebellum. In front of the secondary gustatory nucleus it joins the more ventral bundles of the tractus mesencephalo-cerebellaris posterior and appears to accompany them to the cerebellum. At present nothing further is known with regard to this bundle, but 
certain similarities in relationships suggest that it may be the homologue of the strio-cerebellar system described for certain higher forms, notably birds.

Tractus lobo-cerebellaris. A number of observers have found a connection between the hypothalamus and the cerebellum. This tract has been given almost as many names as there are descriptions of it in the literature. Thus it is the tractus cerebelli ad lobum inferiorem of Mayser (1881), the brachium cerebelli anterio-inferius of Haller (1898), the tractus lobo-cerebellaris of Ariëns Kappers ('21), Addison ('23) and van der Horst ('26), the tractus diencephalo-cerebellaris of Franz ('11) and the tractus hypothalamo-cerebellaris of Addison ('29) and Ariëns Kappers ('29). This tract is usually considered as arising in the lobus inferior hypothalami, since Wallenberg ('07) proved conclusively, by degeneration methods, that it is of hypothalamic origin.

The tractus lobo-cerebellaris, although small, can be demonstrated definitely in both the rainbow and the land-locked salmon trout, where, after leaving the inferior lobe of the hypothalamus, it courses almost directly caudodorsalward toward the cerebellum, passing medial to the acustico-lateral lemniscus and caudal to the nucleus lateralis valvulae. On entering the cerebellum it joins other bundles running toward the caudal end of the corpus cerebelli.

The lobo-cerebellar system in the carp (fig. 28) is much larger than in the trout. Whether all of the fibers of this system arise in the inferior lobe is difficult to determine; however, it is thought that there are other components. The tract is readily followed as it courses dorsalward and slightly caudalward, medial to the acustico-lateral lemniscus and ventral to and behind the tractus mesencephalo-cerebellaris anterior. Many of the fibers pass in front of the secondary gustatory nucleus and end largely in the valvula cerebelli, a part of them turning frontalward to distribute to the more cephalic portion of the unpaired central part and to the lateral lobes of the valvula. The remaining fibers of the tractus lobo-cerebellaris, on reaching a position dorsal to the 
acustico-lateral lemniscus, turn lateralward and then dorsalward, again passing partly in front of and partly lateral to the secondary gustatory nucleus. The most lateral of these fibers are ventral to the tractus mesencephalo-cerebellaris posterior and accompany it into the cerebellum, where they distribute chiefly to the corpus cerebelli. This system is not easily subdivided.

Tractus cerebello-tegmentalis or brachium conjunctivum and the cerebello-motorius system. Franz ('11) and Ariëns Kappers ('21) have described fiber connections which are probably included in the cerebello-motorius system of this account. Later Ariëns Kappers ('29) distinguished a tractus cerebello-diencephalicus which, according to his statement, ends in part in the ventral thalamus and in part can be traced along the fasciculus retroflexus (as Brickner, '29, had described), many of its fibers terminating in the tegmental gray. A comparable system of fibers has been recognized by Addison ('23) who identified a brachium conjunctivum anterius and a tractus cerebello-motorius.

It is difficult to draw a clear distinction between the cerebello-motorius system proper and the cerebello-tegmental system. The cerebello-motorius system is composed of efferent fibers from the cerebellum passing to the motor nuclei of the midbrain, the medulla oblongata and the spinal cord. Accordingly, it is divided into mesencephalic, bulbar, and spinal portions. The tractus cerebello-tegmentalis is composed of fibers which pass from the cerebellum to the diencephalon and to the tegmentum of the midbrain. It also includes fibers (cerebello-motorius in type) which distribute principally to the nucleus of the III nerve.

The tractus cerebello-tegmentalis or brachium conjunctivum in the brook trout and the land-locked salmon trout appears to arise chiefly from the Purkinje cells and from the nucleus cerebelli. It courses forward out of the base of the cerebellum (fig. 26) along with fibers constituting the cerebellomotorius system. The combined bundles run under the cerebellar commissure, where they separate. The cerebellotegmental system continues forward, the fascicles becoming 
somewhat scattered and taking a slightly more ventrolateral position, while the cerebello-motorius system courses close to the ventricular wall. Medial to the acustico-lateral lemniscus, the cerebello-tegmental fibers extend more directly frontalward and, at the level of the decussation of the IV nerve, begin to turn toward the midline, forming a conspicuous decussation (fig. 27) largely ventral to the medial longitudinal fasciculus and situated approximately between the levels of the nuclei of the III and the IV nerves. Scattered fascicles of this system, crossed and uncrossed, continue forward into the tegmentum of the midbrain and into the diencephalon, their exact destination being difficult to determine. Without doubt this tract carries fibers to the nucleus of the III nerve, which constitute, strictly speaking, the cerebello-motorius component.

The fibers forming the cerebello-motorius system in the trout also appear to arise from the stratum Purkinje and from the nucleus cerebelli. As has been stated, they course forward with the fibers of the cerebello-tegmental system but after passing under the cerebellar commissure, the two systems gradually separate, the cerebello-tegmental tract following the path already outlined. The cerebello-motorius system becomes divisible into two parts. 1) A more caudal portion, pars bulbaris, turns more directly toward the midline and, passing partly through the medial longitudinal fasciculus, forms a loose decussation of fibers at levels approximately through the cerebellar commissure. This part of the cerebellomotorius system furnishes crossed and uncrossed fibers to the medial longitudinal fasciculi and fibers which turn caudalward to distribute largely to the motor nuclei of the medulla oblongata. 2) Many of the fascicles unite to form a rather compact bundle, pars mesencephalica, which extends in a frontoventral direction, keeping a position close to the ventricular wall and medial to the cerebello-tegmental tract. It continues forward to the nucleus of the IV nerve, distributing partly to this nucleus and partly to the medial longitudinal fasciculus. It is thought to be largely uncrossed, although certain of the fascicles cross. 
Since in the carp the cerebello-tegmental and the cerebellomotorius bundles are even more difficult to separate into two distinct systems, they will be described together. However, these two systems, on leaving the cerebellum, become grouped into two parts: 1) those passing behind and ventral to the commissure of the secondary gustatory nuclei; 2) those passing dorsal and in front of this commissure.

Those fascicles passing ventral to or behind the commissure arise in the stratum Purkinje of the corpus cerebelli and in the nucleus cerebelli, and are divisible into two components, a bulbar component and a mesencephalic component. The bulbar component, the tractus cerebello-motorius pars bulbaris, is distributed principally to the motor nuclei of the medulla oblongata. The fibers of this component, on leaving the cerebellum, swing more directly ventralward, many of them crossing the midline. Certain of these fibers can be traced directly into the motor nucleus of the $\mathrm{V}$ nerve and others into the medial longitudinal fasciculus. The mesencephalic component, the tractus cerebello-motorius pars mesencephalica, extends forward under the commissure, gradually taking a more ventral position. On approaching the level of decussation of the IV nerve many of its fascicles turn toward the midline and, passing through the medial longitudinal fasciculus, cross to the contralateral medial longitudinal fasciculus through which they probably distribute to motor nuclei of the midbrain. The bulbar and mesencephalic components of the tractus cerebello-motorius appear to correspond to the cerebello-motorius system described for the trout in the preceding account (p. 279).

Those fibers passing dorsal and in front of the commissure in the carp arise in the stratum Purkinje of the corpus cerebelli and in the valvula cerebelli. They pass almost directly ventralward and frontalward and curve toward the midline, where many of them cross in a decussation which extends approximately from a level a little behind the nucleus of the IV nerve to almost the level of the nucleus of the III nerve. This part of the system contains components which represent the 
tractus cerebello-tegmentalis and a part of the tractus cerebello-motorius of the trout. The cerebello-motorius component distributes chiefly to the nuclei of the III and the IV nerves and the tegmental component passes to the tegmentum of the midbrain and to the diencephalon.

In the carp, an uncrossed component of the cerebellomotorius system can be traced directly caudalward in a position close to the ventricular wall. Its fibers distribute in part to the motor cell column along their course. On reaching the level of entrance of the VIII nerve, other fibers of the tract turn lateralward into the ventral nucleus of the acusticolateral area.

Gustatory connections of the area acustico-lateralis and the cerebellum. The sagittally cut pyridine silver preparations of the carp reveal fiber bundles connecting the caudal end of the area acustico-lateralis with the lobus facialis. These fibers are grouped into a smaller, more dorsal set, which passes directly caudalward under the cerebellar crest and enters the dorsal part of the facial lobe, and into fibers which stream out of the more ventral part of the acustico-lateral area and into the facial lobe. It was not possible to determine whether any of the latter fibers reach the vagal lobes. The writer is uncertain as to the direction of conduction of these fibers.

The capsule of fibers surrounding the secondary gustatory nucleus sends fascicles dorsally into the cerebellum and the valvula cerebelli. This connection was observed by Herrick ('05), who lists it as a tertiary gustatory connection. In addition to this connection, he pointed out medullated and unmedullated fiber bundles passing between the secondary gustatory nucleus and the nucleus lateralis valvulae and considered that such connections support the view that the nucleus lateralis valvulae serves, at least in part, as an intermediary station for gustatory impulses going to the cerebellum.

Since the gustatory paths and centers are highly developed in the carp, it is to be expected that the tractus gustato-tectalis described in certain teleosts (Gadus, Lota lota, and Tetrodon) 
by Brickner ('30) would be well developed in this fish. However, the writer fails to find this connection and is uncertain as to its presence in any of the fishes studied. The fibers described by Herrick ('05) from the secondary gustatory nucleus to the hypothalamus are represented probably by fibers in the carp which swing forward and then turn ventrorostrally with the lobo-bulbar fibers to the hypothalamus.

\section{SUMMARY AND DISCUSSION}

It is evident from the foregoing account that a progressive and correlated development of the acustico-lateral area and the cerebellum can be traced from cyclostomes through ganoids into teleosts. Certain phases of this development seem to merit special emphasis and such phases it is proposed to discuss here somewhat more fully.

The acustico-lateral area in cyclostomes presents only the beginning of the nuclear pattern characteristic of higher forms, for while the anlagen of the major acustico-lateral nuclei-such as medial, dorsal and ventral nuclei-can be recognized, their boundaries are ill-defined cephalically while caudally the medial and ventral nuclei become fused into a single cell mass which passes over without sharp demarcation into the other nuclear gray of the medulla oblongata.

The acustico-lateral area in ganoids, as represented by Amia, has ventral and medial nuclei comparable to those of cyclostomes, but lacks a dorsal nucleus of the acustico-lateral area. That such a nucleus may be present in certain of the ganoids is indicated by the accounts of Johnston ('01, for Acipenser) and Hocke Hoogenboom ('29, for Polyodon). On the whole the two nuclei represented in Amia are relatively larger than their homologues in the Petromyzontia.

The acustico-lateral area in the teleosts studied resembles that of the ganoids in its lack of a dorsal nucleus. However, the teleostean medial and ventral nuclei exceed both in size and in nuclear differentiation the corresponding masses in Amia. The acustico-lateral area in teleosts shows a further development recognized by the appearance of two additional 
nuclear masses, a nucleus tangentialis and a nucleus vestibularis descendens, both of which are associated with the acoustic (or VIII) root.

The cerebellum in cyclostomes represents a very primitive stage in the phylogeny of that organ. It is generally recognized that in ontogenetic development, the human cerebellum (Streeter, '12, and others) arises as bilateral outgrowths of the dorsolateral wall of the medulla oblongata, and that such outgrowths fuse secondarily in the midline. That this ontogenetic development is a recapitulation of the phylogenetic history of the cerebellum is indicated by the adult structure of the cyclostome cerebellum, which is scarcely more than a bridge of gray uniting the dorsolateral areas of the two sides and is in direct nuclear continuity, on either side, with the medial nucleus of the acustico-lateral area. The primitive character of the cyclostome cerebellum is indicated further by the simplicity of its stratification, for it exhibits a deep cellular layer (stratum granulosum) and a superficial and essentially molecular layer (stratum fibrosum et moleculare) -that is, a central gray, with peripherally placed afferent and efferent tracts. That there is a tendency toward further differentiation is indicated by the subdivision of the stratum griseum into superficial and deep portions.

The cerebellum of Amia, the representative ganoid especially studied, presents a marked increase in size and differentiation, when compared with that in cyclostomes. In Amia, a corpus cerebelli, paired auricles, paired eminentiae granulares and a valvula can be recognized. A large ventricle extends almost to the tip of the corpus cerebelli, dividing it into lateral halves, a condition which is very primitive, as van der Horst ('26) has stated. The granular layer is highly developed and is bordered by a scattering of Purkinje cells which show a tendency toward layer formation. The molecular layer lies external to the Purkinje cells although it does not completely surround the cellular layers. However, in Amia the fibrous layer in the body of the cerebellum has, for the most part, become separated from a position in relation 
to the molecular layer, thus attaining a position deep to the granular layer. This is representative of an advance in development, since it is an approach to the condition found in higher forms. The auricles in Amia are formed by a forward continuation of the ventral granular layer of the corpus cerebelli. It may be mentioned that in ganoids, which have a dorsal nucleus of the acustico-lateral area situated above the crest, such a nucleus is in continuity with the auricle. The ventral part of the medial nucleus of the acustico-lateral area is continued directly forward into the eminentia granularis. This eminence is formed by a surface accumulation of the granular layer of the cerebellum which is peculiar to many of the Teleostomi. It is evident then, that the nuclear continuity of the medial nucleus of the acustico-lateral area with the cerebellum, which characterizes the region in cyclostomes, is present to a considerable degree in Amia. The valvula cerebelli is very small and is not folded, but it has a fibrous and a granular layer. Where the valvula is in contact with the tegmentum of the midbrain, there is an accumulation of gray designated as the nucleus lateralis valvulae (Herrick, '05). At the base of the cerebellum and extending up into the peduncle for a short distance is a small accumulation of cells which is regarded as the forerunner of the cerebellar nuclei of higher forms.

The cerebellum of teleosts presents a marked advance, in both size and differentiation, as compared to that of Amia. This increase affects most particularly the valvula and the corpus cerebelli, less particularly the eminentia granularis, and least of all the auricle, which, however, is present in all of the Teleostomi studied with the possible exception of the carp, where its presence is suggested. The auricle in the teleosts studied shows a connection with the ventral granular layer, as it did in Amia. It is not continuous with either the eminentia granularis or the gray of the underlying acustico-lateral area. However, the eminentia granularis is continuous with a small extension of the cephalic tip of the medial nucleus, a reminder of its phylogenetic history and at 
the same time an indicator of the increasing nuclear independence of the cerebellum. The corpus cerebelli, in the teleostean material available, does not show a distinct separation into bilateral halves, such as characterizes that region in Amia, and is said to characterize it in certain teleosts, as Megalops (van der Horst, '26). However, a line of fusion in the midplane indicates the bilateral origin of the structure and remnants of the ventricle (the so-called canalis cerebelli) are found in the corpus cerebelli. The layer formation in teleosts shows a marked increase in differentiation compared with that in ganoids. A relatively well-developed layer of Purkinje cells is present forming the outer boundary of the highly developed granular layer. External to the Purkinje cell layer is the molecular layer, and internal to the granular layer is a fibrous layer, formed by afferent and efferent cerebellar tracts. The valvula is perhaps the most characteristic feature of the teleostean cerebellum, the size and number of its folds varying with the animal under consideration and with the relative development of the lateral line system in that animal. Since the valvula extends forward into the optic ventricle, its relative size becomes a very important factor in determining the morphologic relations of the various structures in the midbrain. It is formed by a thickening in the midline in the caudal part of the anterior medullary velum, and this thickening carries forward into the midbrain the decussation of the IV nerve and separates it from the other commissural systems at the base of the cerebellum. The nucleus lateralis valvulae is considerably better developed in teleosts than in Amia. A nucleus cerebelli has been recognized in teleosts, where it is a slightly larger and more discrete nuclear mass and extends somewhat farther into the cerebellum, but otherwise has relations comparable to those described for the homologous mass in Amia.

The connections of the acustico-lateral area in Petromyzontia may be summarized briefly as follows: the dorsal nucleus of the acustico-lateral area receives primarily the dorsal root of the anterior lateral line nerve and a few fibers 
from its ventral root. It has internuclear connections with the other acustico-lateral nuclei and possibly with the cerebellum through the primordial cerebellar crest. The medial nucleus of the acustico-lateral area receives the posterior lateral line nerve, and also a few fibers from the dorsal root and the greater part of the ventral root of the anterior lateral line nerve. It is more than a lateral line center, as some fibers from the acoustic nerve enter it. This nucleus, in addition to internuclear connections with the ventral and dorsal nuclei of the acustico-lateral area, has connections with the cerebellum by way of the bulbo-cerebellar tract and through the primordial cerebellar crest. From this medial nucleus and from the nucleus of the descending root of $\mathrm{V}$ arise fibers which swing ventromedialward, decussate, and then pass forward to the tectal region as the bulbar lemniscus. The ventral nucleus is the chief nucleus of termination for the acoustic nerve; possibly it receives a few lateral line fibers. The nucleus octavo-motorius anterior, which according to the interpretation of the writer, is included in the general acustico-lateral area, gives rise to the coarse-fibered tractus octavo-motorius anterior, which swings ventromedialward and forward to the region of the nucleus of the III nerve. From the dorsal, medial, and ventral nuclei of the acusticolateral area, coarse and fine fibers of comparable function pass to the tegmental gray of the brain stem and to the motor nuclei of the cranial nerves, either directly, as in the case of the motor $\mathrm{V}$ nerve, or indirectly, after a partial decussation, through the medial longitudinal fasciculus. Such fibers constitute the acustico-latero-motorius system. The connections of the acustico-lateral areas of ganoids and teleosts show many resemblances and certain differences when compared with those of the Petromyzontia. The most obvious difference is the absence of a dorsal nucleus of the lateral line area. Another difference is found in the formation of an acusticolateral lemniscus which passes forward to the region of the torus semicircularis. Running with this tract is a tectoacustico-lateral bundle, which distributes to the nuclei of 
the acustico-lateral area. Correlated with the appearance in teleosts of a tangential nucleus and a nucleus vestibularis descendens, to which the acoustic nerve distributes, is the appearance of a descending vestibulo-spinal system. In Amia and the teleosts no system directly comparable to the tractus octavo-motorius anterior of the Petromyzontia has been demonstrated, but the tractus acustico-latero-motorius is larger and more readily delimited than in the lower forms. With the above exceptions, the connections of the acusticolateral area in Amia and in the teleosts studied are for the most part comparable to-although in general somewhat larger than-the connections of the homologous regions in the Petromyzontia.

The connections of the cerebellum in Petromyzontia are as simple in pattern as the primitive structure of that organ would lead one to anticipate. The stream of fibers entering and leaving the cerebellum can be divided only arbitrarily into fiber systems. A part of such fibers interconnect the acustico-lateral area and the cerebellum, partly directly and partly by the primordial cerebellar crest, and in company with these fascicles run direct root fibers of the lateral line, acoustic, and possibly the trigeminal nerves. From the spinal cord and lower bulbar region ascending bundles pass forward to the acustico-lateral regions and to the cerebellum, constituting the spino-acustico-latero-cerebellar system. Part of these various systems entering the cerebellum terminate on the same side, others cross in the cerebellar commissure. The remaining cerebellar tracts appear to pass from the cerebellum as a single system of fibers which fan out later to their various destinations. For convenience of description they have been termed (beginning dorsally): 1) the tractus cerebello-tectalis, which is accompanied by a tecto-cerebellar connection, both bundles interrelating the optic tectum and the primordial torus semicircularis with the cerebellum; 2) the tractus cerebellotegmentalis, distributing to the tegmentum of the bulb and the midhrain and nossiblv to the diencenhalon: 3) the trastus 
lobo-cerebellaris, swinging dorsocaudalward from the hypothalamic region and the tegmentum to the cerebellum; 4) the tractus cerebello-motorius, the more cephalic fibers of which accompany the tractus octavo-motorius anterior to the region of the nucleus of the III nerve, while the more caudal fibers, swinging ventralward fairly close to the ventricle, reach the motor nucleus of the $\mathrm{V}$ nerve, possibly the motor nuclei of other cranial nerves, and the homolateral and contralateral medial longitudinal fasciculi.

The connections of the cerebellum in Amia, in spite of the increased development and differentiation of this region, show many resemblances to those just described in cyclostomes. Lateral line root fibers in Amia distribute to the eminentia granularis, to the valvula and possibly to the auricle, while root fibers of the acoustic nerve can be traced to the eminentia granularis. Secondary fibers between the acustico-lateral area and the cerebellum pass either through the bulbo-cerebellar tract or by way of the cerebellar crest; both of these fiber systems distribute to the eminentia granularis, the corpus cerebelli and probably to the auricle, and the bulbo-cerebellar fibers reach also the valvula cerebelli. The spino-cerebellar system, while larger in Amia than in cyclostomes has the same course. It sends fibers to the corpus cerebelli and passes in intimate relation to the eminentia granularis to which it may contribute also. As they leave the cerebellum the remaining bundles are grouped in Amia much as in cyclostomes and fan out to their various destinations in a similar manner in both forms. The system is larger in the ganoid and has received certain additional components, among which should be mentioned the tractus mesencephalocerebellaris posterior (from the nucleus lateralis valvulae to the valvula and the corpus cerebelli), which runs ventral to the connection between the torus semicircularis and the cerebellum. This latter connection is larger in Amia than in cyclostomes, but consists in both forms of both crossed and uncrossed bundles. For the most part, the other systems are so comparable in the ganoid Amia and in cyclostomes that they do not require further discussion. 
The connections of the cerebellum in teleosts show many relations comparable to those just summarized for Amia. Within the cerebellum, the regional distribution of the lateral line nerves and the acoustic nerve and of the secondary connections from the acustico-lateral area has a like pattern in both orders of fishes, but the number of fibers is greater and the bundles more sharply delimited in the teleosts than in the ganoids. The spino-cerebellar system shows various modifications in the different teleosts, dependent to a large extent upon the size of the root fibers of certain of the cranial nerves and particularly upon the development of the gustatory paths and centers in the upper part of the bulb. Thus in forms where the gustatory system is not particularly highly developed, the fascicles of the spino-cerebellar tract have much the same relations as in Amia, but in fishes, such as the carp, where the cranial nerve roots entering the upper end of the bulb are especially large, and the secondary gustatory tract and nucleus are developed especially well, the spino-cerebellar tract breaks up into a number of fascicles which pass around and between these structures in their attempt to reach the cerebellum by the shortest possible course. It is evident, then, that the spino-cerebellar tract in these forms is a continuous system of fibers, a division of which into dorsal and ventral spino-cerebellar systems would be purely arbitrary. The fiber bundles interconnecting the cerebellum with the tectum, the torus semicircularis, the tegmental and the hypothalamic regions and the motor nuclei of the cranial nerves, which together formed a continuous band of fibers as they left the cerebellum in cyclostomes and to a considerable degree in the ganoid Amia, are broken up into a number of components in teleosts, so that the following tracts, which with few exceptions have homologues in the ganoid brain, stand out as distinct fiber bundles in the brain of the teleost. These are: 1) the tractus mesencephalo-cerebellaris posterior, from the nucleus lateralis valvulae to the valvula and the corpus cerebelli; 2) the tractus mesencephalo-cerebellaris anterior. from the cephalic end of the optic tectum to the 
corpus cerebelli; accompanied by 3 ) a cerebello-tectal connection from the corpus cerebelli to the afferent layers at the cephalic end of the tectum ; 4) the tractus lobo-cerebellaris, from the hypothalamic region to the cerebellum; 5) the tractus cerebello-tegmentalis, partially crossed, to the tegmental region of the midbrain and possibly to the diencephalon; 6) the tractus cerebello-motorius, to the motor nuclei of the midbrain and bulb, and accompanied by some cerebello-tegmental fibers. To these might be added other bundles mentioned in the description but not as yet completely analyzed.

The nuclear configuration and fiber connections of the acustico-lateral and cerebellar areas of the cyclostomes, ganoids and teleosts studied afford an excellent illustration of the progressive development and differentiation of these areas in passing from primitive and more generalized to more highly specialized forms. That such morphologic differences are in direct relation with and are expressions of the varying degrees of specialized behavior found in these animals is self evident.

\section{LITERATURE CITED}

ADdens, J. L. 1928 The eye-muscle nerves of petromyzonts, especially in their general morphological significance. Kon. Akad. v. Wetensch. te Amsterdam, Proc. sect. sc., vol. 31, pp. 733-748.

Addison, W. H. F. 1923 A comparison of the cerebellar tracts in three teleosts. J. Comp. Neur., vol. 36, pp. 1-35.

1929 The phylogeny of the afferent cerebellar pathways. The Cerebellum, pp. 329-333, VIth Research Publ. of Assoc. for Research in Nerv. and Ment. Diseases. Baltimore, The Williams and Wilkins Co.

Aнlborn, F. 1883 Untersuchungen über das Gehirn der Petromyzonten. Zeit. f. wissensch. Zool., Bd. 39, s. 191-294.

ARIËNS KAPPERS, C. U. 1906 The structure of the teleostean and selachian brain. J. Comp. Neur., vol. 16, pp. 1-112.

1907 Untersuchungen über das Gehirn der Ganoiden Amia ealva und Lepidosteus osseus. Abhandl. d. Senckenb, nat. Gesellsch,, Frankfurt am Main, Bd. 30, \$. 449-500.

1920-1921 Die vergleichende Anatomie des Nervensystems der Wirbeltiere und des Menschen. I. Abschnitt, 1920; II. Abschnitt, 1921. Haarlem, F. F. Bohn.

1929 The evolution of the nervous system. Haarlem, E. F. Bohn.

Ariëns Kappers, C. U., G. CarL Huber and E. C. Crosby 1936 The comparative anatomy of the nervous system of vertebrates including man. New York, The Macmillan Co. 
Bartelmez, G. W. 1915 Mauthner's cell and the nucleus motorius tegmenti. J. Comp. Neur., vol. 25, pp. 87-128.

Bartelmez, G. W. and N. L. HoERR 1933 The vestibular club endings in Ameiurus. J. Comp. Neur., vol. 57, pp. 401-428.

BeccarI, N. 1930 Il nucleo tangenziale del acustico ed il reflesso vistibulooculomotoria ne pesci teleostei. Bol. d. Soc. Ital. di Biol. Sper., vol. 5, pp. 1-4.

1934 Contributi alla migliore conoscenza delle terminazioni centrali del nervo acustico nei pesci. Psychiat. en Neurol. Bl., Feestbundel aan C. U. Ariëns Kappers, pp. 297-309.

Berkelbach VAN DER SPRENKEL, H. 1915 The central relations of the cranial nerves of Silurus glanis and Mormyrus caschive. J. Comp. Neur., vol. 25, pp. 5-63.

Bianchi, A. 1903 Sulle vie di connessione del cervelletto. Arch. ital. di anat. e di embriol., vol. 2, pp. 426-517.

BrICKNer, R. M. 1929 A description and interpretation of certain parts of the teleostean midbrain and thalamus. J. Comp. Neur., vol. 47, pp. 225-282.

1930 A new tract in Herrick's gustatory system in certain teleosts.

J. Comp. Neur., vol. 50, pp. 153-157.

BuRckhardT, R. 1897 Beiträge zur Morphologie des Kleinhirns der Fische. Arch. f. Anat. u. Physiol., Anat. Abt., S. 111-136.

BURR, H. S. 1928 The central nervous system of Orthagoriscus mola. J. Comp. Neur., vol. 45, pp. 33-128.

Charlton, H. H. 1933 The optic tectum and its related fiber tracts in blind fishes. J. Comp. Neur., vol. 57, pp. 285-325.

Clark, W. B. 1906 The cerebellum of Petromyzon fluviatilis. J. Anat., vol. 40, pp. 318-325.

CONEL, J. L. 1929 The development of the brain of Bdellostoma stouti. I. External growth changes. J. Comp. Neur., vol. 47, pp. 343-403. 1931 The development of the brain of Bdellostoma stouti. II. Internal growth changes. J. Comp. Neur., vol. 52, pp. 365-499.

EDINGER, L. 1900 The anatomy of the central nervous system. Philadelphia, F. A. Davis Company.

Franz, V. 1911 Das Kleinhirn der Knochenfische. Zool. Jahrb.. Abt. f. Anat., Bd. 32, S. 401-464.

1911 a Das Mormyridenhirn. Zool. Jahrb., Abt. f. Anat., Bd. 32, S. 465-492.

FUSARI, R. 1887 Untersuchungen über die feinere Anatomie des Gehirns der Teleostier. Internat. Monatschr. f. Anat. u. Physiol., Bd. 4, S. 275-300.

van Gehuchiten, A. 1893 Contribution a l'étude du système nerveux Téléostéens. La Cellule, 'T. $10_{2}$, pp. 255-295.

Haller, B. 1898 Von Bau des Wirbeltiergehirns. I. Salmo und Seyllium. Morphol. Jahrb., Bd. 26, S. 345-641.

HeRrick, C. J. 1899 The cranial and first spinal nerves of Menidia: A contribution upon the nerve components of bony fishes. J. Comp. Neur., vol. 9, pp. 153-455.

1901 The cranial nerves and cutaneous sense organs of the North American siluroid fishes. J. Comp. Neur., vol. 11, pp. 177-249. 
HERRICK, C. J. 1905 The central gustatory paths in the brains of bony fishes. J. Comp. Neur., vol. 15, pp. $375-456$.

1906 On the centers for taste and touch in the medulla oblongata of fishes. J. Comp. Neur., vol. 16, pp. 403-439.

1907 The tactile centers in the spinal cord and brain of the sea robin, Prionotus carolinus L. J. Comp. Neur., vol. 17, pp. 307-328.

1924 Origin and evolution of the cerebellum. Arch. Neurol. and Psychiat., vol. 11, pp. 621-652.

1930 The medulla oblongata of Necturus. J. Comp. Neur., vol. 50, pp. 1-96.

Hocke Hoogenboom, K. J. 1929 Das Gehirn von Polyodon folium Lacep. Jahrb. f. Morphol. u. mikr. Anat.; Abt. 2, Zeitschr. f. mikr.-anat. Forsehung, Bd. 18, S. 311-392.

vaN Hoevelu, J. J. L. D. 1916 The phylogenetic development of the cerebellar nuclei. Kon. Akad. v. Wetensch. te Amsterdam, Proc. sect. sc., vol. 18, pp. 1421-1434.

Holmaren, N. 1919 Zur Anatomie des Gehirns von Myxine. Kungl. Svenska Vetenskapsakad. Handl., Bd. 60, no. 7.

Holmaren, N. AND C. J. vaN DER HorsT 1925 Contribution to the morphology of the brain of Ceratodus. Acta Zool., Bd. 6, pp. 59-165.

VAN DER HoRst, C. J. 1925 The cerebellum of fishes. I. General morphology of the cerebellum. Kon. Akad. v. Wetensch. te Amsterdam, Proc. Sect. sc., vol. 28 , pp. $735-746$.

1926 The cerebellum of fishes. II. The cerebellum of Megalops cyprinoides and its connections. Kon. Akad. $\nabla$. Wetensch. te Amsterdam. Proc. seet. sc., vol. 29, pp. 44-53.

Huber, G. CARL 1927 New method of fixation and staining of the central nervous system for purpose of study of eytoarchitecture. Contributions to Medical Science. Dedicated to Aldred Scott Warthin. Pp. 1-12. Ann Arbor, Wahr.

Huber, G. Cart aNd E. C. Crosby 1933 The reptilian optic tectum. J. Comp. Neur., vol. 57, pp. 57-163.

HUBER, G. CARL AND S. R. GUILD 1913 Observations on the peripheral distribution of the nervus terminalis in Mammalia. Anat. Rec., vol. 7, pp. 253-272.

JACKsON, W. AND W. ClaRke 1876 The brain and cranial nerves of Echinorhinus spinosus. J. Anat., vol. 10, pp. 75-107.

JANsEN, J. 1930 The brain of Myxine glutinosa. J. Comp. Neur., vol. 49, pp. $359-507$.

JELENEFF, A. 1879 Histologische Untersuchung des kleinen Gehirnes der Neunauge (Petromyzon fluviatilis). Bull. Imper, Acad. sc. St. Petersbourg, Sér. 3, pp. 334-345.

Johnston, J. B. 1898 Hlindbrain and cranial nerves of Acipenser. Anat. Anz., Bd. 14, S. 580-602.

1901 The brain of Acipenser. Zool. Jahrb., Abt. f. Anat., Bd. 15, S. $59-250$.

1902 The brain of Petromyzon. J. Comp. Neur., vol. 12, pp. 1-86. 1906 The nervous system of vertebrates. Philadelphia, P. Blakiston's Son and Co. 
Kingsbury, B. F. 1897 The oblongata in fishes (especially of Amia and Amiurus). J. Comp. Neur., vol. 7, pp. 1-36.

Koox, F. H. 1917 The inferior olive in vertebrates. Folia neuro-biol., Bd. 10, S. $206-369$.

LARSELL, O. 1925 Development of the cerebellum in the frog in relation to the vestibular and lateral line system. J. Comp. Neur., vol. 39, pp. 249-289. 1929 The comparative morphology of the membranous labyrinth and the lateral line organs in their relation to the development of the cerebellum. The Cerebellum, pp. 297-328. VIth Research Publ. of Assoc. for Research in Nerv. and Ment. Diseases. Baltimore, The Williams and Wilkins Co.

1932 The develoment of the cerebellum in Amblystoma. J. Comp. Neur., vol. 54, pp. 357-435.

Mayser, P. 1881 Vergleichend anatomische Studien ïber das Gehirn der Knochenfische mit besonderer Berïcksichtigung der Cyprinoiden. Zeit. f. wissensch. Zool., Bd. 36, S. 259-366.

NoRRIs, H. W. 1925 Observations upon the peripheral distribution of the cranial nerves of certain ganoid fishes (Amia, Lepidosteus, Polyodon, Seapherhynchus and Acipenser). J. Comp. Neur., vol. 39, pp. 345-432.

Palmaren, A. 1921 Embryological and morphologieal studies on the midbrain and cerebellum of vertebrates. Acta Zool., Bd. 2, pp. 1-94.

PAPEZ, J. W. 1929 Comparative neurology. New York, Thomas Y. Crowell Co.

Pearson, A. A. 1936 The acustico-lateral nervous system in fishes. J. Comp. Neur., vol. 64, pp. 235-273.

RAMÓN Y CAJAL, S. 1908 Sur un noyau spécial du nerf vestibulare des poissons et des oiseux. Trab. d. lab. de invest. biol. Univ. de Madrid, T. 6, pp. 1-20.

RobIN, C. 1849 System nèrveus des Lamproies. Compt. rend. Soc. de biol., pp. 6-7.

Roнm, J. V. 1882 Ueber den Ursprung des Nervus acusticus bei Petromyzonten. Sitzungsb. d. K. Akad. d. Wissensch. zu Wien, Math.-nat. Cl., Bd. 85, S. 245-267.

SchaPER, A. 1893 Zur feineren Anatomie des Kleinhirns der Teleostier. Anat. Anz., Bd. 8, S. 705-720.

1894 Die morphologische und histologische Entwickelung des Kleinhirns der Teleostier. Anat. Anz., Bd. 9, S. 489-501.

1894 a Die morphologische und histologisehe Entwickelung des Kleinhirns der Teleostier. Morphol. Jahrb., Bd. 21, S. 625-708.

1899 Zur Histologie des Kleinhirns der Petromyzonten. Anat. Anz., Bd. 16, S. $439-446$.

Schepman, A. M. H. 1918 De octavolaterale zintuigen en hun verbindingen in de hersenen der vertebraten. Dissertatie, Amsterdam.

STREETER, G. L. 1912 Manual of human embryology edited by F. Keibel and F. P. Mall. Philadelphia and London, J. B. Lippineott Co., 1910-1912.

Tello, F. 1909 El encefalo de los teleostes. Trab. d. lab. de invest. biol. Univ. de Madrid, vol. 7, pp. 1-29. 
TrETJAKOFF, D. 1907 Die peripherische und zentrale Endigung des Gehörnerven bei Ammocoetes und Petromyzon fluviatilis. Folia neurobiol., Bd. 1, S. 14-29.

1909 Das Nervensystem von Ammocoetes. II. Gehirn. Arch. $f$. mikr. Anat., Bd. 74, S. 636-779.

Tuge, H. 1934 Studies on cerebellar function in the teleost. I. Reactions resulting from cerebellar ablation. J. Comp. Neur., vol. 60, pp. 201-224. 1934 a Studies on cerebellar function in the teleost. II. Is there a cerebello-tectal path Marchi method. J. Comp. Neur., vol. 60, pp. 225-236.

Wallenbler, A. 1907 Beiträge zur Kenntnis des Gehirns der Teleostier und Selachier. Anat. Anz., Bd. 31, S. 369.

Weston, J. K. 1936 The reptilian vestibular and cerebellar gray with fiber connections. J. Comp. Neur., vol. 65, pp. 93-199. 